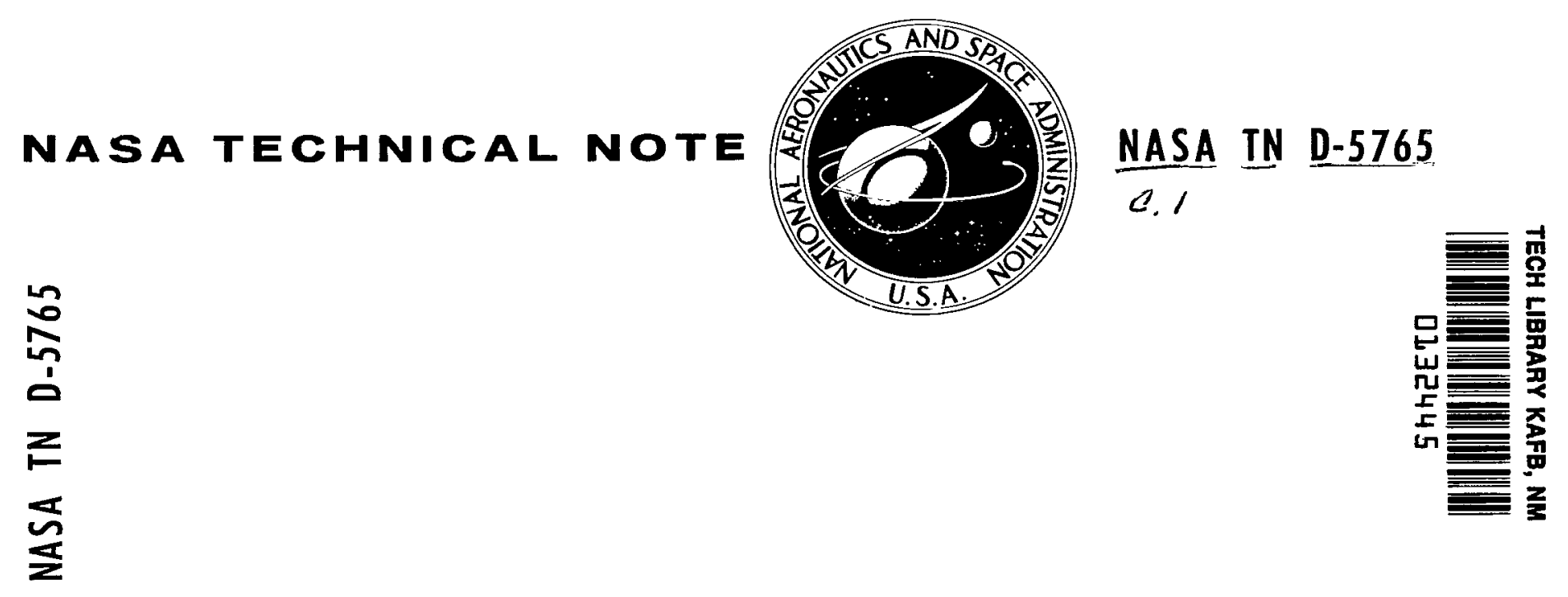

IOAN COPY: RETURN TO AFWL (WLOL)

KIRTTAND AFB, N MEX

\title{
STUDY OF THE ODD STRONTIUM ISOTOPES WITH STRIPPING AND PICKUP REACTIONS
}

by Robert W. Bercaw and Robert E. Warner

Lewis Research Center

Cleveland, Obio 44135

NATIONAL AERONAUtICS AND SPACE ADMINISTRATION - WASHINGTON, D. C. - APRIL 1970 
1. Report No. NASA TN D-5765

2. Government Accession No.

4. Title and Subtitle STUDY OF THE ODD STRONTIUM ISOTOPES WITH STRIPPING AND PICKUP REACTIONS

7. Author(s) Robert W. Bercaw, Lewis Research Center; and Robert E. Warner, Oberlin College, Oberlin, Ohio

9. Performing Organization Name and Address

Lewis Research Center

National Aeronautics and Space Administration

Cleveland, Ohio 44135

12. Sponsoring Agency Name and Address

National Aeronautics and Space Administration

Washington, D.C. 20546

15. Supplementary Notes

16. Abstract

The $(d, t)$ and $(d, p)$ reactions induced by $20.65 \mathrm{MeV}$-deuterons have been used to study the levels of ${ }^{87} \mathrm{Sr}$ and ${ }^{85} \mathrm{Sr}$ up to an excitation of $3 \mathrm{MeV}$. The mass defect of ${ }^{83} \mathrm{Sr}$ has been determined by the $(d, t)$ reaction, and its level structure below $3 \mathrm{MeV}$ has been investigated. The cross sections have been analyzed with the distorted-wave Born approximation (DWBA) to determine the orbital of momenta the neutron transfers and the spectroscopic factors. Tentative spin assignments have been made on the basis of sum values and the $j$-dependence of the cross section.
17. Key Words (Suggested by Author(s))

Reactions

Level structure

Nuclear

Deuteron reduced

Strontium
18. Distribution Statement

Unclassified - unlimited
19. Security Classif. (of this report) Unclassified
20. Security Clossif. (of this poge) Unclassified

\begin{tabular}{|c|c|} 
21. No. of Pages & 22. Price* \\
54 & $\$ 3.00$
\end{tabular}

* For sale by the Clearinghouse for Federal Scientific and Technical Information Springfield, Virginia 22151 


\title{
STUDY OF THE ODD STRONTIUM ISOTOPES WITH STRIPPING
}

\author{
AND PICKUP REACTIONS \\ by Robert W. Bercaw and Robert E. Warner*† \\ Lewis Research Center
}

\section{SUMMARY}

The $(d, t)$ and $(d, p)$ reactions induced by $20.65-\mathrm{MeV}$ deuterons have been used to study the levels of strontium-87 and strontium-85 up to an excitation of $3 \mathrm{MeV}$. The mass defect of strontium -83 has been determined by the $(d, t)$ reaction, and its level structure below $3 \mathrm{MeV}$ has been investigated. The cross sections have been analyzed with the distorted-wave Born approximation (DWBA) to determine the $l$-values of the neutron transfers and the spectroscopic factors. Tentative spin assignments have been made on the basis of sum values and the $j$-dependence of the cross sections.

\section{INTRODUCTION}

Nuclei lying on a closed shell of either protons (or neutrons) have always been of particular interest because of their relative simplicity. Presumably, their structures involve only neutron (or proton) configurations. This simplification is especially important for the study of the region immediately following the $f_{7 / 2}$ shell because there are four nearly degenerate shells (see fig. 1). The proton shell at $Z=28$ and the neutron shell at $N=50$ have been used extensively for this purpose. These shells allow the study of single nucleon configurations for $28<\mathrm{N}(\mathrm{Z}) \lesssim 44$, but unfortunately they do not allow the study of the major shell closure at $N(Z)=50$. The present experiments were designed to cover this gap by studying the structure of the odd strontium ( $\mathrm{Sr}$ ) isotopes.

We have investigated the structure (refs. 1 and 2 ) of ${ }^{83} \mathrm{Sr}$ with the (d,t) reaction and the structure of ${ }^{85} \mathrm{Sr}$ and ${ }^{87} \mathrm{Sr}$ with both the $(d, t)$ and the $(d, p)$ reactions. The $(d, t)$ reaction

*Oberlin College, Oberlin, Ohio.

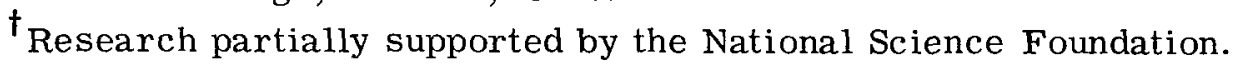




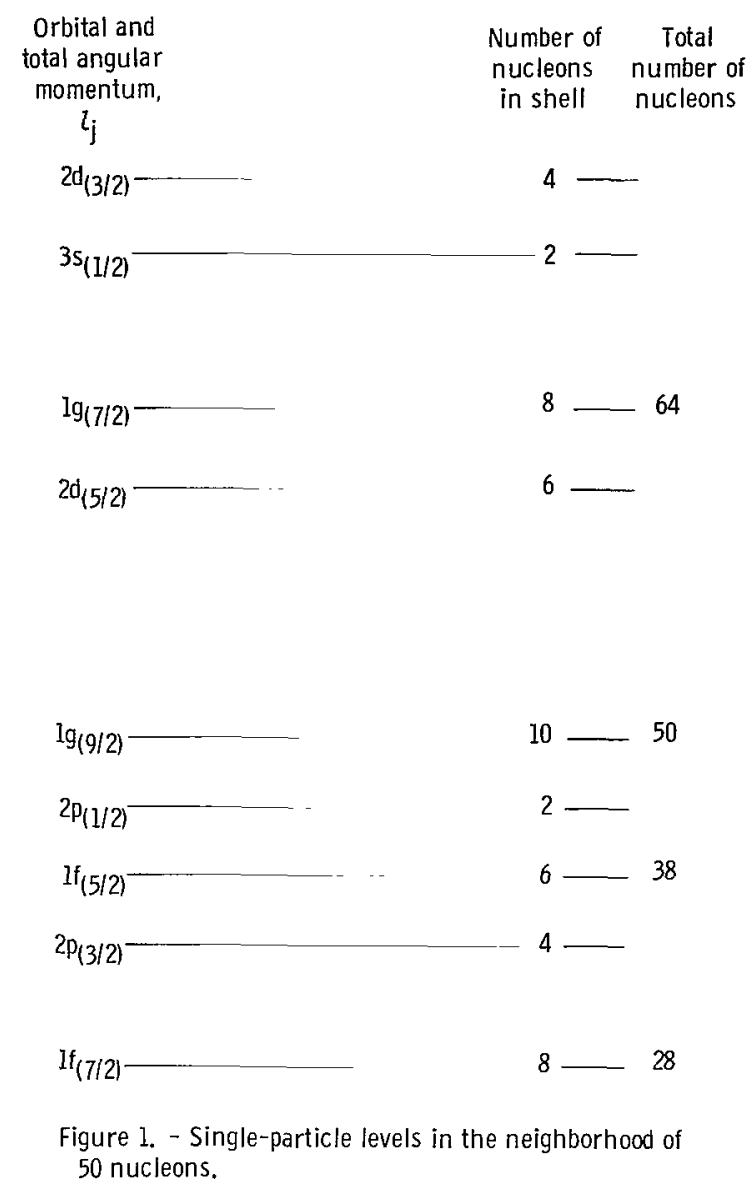

was considered the primary tool since in the strontium isotopes the neutron shells of interest are full or nearly so and states based on them should be strongly populated. The next major shell, beginning with the $2 \mathrm{~d}_{5 / 2}, 3 \mathrm{~s}_{1 / 2}$, and $2 \mathrm{~d}_{3 / 2}$ orbitals, starts about $2 \mathrm{MeV}$ above the top of the $\mathrm{N}=50$ shell. Since this is not excessive the presence of states based on these shells may complicate either the experimental or theoretical picture. The (d, p) studies were designed to cover these contingencies as well as to provide a more accurate measurement of the degree of emptiness of the nearly full states.

The strontium isotopes were chosen for study because the proton shells at strontium $(\mathrm{Z}=38)$ are rather well closed. Evidence for this comes from the theoretical and experimental work performed over the past few years on the proton configurations in $N=50$ nuclei. The theoretical studies (refs. 3 to 5 ) have generally assumed that the $1 f_{5 / 2}$ and $2 \mathrm{p}_{3 / 2}$ proton shells have closed at strontium $(\mathrm{Z}=38)$ and that only the $2 \mathrm{p}_{1 / 2}$ and $\lg _{9 / 2}$ shells need be used as a basis to construct the states of the heavier elements. These studies have been relatively successful in explaining the available data. The experimental evidence comes from studies of proton stripping (refs. 6 and 7) and pickup 
(refs. 8 and 9 ) on ${ }^{88} \mathrm{Sr}$. Yttrium-89 has a $1 / 2^{-}$ground state and a $9 / 2^{+}$level at $0.9 \mathrm{MeV}$ which are usually interpreted as $2 \mathrm{p}_{1 / 2}$ and $1 \mathrm{~g}_{9 / 2}$ single-particle states outside of the ${ }^{88} \mathrm{Sr}$ core. It also has a pair of states at 1.49 and $1.73 \mathrm{MeV}$, with $\mathrm{J}^{\pi}$ of $3 / 2^{-}$and $5 / 2^{-}$, which have been interpreted as either a weak coupling of the $1 / 2^{-}$ground state to the $2^{+}$ photon in the ${ }^{88} \mathrm{Sr}$ core or as $2 \mathrm{p}_{3 / 2}$ and $1 \mathrm{f}_{5 / 2}$ hole states with the particle being promoted to couple with the odd $2 \mathrm{p}_{1 / 2}$ particle. Alpha scattering and transfer reaction studies (refs. 8 and 9) agree that the hole-state picture is closer to the truth.

The reaction ${ }^{88} \mathrm{Sr}\left({ }^{3} \mathrm{He}, \mathrm{d}\right){ }^{89} \mathrm{Y}$, being a one-step process, cannot populate either of these states in the weak coupling model and also cannot populate them in the hole-state model if the shells in ${ }^{88} \mathrm{Sr}$ are full. Thus to the extent that the hole-state model is true, the cross section for this reaction is a direct measure of the emptiness of the shells. The transition to the 1.49-MeV state was observed to have one-fourth the strength of the ground-state transition in one $\left({ }^{3} \mathrm{He}, \mathrm{d}\right)$ study but was not observed in the other; in neither case was the $1.73-\mathrm{MeV}$ level populated.

The shell closure at ${ }^{88} \mathrm{Sr}$ has also been studied by looking for admixtures of the orbitals in its ground state (refs. 8 and 9 ). No $l=4$ transitions $\left(g_{9 / 2}\right)$ have been observed in the $\left(\mathrm{d},{ }^{3} \mathrm{He}\right)$ reaction, but a second weak $l=1$ transition has been seen going to a state in rubidium-87 at $0.84 \mathrm{MeV}$. The spin of this state is unknown and could also be $j=3 / 2$ like the ground state, but it has roughly the correct excitation to be a $p_{1 / 2}$ state. Its spectroscopic factor is about one-fourth that of the ground state. These data indicate that the $2 \mathrm{p}_{3 / 2}, 1 \mathrm{f}_{5 / 2}$ shell closure is rather good, but that there may be as much as 25 percent admixture of $2 \mathrm{p}_{1 / 2}$ in the $2 \mathrm{p}_{3 / 2}$ shell.

The strontium isotopes probably offer the best region for studying the singleparticle states for $\mathrm{N}<49$. The heavier elements are not stable for $\mathrm{N}<50$ and so prevent reaction studies of fewer neutrons. Krypton is suitable, but it is a gas, and its lighter isotopes have not been available in an enriched form. Selenium and other lighter elements have been studied, but their proton configurations appear to be quite complex.

\section{EXPERIMENT AND DATA REDUCTION}

Most of the experimental apparatus is conventional and will only be briefly described. The deuteron beam was accelerated by the Lewis 60-inch (1.5-m) cyclotron and was analyzed by a $45^{\circ}$ double focusing wedge magnet. The image of the analysis slit was then picked up by a quadrupole doublet and refocused at the center of a 60-inch (1. 5-m) scattering chamber. This system produced a 20.65- MeV deuter on beam having an energy spread of about $40 \mathrm{keV}$ full width, a horizontal width of $0.5 \mathrm{millimeter}$, and a horizontal divergence of $0.3^{\circ}$ full width. The height of the spot was about 1 centimeter. The scattering angles were determined to within $0.1^{\circ}$. A more complete description of the system was given by Stewart et al. (ref. 10). The detectors, located 24.8 
centimeters from the target, subtended a linear angle of $0.69^{\circ}$ and a solid angle of $3.07 \times 10^{-4}$ steradians.

Two sets of experiments were made. The first, for which the data are given in appendixes $\mathrm{A}$ and $\mathrm{B}$, utilized a silic on detector telescope consisting of a 200-micron passing or $\Delta \mathrm{E}$ surface barrier detector and a 5-millimeter lithium drifted stopping or $\mathrm{E}$ detector (supplied by N. Baron of Lewis). This telescope allowed simultaneous recording of protons, deuterons, and tritons which gave an average resolution of 90 to $100 \mathrm{keV}$ full width half maximum (FWHM). Measurements were made on all three isotopes over the range of $16^{\circ}$ to $120^{\circ}$. Several weak transitions found in these data could not be analyzed because of the poor statistics. The measurements from $14^{\circ}$ to $90^{\circ}$ on ${ }^{88} \mathrm{Sr}$ and ${ }^{86} \mathrm{Sr}$ were therefore repeated with improved statistics and instrumentation. In the second experiment, for which the data are given in appendix $\mathrm{C}$, the 5-millimeter $\mathrm{E}$ detector was replaced with a 1.5-millimeter detector having higher resolution, and the tube preamplifiers were replaced with transistorized units. Since the thinner detector would only stop deuterons and tritons, an additional 5-millimeter detector was placed next to the telescope to detect the protons. The telescope yielded an overall resolution of about $70 \mathrm{keV}$ FWHM and significantly improved on the $(\mathrm{d}, \mathrm{t})$ results of the previous runs. But the 5-millimeter detector had deteriorated somewhat, and the $(d, p)$ results did not yield any significant new data.

The electronics used in both experiments consisted of the usual charge sensitive preamplifiers and single-delay-line shaped amplifiers plus the power law particle identifier designed by Goulding and Landis (ref. 11). The output of the identifier drove a stacked set of three single-channel analyzers whose outputs were used to generate signals to route the mixed linear signals into one of three groups in the multichannel analyzer. Particle separation was essentially perfect over the energy range studied. A single detector $(1.5 \mathrm{~mm})$ set at $45^{\circ}$ was used to monitor the number of elastically scattered deuterons and hence yielded the product of the target density and beam charge. This allowed the data to be corrected for the effects of the nonuniformity of the available targets. Analyzer live time was measured by recording the monitor counts with two scalers, one of which was gated by the gate signal of the multichannel analyzer. The yield was then corrected by multiplying it by the ratio of the two scaler readings.

Two types of targets were used in the experiment. The isotopes for both, obtained from Oak Ridge National Laboratory, had the concentrations listed in table I. The targets used for the first set of experiments consisted of 0.2 to 0.4 milligram per square centimeter of metallic strontium on backings of approximately 40 microgram per square centimeter VYNS, a polyvinylchloride-acetate copolymer (ref. 12). They were prepared by reducing strontium oxide with aluminum; simultaneously the freed metallic strontium was evaporated (this is basically the method of J. M. Sauer, ref. 13). The VYNS backing was chosen because it was the only material for which a thin film would hold up 
TABLE I. - ISOTOPIC ENRICHMENTS

OF TARGET MATERIALS USED

IN EXPERIMENT

\begin{tabular}{|c|r|r|r|r|}
\hline \multirow{2}{*}{ Target } & \multicolumn{4}{|c|}{ Percentage of isotope } \\
\cline { 2 - 5 } & \multicolumn{1}{|c|}{88} & 87 & 86 & 84 \\
\hline 88 & 99.8 & 0.1 & 0.1 & ---- \\
86 & 1.7 & .7 & 97.6 & ---- \\
84 & 17.1 & 2.2 & 5.1 & 75.6 \\
\hline
\end{tabular}

under the evaporation of a relatively thick film of strontium. The evaporation apparatus consisted of a crucible in the form of a 3-millimeter vertical tantalum tube open at the top, and a target frame suspended about 7 centimeters above it. After evaporation, the frame was withdrawn into a vacuum cell and transferred to the scattering chamber.

The oxide was prepared in two steps from the nitrate supplied by Oak Ridge National Laboratories. Strontium carbonate was first precipitated from a solution of the nitrate by adding sodium carbonate. Then, after washing and drying, it was reduced to oxide by heating it in vacuum in the evaporation crucible. The oxide was then ground, mixed with fine aluminum dust, and returned to the crucible for reduction.

During the course of the experiment, the metallic strontium slowly oxidized in the scattering chamber vacuum and hence the value of having a metallic target was mostly lost. The chlorine in the VYNS also caused some contamination of the spectra. Therefore the second set of targets (supplied by M. Friedman) was made by evaporating the strontium onto carbon coated slides. The strontium was then allowed to oxidize, and the carbon backed oxide was floated off the slides and mounted on the target frames.

The actual beam energy and zero angle were determined by scattering from a thin $\mathrm{CH}_{2}$ target. The zero was determined by observing the energy of the deuterons scattered by hydrogen to the left and the right. Although this gave a correction accurate to ${ }_{ \pm 0} 05^{\circ}$, the beam direction was only reproducible to $0.1^{\circ}$. The beam energy was determined to be $20.65 \pm 0.05 \mathrm{MeV}$ by finding a pair of angles which yielded the same energies for deuterons elastically and inelastically (4. 434-MeV state) scattered by carbon-12.

The energy response of the electronics was assumed to be linear over the range of energies encountered in the experiment. Although there may have been some nonlinearity, it was not sufficiently large or well defined to justify a correction. The energy calibration points in the $(d, t)$ experiments were taken from the ground-state transition energies, the oxygen contaminant reaction ${ }^{16} \mathrm{O}(\mathrm{d}, \mathrm{t}){ }^{15} \mathrm{O}$, and any well known strontium 
excited states. However, in the case of ${ }^{84} \mathrm{Sr}(\mathrm{d}, \mathrm{t})^{83} \mathrm{Sr}$, for which the ground state $\mathrm{Q}$ was not well known, the energy calibration was derived from the $Q$ of the contaminant reaction ${ }^{88} \operatorname{Sr}(\mathrm{d}, \mathrm{t}){ }^{87} \mathrm{Sr}$. The $(\mathrm{d}, \mathrm{p})$ calibrations were made in a similar fashion with the lower energies being related to ${ }^{12} \mathrm{C}(\mathrm{d}, \mathrm{p}){ }^{13} \mathrm{C}$ and ${ }^{16} \mathrm{O}(\mathrm{d}, \mathrm{p}){ }^{17} \mathrm{O}$. In a number of experiments there were contaminant peaks in the midst of the spectra. These were checked against the calibrations and were generally found to be consistent with them.

In the evaluation of the experimental data, each spectrum produced a set of values for the excitation energies. These were averaged to produce the quoted values. The statistical uncertainties in these energies were about 6 to $8 \mathrm{keV}$ per MeV of excitation in the first set of experiments and about $2 \mathrm{keV}$ per $\mathrm{MeV}$ in the second set. A somewhat larger error, $10 \mathrm{keV}$ per $\mathrm{MeV}$, is estimated for the uncertainty of the energy calibration of the electronics. The overall uncertainty in the quoted energy values is estimated at 10 to $12 \mathrm{keV}$ per $\mathrm{MeV}$.

A great deal of effort was made to extract the maximum amount of information from the data. Since the experimental resolution ranged from 70 to $199 \mathrm{keV}$ FWHM, the weaker peaks did not protrude distinctly from the background and contaminants. The first step in the analysis was to identify the transitions of interest.

In the first of two methods used the strontium transitions were determined by their kinematics. Peaks were located by scanning the spectra either visually or by a statistical computer routine (unpublished program by T. E. Fessler of Lewis). The energy differences between the ground-state transition and the suspected transition were then plotted as a function of angle. Since the kinematic shifts are small for strontium, true transitions appear as nearly horizontal lines. Light contaminant reactions appear as sloping lines and statistical fluctuations as isolated points.

In the second method, a number of spectra taken at many different angles were summed to produce a spectrum having much better statistics. In order to do this, it was first necessary to correct the spectra for kinematic shifts and gain drifts so that corresponding peaks were alined. It was assumed that nonlinear corrections are small (i. e., that all peaks will be alined if any two well separated peaks are alined). A leastsquares analysis was made as described in the next section to find the locations of the strong peaks. The spectra were shifted, stretched, and normalized using the locations of two of the strong peaks, and then summed into a single spectrum. No attempt was made to include all of the spectra or to normalize them in proportion to the cross section. The advantage of this method is that, in addition to reducing statistical fluctuations, contaminants from reactions on light nuclei do not appear as peaks in the sum spectra because of their greater kinematic shifts with angle.

Sum spectra for the $(d, t)$ experiments are shown in figures 2 and 3 . Results of the two methods are in good agreement, although a few poorly resolved peaks were seen only by the second method. The sensitivity of the two analyses to the presence of heavy 

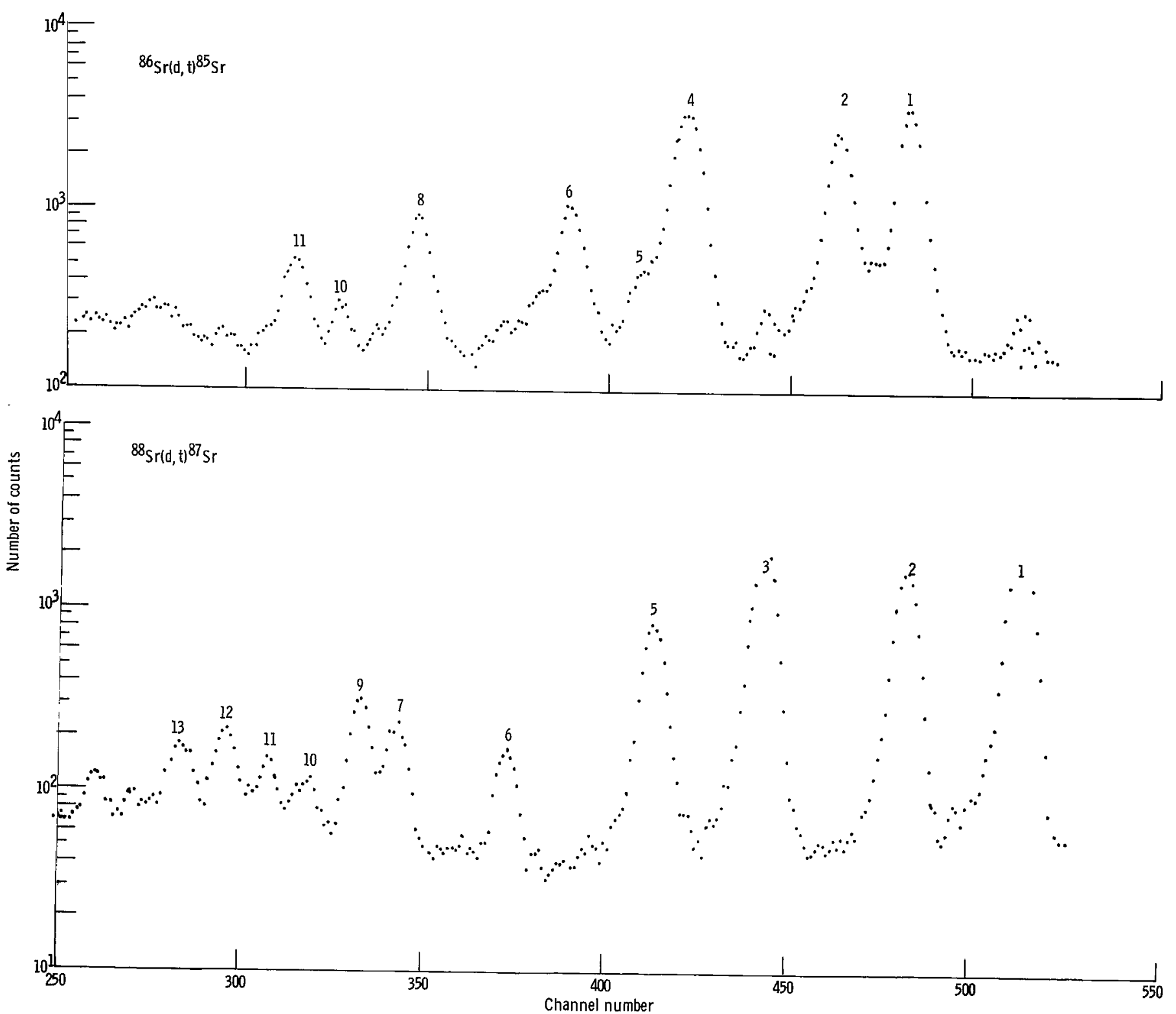

Figure 2. - Summed spectra for the ${ }^{86} \mathrm{Sr}(d, t)^{85} \mathrm{Sr}$ and ${ }^{88} \mathrm{Sr}(\mathrm{d}, \mathrm{t})^{87} \mathrm{Sr}$ reactions. These spectra are generated by summing the spectra taken at many different angles, Numbered peaks originate from the transitions of interest; their properties are given in table III. There was a 1.7 percent ${ }^{88} \mathrm{Sr}$ contamination in the ${ }^{86} \mathrm{Sr}$ target
and the resulting peaks are clearly visible. 


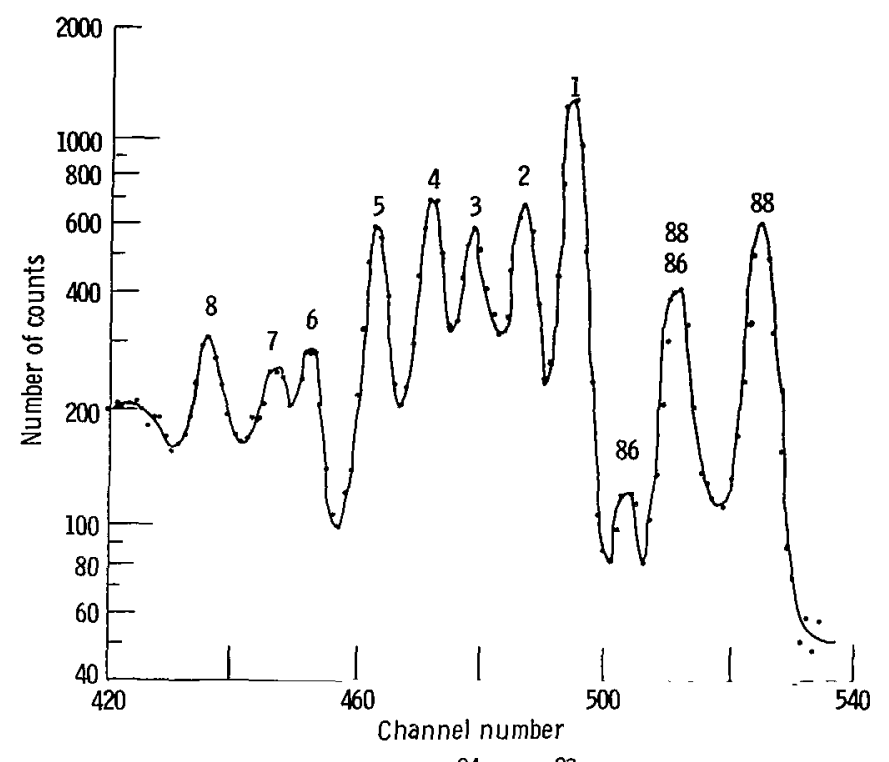

Figure 3. - Summed spectra for ${ }^{84} \mathrm{Sr}(\mathrm{d}, \mathrm{t})^{83} \mathrm{Sr}$ reaction. The numbered peak are due to the transitions of interest; properties are given in table V. First three peaks are due entirely to the 17 percent ${ }^{88} \mathrm{Sr}$ contaminations in the target. Spectrum cannot be compared directly with ${ }^{86} \mathrm{Sr}$ and $88 \mathrm{sr}$ spectra since conversion gain is different.

contaminants is not great, but it is sufficient to demonstrate the absence of tantalum, the only likely one. The second method was not used to study the $(d, p)$ results because of the large contributions from the oxygen and carbon contaminants.

At each angle the areas of the peaks were extracted by fitting Gaussian curves to the peaks with a nonlinear least squares computer routine. A semilogarithmic background was assumed. Its amplitude was adjusted to pass through the minima between well separated peaks. The strong peaks were fitted using both a constant width and by allowing the width to vary for the minimum $x^{2}$. Very little difference was found in the resulting areas. In analyzing the weak peaks, it was found that the peak widths were poorly defined, so the widths were fixed at the values established by fitting the strong peaks. A number of researchers have found it necessary to use skewed Gaussians in analyzing their spectra. We also found this necessary in analyzing the earlier data; however, the peaks became more symmetrical in the later runs. We attribute this to improvements in the electronics in the interim and primarily to the substitution of the more linear transistorized preamplifiers and improved baseline restoration techniques.

Relative cross sections were determined by normalizing the runs with the monitor counter $\left(45^{\circ} \mathrm{lab}\right)$; the integrated charge measurements were almost useless because of target nonuniformities. The question of relating the cross sections of the different isotopes was investigated by measuring their deuteron elastic scattering cross sections. No significant differences in shape were observed between $20^{\circ}$ and $50^{\circ}$, so we assumed that the absolute cross sections were identical as well. The absolute cross sections 
were established by comparing the relative scattering cross sections to optical-model predictions. No suitable optical-model studies have been made at $21 \mathrm{MeV}$. But the average potentials derived at 26 (ref. 14) and $15 \mathrm{MeV}$ (ref. 15) were very similar, and it was felt that it would be reasonable to interpolate between them. Potential set $B$ of reference 15 at $15 \mathrm{MeV}$ and potential set 2 of reference 14 at $26 \mathrm{MeV}$ were used. The resulting fits to the strontium elastic scattering data were quite satisfactory. The normalization was checked by comparing the optical model predictions with the ${ }^{90} \mathrm{Zr}(\mathrm{d}, \mathrm{d}){ }^{90} \mathrm{Zr}$ cross sections at $20.4 \mathrm{MeV}$ measured (private communication from M. Friedman) with a target of accurately known density. The results agreed within 5 percent, and we believe that the normalization of the data is accurate to 10 percent or better.

\section{DISTORTED-WAVE BORN APPROXIMATION ANALYSIS}

The $(d, p)$ and $(d, t)$ angular distributions were analyzed with the distorted-wave code DRC (ref. 16) a general reaction code using spin independent optical potentials. Spectroscopic factors were extracted by normalizing the experimental and theoretical cross sections at the first observed stripping peak and using the relation

$$
\frac{\mathrm{d} \sigma}{\mathrm{d} \Omega}(\exp )=\mathrm{S} \frac{\mathrm{d} \sigma}{\mathrm{d} \Omega}(\mathrm{DRC})
$$

(Symbols are defined in appendix D.)

The optical potentials used in this work were taken from the literature and are of the conventional form containing a real part

$$
-V_{s} f\left(r, r_{s}^{\prime}, a_{s}\right)
$$

and an imaginary part

$$
-W_{s} f\left(r, r_{w}^{\prime}, a_{w}\right)-4 a_{d} w_{d} \frac{d}{d r}\left[f\left(r, r_{d}^{\prime}, a_{d}\right)\right]
$$

The function $f$ is the Woods-Saxon form factor

$$
f\left(r, r^{\prime}, a\right)=\left(1+\exp \frac{r-r^{\prime} A^{1 / 3}}{a}\right)^{-1}
$$


where $\mathrm{A}$ is the atomic mass number and the various parameters are listed in table II. A diffuse coulomb potential is also included. The proton parameters are taken from the $30 \mathrm{MeV}$ analysis of Satchler (ref. 17) and are derived from his average potential set 1 , neglecting the spin-orbit term. The triton parameters are taken from the $20-\mathrm{MeV}$ studies at Los Alamos (ref. 18). They are identical to those in the set given for zirconium-90 which has a depth equal to about three times that of a proton optical potential. It is assumed that these potentials are still valid at the energies found in these experiments. The deuter on potential used to generate elastic cross sections for the normalization of the data was also used for the DWBA calculations.

Since DRC calculates only stripping cross sections, the $(d, t)$ cross sections were found by calculating the stripping cross section for the inverse $(t, d)$ reaction and then invoking the detailed balance relation. For a zero spin target it is

$$
\frac{d \sigma}{d \Omega}(d, t)=\left[\frac{2}{3}(2 J+1)\left(\frac{M}{M+1}\right)^{2} \frac{M_{t} E_{t}}{M_{d} E_{d}}\right] \frac{d \sigma}{d \Omega}(t, d)
$$

where $J$ is the spin and $M$ is the mass of the final nucleus in the $(d, t)$ reaction. The masses $M_{t}$ and $M_{d}$ and the energies $E_{t}$ and $E_{d}$ of the triton and deuteron are taken in the laboratory frame.

The bound-state wave functions were taken to be the eigenfunctions of a single particle in a Woods-Saxon (eq. (2c)) well containing a spin-orbit term of the Thomas-Fermi type, that is,

$$
-\mathrm{V}_{\mathrm{So}} x_{\pi}^{2} \vec{\sigma} \cdot \vec{l} \frac{1}{\mathrm{r}} \frac{\mathrm{d}}{\mathrm{dr}}\left[\mathrm{f}\left(\mathrm{r}, \mathrm{r}_{\mathrm{s}}, \mathrm{a}_{\mathrm{s}}\right)\right]
$$

where

$$
\vec{\sigma} \cdot \vec{\imath}=\left(\begin{array}{c}
-l-1 \\
l
\end{array}\right) \quad \text { for } \quad \mathrm{j}=\left(\begin{array}{l}
l-\frac{1}{2} \\
l+\frac{1}{2}
\end{array}\right)
$$

Here $\lambda_{\pi}$ is the Compton wavelength of the pion, and $j$ and $l$ are the total and orbital angular momenta of the particle. Since there are no universally accepted parameters for the bound-state potential well, two quite different sets were used in order to estimate the uncertainty in the analysis. Potential set $A$ in table II was taken from an optical model study of the scattering of $20-\mathrm{MeV}$ protons (ref. 19). Potential set B was taken 
TABLE П. - PARAMETERS USED IN DWBA

ANALYSIS OF THE DATA

[The potential depths are in MeV and the geometrical dimensions are in femtometers (fermis).]

\begin{tabular}{|c|c|c|c|c|c|}
\hline & \multirow[t]{2}{*}{ Proton } & \multirow[t]{2}{*}{ Deuteron } & \multirow[t]{2}{*}{ Triton } & \multicolumn{2}{|c|}{ Neutron } \\
\hline & & & & $\begin{array}{c}\text { Potential } \\
\text { set A }\end{array}$ & $\begin{array}{c}\text { Potential } \\
\text { set } \mathrm{B}\end{array}$ \\
\hline $\mathrm{v}_{\mathrm{s}}$ & 54.43 & 96.6 & 152.0 & $-\cdots$ & ---- \\
\hline$r_{s}$ & 1. 12 & 1. 134 & 1.24 & 1.25 & 1.295 \\
\hline$a_{s}$ & .75 & .864 & .684 & .675 & .62 \\
\hline$w_{s}$ & --.-- & -..-- & 19.6 & -..- & ---- \\
\hline$r_{w}$ & $-\cdots-$ & ----- & 1.48 & $\cdots$ & ---- \\
\hline$a_{w}$ & ---- & $-\cdots$ & .771 & $-\cdots$ & ---- \\
\hline$w_{d}$ & 6.36 & 17.83 & -....- & --- & $\cdots$ \\
\hline $\mathrm{r}_{\mathrm{d}}$ & 1. 33 & 1. 377 & - & ---- & 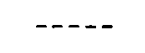 \\
\hline$a_{d}$ & .62 & .633 & 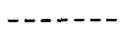 & ----- & ---- \\
\hline $\mathrm{v}_{\text {so }}$ & $-\cdots-$ & ----- & - - - & 6.0 & 9.5 \\
\hline$\beta_{\mathrm{NL}}$ & .85 & .54 & .2 & .85 & .85 \\
\hline$\beta_{\mathrm{FR}}$ & 1.25 & $-\cdots$ & 1.69 & $-\ldots$ & ---- \\
\hline
\end{tabular}

from a study of the systematics of neutron single-particle levels (ref. 20). In both cases the depth $V_{S}$ of the Woods-Saxon well was adjusted by the program until the experimental binding energy of the state being analyzed was achieved.

The DRC program uses local optical potentials and approximates the stripping interaction by a $\delta$-function potential. These simplifications have been discussed in several recent papers, and it has been suggested that they may cause significant errors. We have used the local energy approximation (ref. 21) to correct for the nonlocalities of the optical potentials and the finite range of the stripping interactions. Both corrections generate form factors that are folded into the overlap integral and have the effect of reducing the contribution from the center of the nucleus. In the $(d, p)$ reaction the finite range correction (ref. 22) multiplies the bound-state wave function by

$$
F_{F R}(r)=1-\left[U_{d}^{+}(r)-U_{n}(r)-U_{p}(r)-E_{B}\right] \frac{M_{n} M_{p} \beta_{r}}{2 \hbar^{2} M_{d}}
$$

where the $M_{i}$ and $U_{i}$ are the masses and local optical potentials for the three particles, $E_{B}$ is the binding energy of the deuteron, and $\beta_{r}$ is the range of the $n-p$ inter- 
action. In the $(d, t)$ reaction, $U_{p}$ and $M_{p}$ refer to the triton, $E_{B}$ to the energy required to dissociate a triton into a neutron and a deuteron, and $\beta_{r}$ to the range of the interaction between the two. The nonlocality correction (ref. 21) multiplies each of the wave functions of the three particles by a form factor:

$$
\mathrm{F}_{\mathrm{NL}}(\mathrm{r})=\left[\frac{1-\mathrm{M}_{\mathrm{i}} \beta_{\mathrm{i}}^{2} \mathrm{U}_{\mathrm{i}}(\mathrm{r})}{2 \hbar^{2}}\right]^{-1 / 2}
$$

It is necessary to normalize the bound-state wave function after the form factor has been folded in. The ranges of the stripping interactions $\beta_{r}$ and the nonlocalities $\beta_{i}$ have been taken from Bassel (ref. 23). The corrections markedly improved the quality of the fits to the $(d, p)$ distributions, but had little effect on the $(d, t)$ cross sections except for a 30 percent change in normalization. The uncorrected calculations were used for analyzing the $(d, t)$ results.

The ${ }^{88} \mathrm{Sr}(\mathrm{d}, \mathrm{t}){ }^{87} \mathrm{Sr}$ reaction provides a good test of the DWBA: ${ }^{88} \mathrm{Sr}$ is a closed-shell

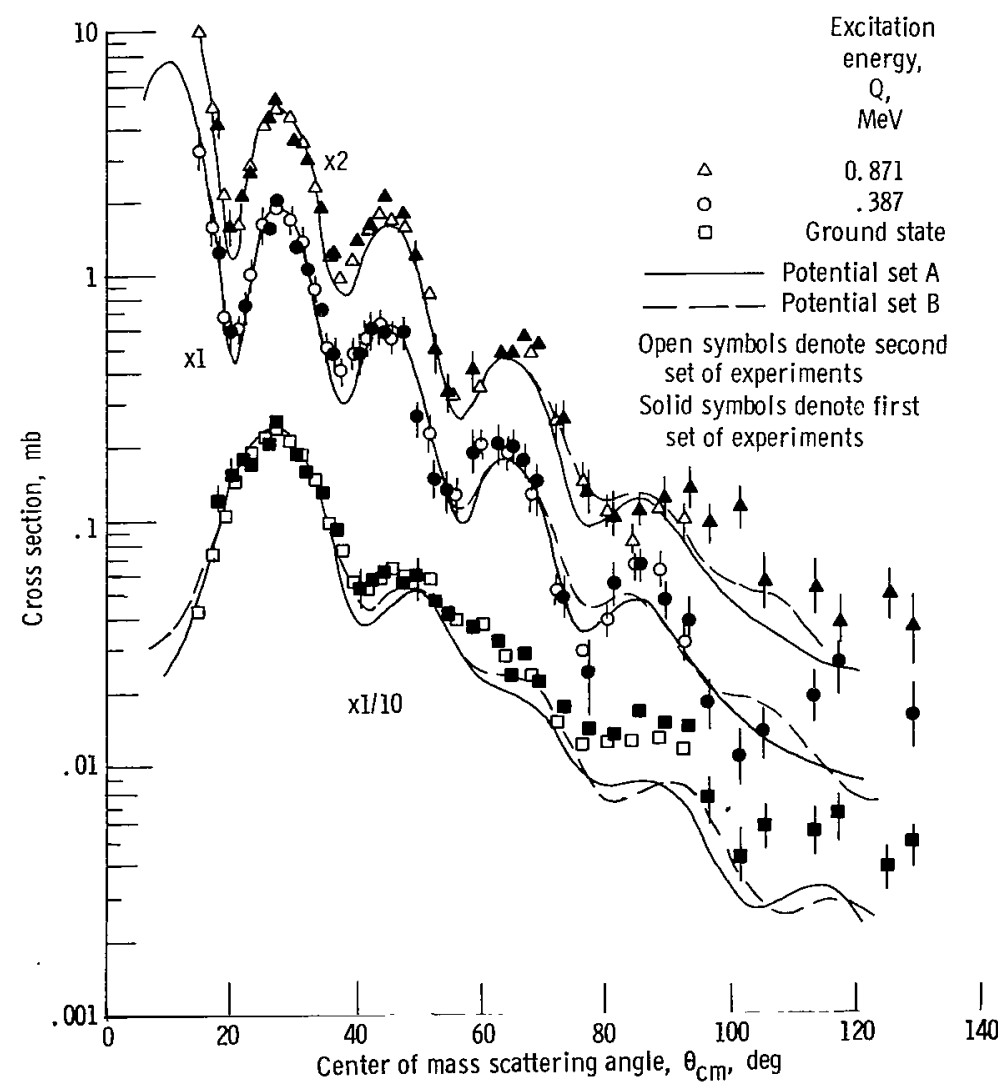

Figure 4. - Comparison of DWBA calculations with angular distributions of first three triton groups in ${ }^{88} \mathrm{Sr}(d, \mathrm{t})^{87} \mathrm{Sr}$ reaction. 
nucleus, and the levels of ${ }^{87} \mathrm{Sr}$ provide a wide range of $l$-values. The ground-state transfer is $l=4, j=9 / 2$. The first two excited state transfers have $l=1$ and are believed to have different $\mathrm{j}$-values (1/2 and 3/2). These three states lie within $1 \mathrm{MeV}$ of each other, minimizing effects of the energy dependence of the reaction.

It is seen in figure 4 that the DWBA does quite well. No attempt was made to optimize the parameters, yet the fits to the stripping peaks are nearly perfect, and the agreements at larger angles are generally better than about 25 percent. Some variations on the optical potentials were tried, but the shape of the reaction cross section was rather insensitive to the details of the potential. This is probably due to the strong absorption in both the deuteron and triton channels. Most of the contribution from the interior is eliminated, and the reaction is dominated by the surface where the shapes of the wave functions are unaffected by small changes in the potentials. There are noticeable differences between the angular distributions computed using bound-state potentials $A$ and $B$, but they are not sufficient to determine the correct potential.

The spectroscopic factors extracted according to equation (1) are listed in table III. The DWBA calculations were made with bound-state potential $A$, and no correction was made for nonlocal and finite-range effects. They also include a multiplication factor of 3.33 which is taken from Bassel's (ref. 23) analysis of the triton internal wave function. The spectroscopic factors for the ${ }^{88} \mathrm{Sr}(\mathrm{d}, \mathrm{t}){ }^{87} \mathrm{Sr}$ reaction should obey the sum rule for closed shells (ref. 24), that is,

$$
\sum S=\frac{N-Z}{2 T+1}
$$

Here, $\mathrm{N}$ and $\mathrm{Z}$ are the numbers of neutrons and protons in the $l, \mathrm{j}$ shell of the target nucleus, and $\mathrm{T}$ is its isotopic spin. The sums over the experimental S-values were carried out and are listed in table IV along with the theoretical values computed from the right-hand side of equation (6). The j-value assignments used are discussed in the next section and are listed in table III. The agreement is very good, but the overall normalization is fortuitous. Including the nonlocal and finite-range corrections reduces it by about 30 percent, and the use of potential $B$ has a similar effect.

The use of bound-state potential $B$ has been eliminated from the analysis because its use violates the uniform satisfaction of the sum rules. The primary change in going to potential $B$ (other than a change in the normalization) is to decrease the $\mathrm{g}_{9 / 2}$ spectroscopic factors by about 30 percent relative to those for $l=1$. Since there is very little splitting of the $l=4$ strength, it is unlikely that much of its strength is missing from the sum. Renormalizing its sum to the theoretical value (ref. 24) results in excessive values for both the p-shell sums.

To what extent can the relative spectroscopic factors be trusted? Apart from the 
TABLE III. - SUMMARY OF RESULTS FOR LEVELS OF STRONTIUM

(a) Strontium-87; obtained from (d, t) and (d, p) reactions; groundstate $Q$-values, -4.86 and $6.21 \mathrm{MeV}$, respectively

\begin{tabular}{|c|c|c|c|c|c|c|}
\hline \multirow{3}{*}{$\begin{array}{c}\text { Kinetic } \\
\text { energy, } \\
\text { E, } \\
\text { MeV }\end{array}$} & \multirow[t]{3}{*}{ Level } & \multirow{3}{*}{$\begin{array}{c}\text { Orbital } \\
\text { momentum, } \\
l\end{array}$} & \multirow{3}{*}{$\begin{array}{c}\text { Total angular } \\
\text { momentum, } \\
\mathrm{j}\end{array}$} & \multicolumn{3}{|c|}{ Reaction } \\
\hline & & & & $(d, t)$ & \multicolumn{2}{|c|}{$(d, p)$} \\
\hline & & & & \multicolumn{2}{|c|}{$\begin{array}{l}\text { Spectrosc opic } \\
\text { factor, S }\end{array}$} & $(2 j+1) S$ \\
\hline 0 & 1 & 4 & $9 / 2$ & 9.3 & 0.127 & 1.27 \\
\hline .38 & 2 & 1 & $1 / 2$ & 1.85 & .09 & .18 \\
\hline .87 & 3 & 1 & $3 / 2$ & 2.71 & .064 & .25 \\
\hline 1.22 & 4 & 2 & $5 / 2$ & $\cdots$ & .11 & .64 \\
\hline 1.25 & 5 & 3 & $5 / 2$ & 4.15 & ---- & --- \\
\hline 1.76 & 6 & 2 & $5 / 2$ & $<.1$ & .46 & 2.77 \\
\hline 2.11 & 7 & 1 & $(1 / 2)$ & .35 & --- & $-\ldots$ \\
\hline & & & $(3 / 2)$ & .31 & --- & -- \\
\hline 2. 16 & 8 & 0 & $1 / 2$ & -.-- & .35 & .70 \\
\hline 2.23 & 9 & (4) & $(9 / 2)$ & 1.7 & -.- & $-\cdots$ \\
\hline 2.41 & 10 & 3 & $5 / 2$ & .70 & --- & $\ldots$ \\
\hline 2.54 & 11 & (a) & (a) & & --.- & --- \\
\hline 2.69 & 12 & 1 & $(3 / 2)$ & .53 & & \\
\hline 2.84 & 13 & (1) & $(3 / 2)$ & .42 & ---- & --- \\
\hline
\end{tabular}

(b) Strontium-85; obtained from $(d, t)$ and $(d, p)$ reactions; groundstate $Q$-values, -5.27 and $6.26 \mathrm{MeV}$, respectively

\begin{tabular}{|l|c|l|c|c|c|c|}
\hline 0 & 1 & 4 & $9 / 2$ & 7.62 & 0.21 & 2.09 \\
.24 & 2 & 1 & $1 / 2$ & 1.51 & .27 & .54 \\
.75 & 3 & 2 & $5 / 2$ & --- & .14 & .86 \\
.76 & 4 & 1 & $3 / 2$ & 2.11 & --- &.-- \\
.91 & 5 & 3 & $5 / 2$ & .59 & --- & -- \\
1.15 & 6 & 1 & $3 / 2$ & .68 & --- & --- \\
1.36 & 7 & 2 & $5 / 2$ & --- & .33 & 1.99 \\
1.67 & 8 & 1 & $(1 / 2)$ & .84 & --- & --- \\
& & & $(3 / 2)$ & .74 & -- & --- \\
1.82 & 9 & 2 & $5 / 2$ & --- & .10 & .59 \\
1.93 & 10 & 1 & $(3 / 2)$ & .20 & --- &.-- \\
2.09 & 11 & 3 & $5 / 2$ & 1.83 & --- & --- \\
\hline
\end{tabular}

(c) Strontium-83; obtained from (d,t) reaction; ground-state Q-value, $-5.78 \mathrm{MeV}$

\begin{tabular}{|c|c|c|c|c|}
\hline $\begin{array}{c}\text { Energy, } \\
\text { E, } \\
\text { MeV }\end{array}$ & Level & $\begin{array}{c}\text { Orbital } \\
\text { momentum, } \\
l\end{array}$ & $\begin{array}{l}\text { Total angular } \\
\text { momentum, } \\
\mathbf{j}\end{array}$ & \begin{tabular}{|} 
Spectro- \\
sc opic \\
factor, \\
S
\end{tabular} \\
\hline 0 & 1 & 4 & $9 / 2$ & 6.10 \\
\hline .25 & 2 & 1 & $(1 / 2)$ & .96 \\
\hline .47 & 3 & 3 & $(5 / 2)$ & 3.66 \\
\hline .68 & 4 & 1 & $(3 / 2)$ & 1.34 \\
\hline .96 & 5 & (1) & $(3 / 2)$ & .87 \\
\hline 1.23 & 6 & -- &.-- & --- \\
\hline 1.41 & 7 & -- & -... & $\therefore$ \\
\hline 1.75 & 8 & --. & ---- & --- \\
\hline
\end{tabular}


TABLE IV. - COMPARISON OF THE SUMS OF SPECTROSCOPIC

FACTORS FOR THE DIFFERENT ISOTOPES OF STRONTIUM

AS OBTAINED BY THE (d,t) REACTION

[The last column gives the sum rule limit for a closed shell. The numbers in the parentheses are the sums assuming that all $\ell=1$ states except the first are $j=3 / 2$.]

\begin{tabular}{|c|c|c|c|c|}
\hline \multirow{3}{*}{$\begin{array}{c}\text { Orbital and total } \\
\text { angular momentum, } \\
l, \mathrm{j}\end{array}$} & \multicolumn{4}{|c|}{ Strontium isotope } \\
\hline & 88 & 86 & 84 & Full shell \\
\hline & \multicolumn{4}{|c|}{ Spectroscopic factor, $\mathbf{S}$} \\
\hline $\mathrm{g}_{9 / 2}$ & 11.0 & 7.62 & 6.1 & 10.0 \\
\hline$p_{1 / 2}$ & $\begin{array}{c}2.20 \\
(1.85)\end{array}$ & $\begin{array}{c}2.35 \\
(1.51)\end{array}$ & $(0.96)$ & 2.0 \\
\hline $\mathrm{p}_{3 / 2}$ & $\begin{array}{c}3.66 \\
(3.97)\end{array}$ & $\begin{array}{c}2.99 \\
(3.73)\end{array}$ & 2.21 & 3.64 \\
\hline$f_{5 / 2}$ & 4.85 & 2.42 & 3.66 & 5.45 \\
\hline$g+p$ & 16.8 & 12.9 & 9.3 & 15.64 \\
\hline
\end{tabular}

experimental uncertainty of the cross section, the major source of uncertainty comes from a lack of knowledge of the bound-state potential used in the DWBA calculations. Four types of states are populated in the $(\mathrm{d}, \mathrm{t})$ reactions: $1 \mathrm{~g}_{9 / 2}, 2 \mathrm{p}_{1 / 2}, 2 \mathrm{p}_{3 / 2}$, and $1 f_{5 / 2}$. The theoretical ratio $\sigma\left(g_{9 / 2}\right) / \sigma(p)$ was not well defined for the potentials tried, thus the relative spectroscopic factors for $\mathrm{p}$ and $\mathrm{g}$ states are not well defined. On the other hand, the sum rules were uniformly satisfied in the ${ }^{88} \mathrm{Sr}(\mathrm{d}, \mathrm{t}){ }^{87} \mathrm{Sr}$ reaction, which indicates that relative S-values are quite good. This argument cannot be used to estimate the uncertainty due to spin dependence, as the $\mathrm{j}$-values of the $l=1$ states are not well defined. It should be small (less than 10 percent) since it depends on $\vec{l} \cdot \vec{\sigma}$ which is small.

If figure 4 is inspected closely it is seen that there is a significant difference between the depths of the minima of the $j=1 / 2$ and $3 / 2$ data near $80^{\circ}$ and $100^{\circ}$. This is similar to the $j$-dependence found in other studies and was somewhat useful in determining the $j$-values for other $l=1$ transitions.

A similar study was carried out for the ${ }^{88} \operatorname{Sr}(d, p){ }^{89} \mathrm{Sr}$ reaction. The strongly popu- 
lated low lying states of ${ }^{89} \mathrm{Sr}$ are based on the $2 \mathrm{~d}_{5 / 2}, 3 \mathrm{~s}_{1 / 2}$, or $2 \mathrm{~d}_{3 / 2}$ single-particle orbitals. The zero-range DWBA was much less accurate in describing these data than the data for the $(d, t)$ studies. This was especially true for the $1.031-\mathrm{MeV}$ state which is an $l=0$ transfer. The calculation predicted a peak at either $20^{\circ}$ or $40^{\circ}$ depending on whether a conventional cutoff was used or not, but it did not predict the double peak seen in the data. The calculations were then repeated including nonlocal and finiterange corrections having the parameters of references 22 and 23 . Very satisfactory fits were produced for both the $l=0$ and $l=2$ distributions (fig. 5). Potential set A was used for all the calculations, but set B produced essentially the same results.

There is some evidence of a $\mathrm{j}$-dependence in the $l=2$ distributions if it is as-

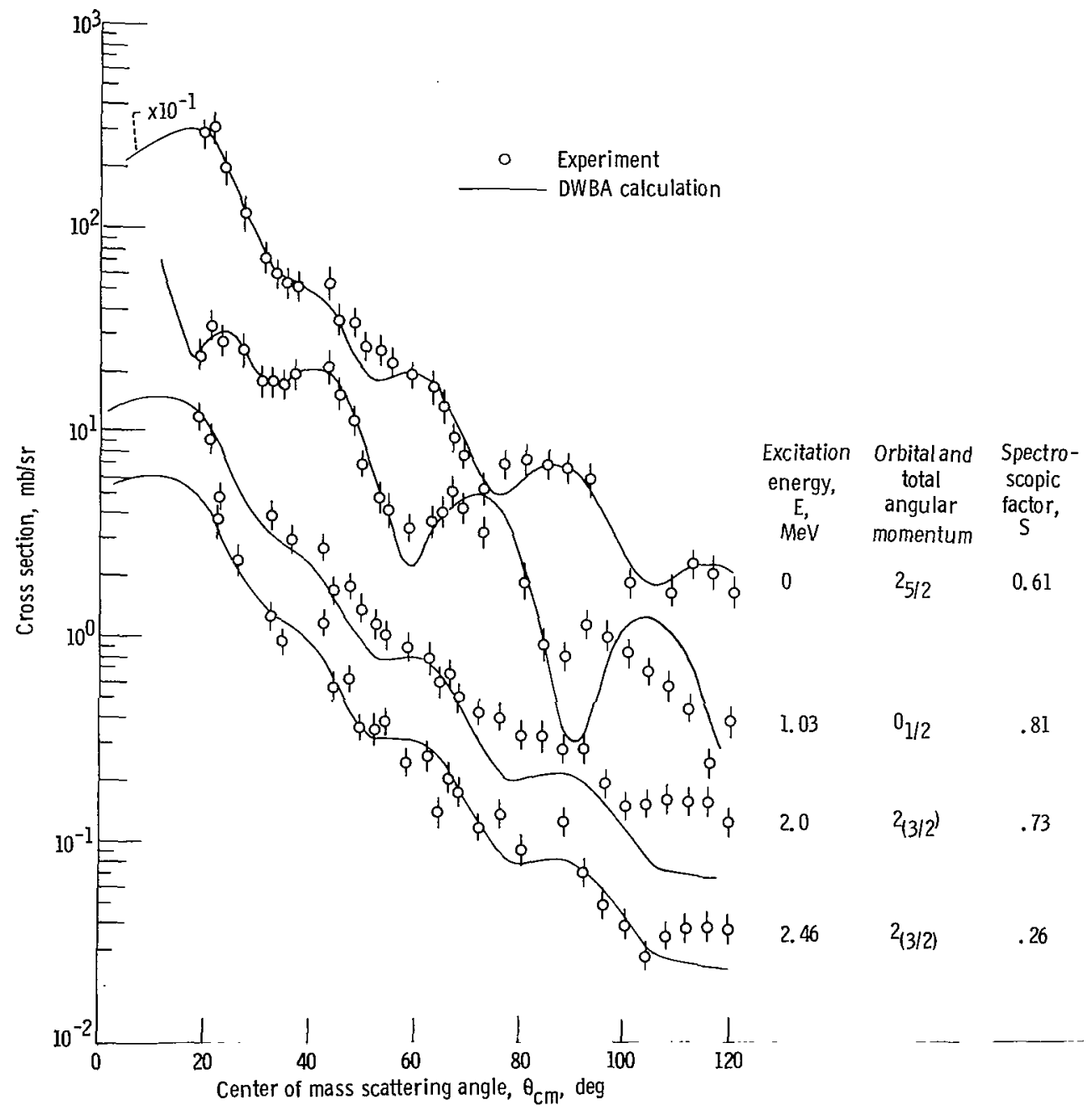

Figure 5. - Comparison of DWBA calculations with angular distributions of proton groups in ${ }^{88} \mathrm{Sr}(\mathrm{d}, \mathrm{p}){ }^{89} \mathrm{Sr}$ reaction. The $2.0-\mathrm{MeV}$ group is unresolved sum of two strong orbital momentum $l=2$ transitions to states at 1.931 and $2.000 \mathrm{MeV}$ plus two weak nonstripping transitions to states at 2.059 and $2.071 \mathrm{MeV}$ (These states have been resolved in ref. 25). 
sumed that only the ground state is $j=5 / 2$. The ground-state distribution shows more oscillatory behavior than either the transitions to the unresolved $1.931-$ and $2.000-\mathrm{MeV}$ states or the $2.455-\mathrm{MeV}$ state.

On the other hand, the $j$-dependence may be illusory since the $(d, p)$ data were not as clean as those in the $(d, t)$ reactions. There were a number of weak contaminants in the spectra (ref. 25) and the transitions to the 1.931- and 2.000-MeV levels were not resolved from two weak nonstripping transitions to levels at 2.051 and $2.071 \mathrm{MeV}$.

Not much can be said about the normalization. There is considerable fragmentation of the $l=2$ states and Cosman et al. (ref. 25) have shown that about 30 percent of the $l=0$ strength lies in states not observed in this experiment. If this same factor is applied to the present data, the $3 \mathrm{~S}_{1 / 2}$ sum rule is exceeded by 15 percent. The $2 d_{5 / 2}$ sum rule however is only 60 percent filled by the ground-state transition. It is most likely that some of the higher $l=2$ states should be assigned $j=5 / 2$. The two higher $l=2$ groups that we observed, which comprise only about half of the strength seen by Cosman et al., already exceed the $\mathrm{j}=3 / 2$ sum rule.

\section{INDIVIDUAL LEVELS}

\section{Levels of Strontium-87}

The cross sections found in the $(d, p)$ and $(d, t)$ experiments are shown in figures 6 to 9 . A summary of the results of the experiments on ${ }^{87} \mathrm{Sr}$ is given in table III and a comparison of the observed levels with data from other sources is shown in figure 10. The Nuclear Data Sheets (ref. 26) summarize a number of experiments on the structure of ${ }^{87} \mathrm{Sr}$. It is fairly well agreed that the ground state has $\mathrm{J}^{\pi}=9 / 2^{+}$, that the first excited state at $388 \mathrm{keV}$ has $1 / 2^{-}$, and that the next state at $874 \mathrm{keV}$ probably has $3 / 2^{-}$. An additional state at $1.22 \mathrm{MeV}$ has been identified (refs. 27 and 28). There have been subsequent studies using the $(\mathrm{d}, \alpha)$ reaction (ref. 29) and also neutron capture gamma rays (ref. 30). These have yielded several new states but little information about the nature of these states. There recently appeared a paper on the $\left({ }^{3} \mathrm{He}, \alpha\right)$ reaction (refs. 31 and 32) in which additional spin assignments are made.

The data on the first three states have already been discussed in the previous section, and it is sufficient to say that they are in good agreement with the Nuclear Data Sheets. The data strongly support a $3 / 2^{-}$assignment for the $874-\mathrm{keV}$ state. An assignment of $1 / 2^{-}$for both it and the $388-\mathrm{keV}$ state greatly violates the $l=1, j=1 / 2$ sum rule.

The state at $1.25 \mathrm{MeV}$ is strongly populated by the $(\mathrm{d}, \mathrm{t})$ reaction, and the data are consistent with an $l=3$ transfer corresponding to the expected $f_{5 / 2}$ neutron pickup. 


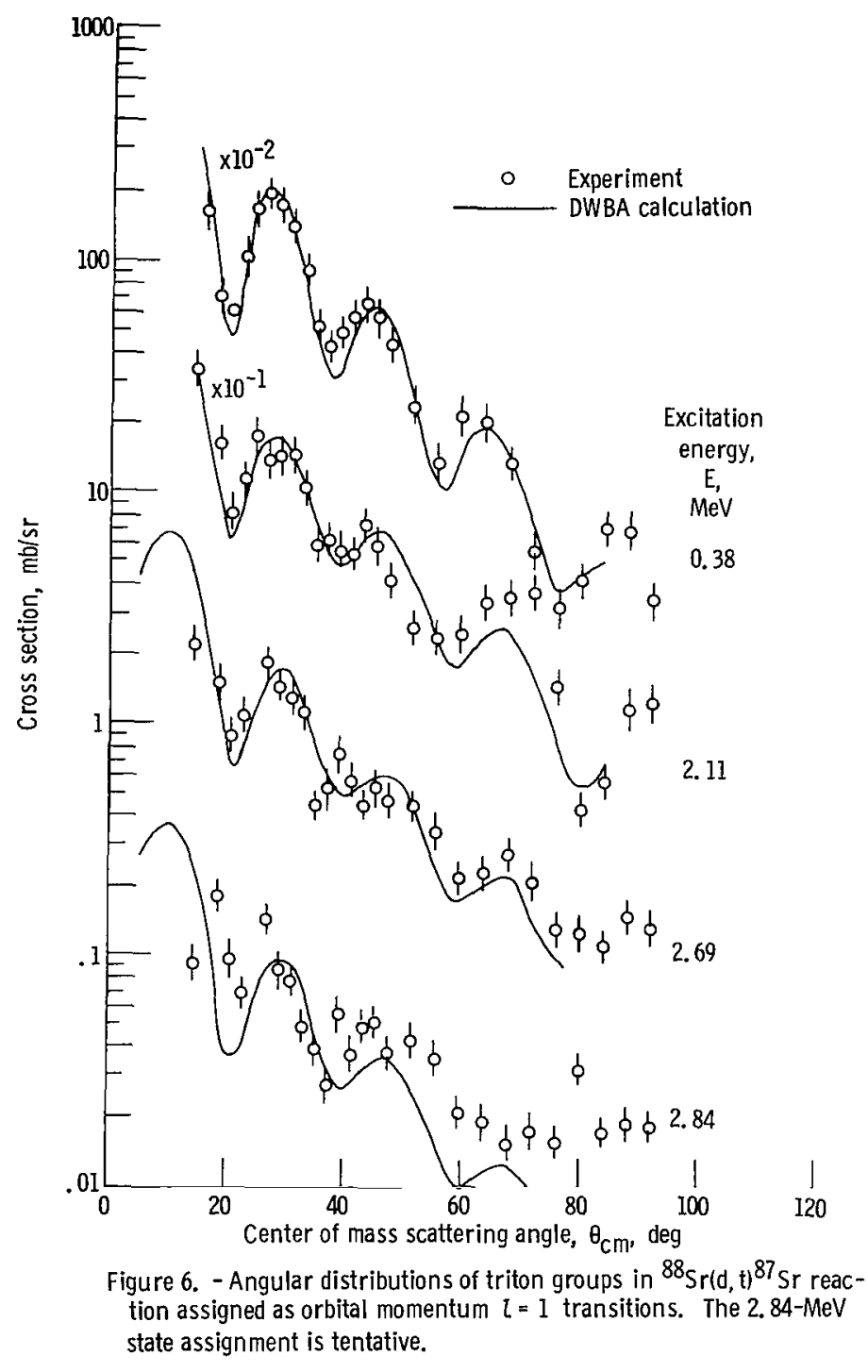



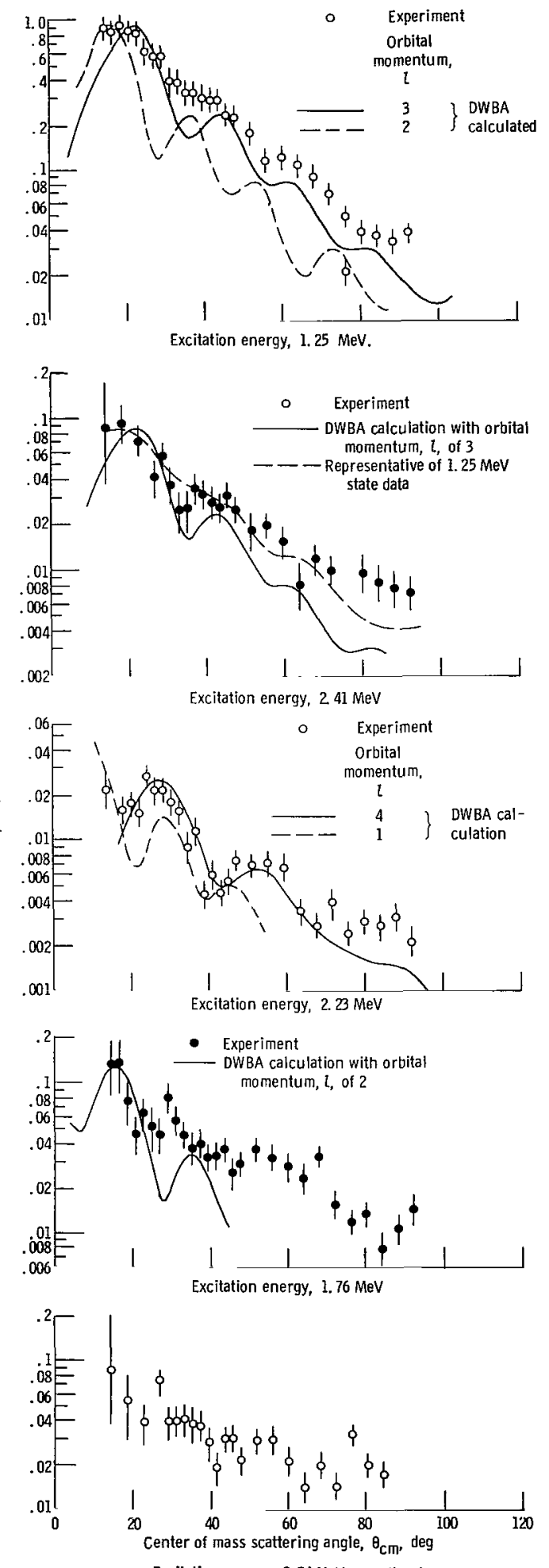

Excitation energy, $2.54 \mathrm{MeV}$; nondirect

Figure 7. - Angular distributions of triton groups in ${ }^{88} \mathrm{Sr}(\mathrm{d}, \mathrm{t})^{87} \mathrm{Sr}$ reaction assigned orbital momentum values other than one. (The 2. 23-MeV data are probably a mixture of $l=4$ and $l-1$ transitions to two unresolved states.)

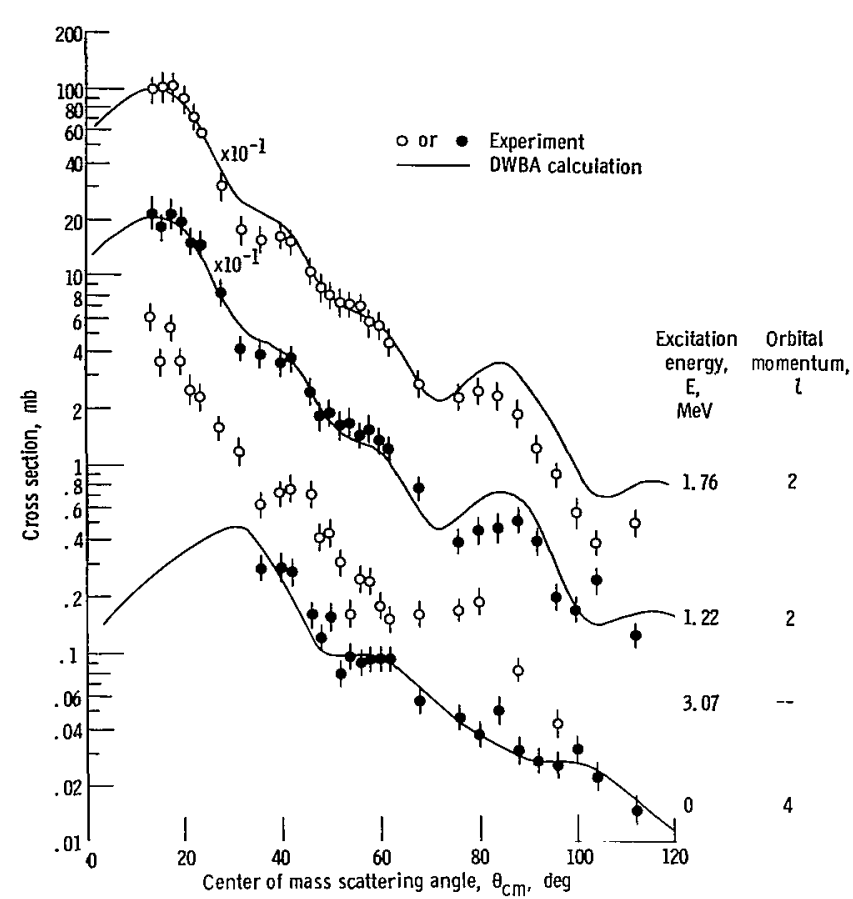

Figure 8. - Angular distributions of high orbital momentum transitions in ${ }^{86} \mathrm{Sr}(\mathrm{d}, \mathrm{p})^{87} \mathrm{Sr}$ reaction.

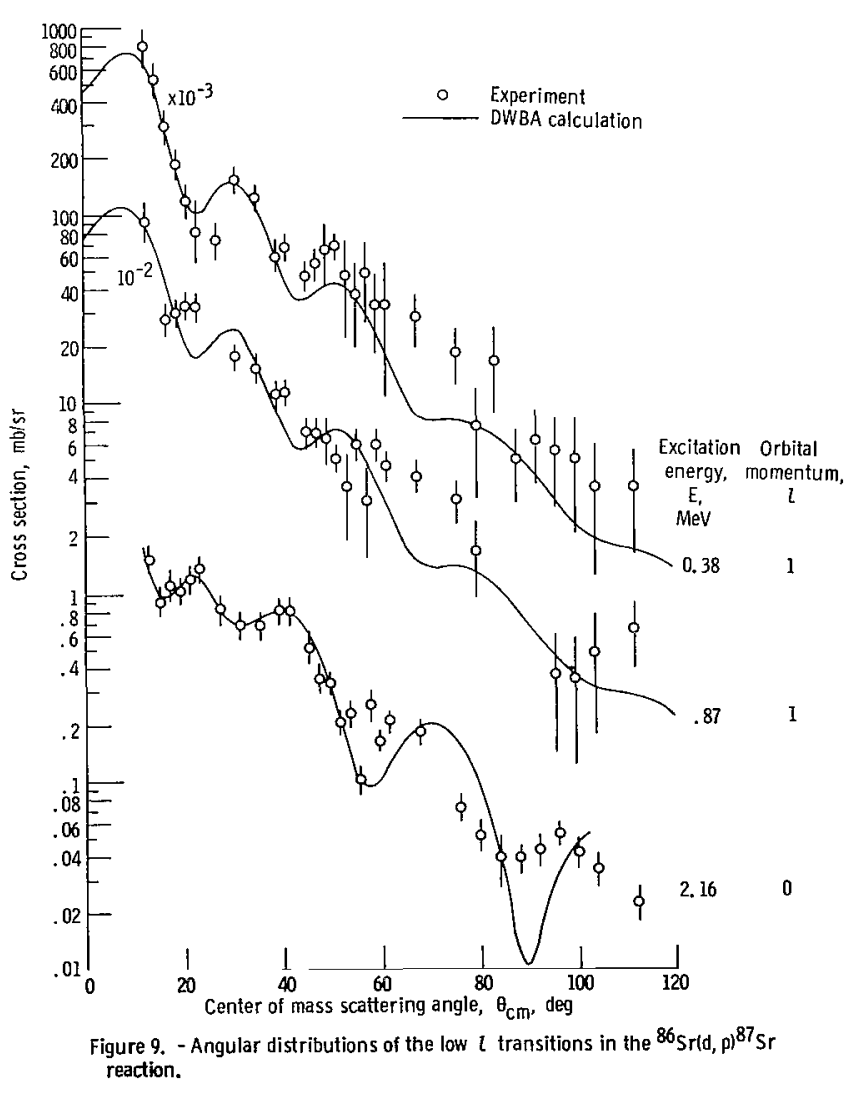




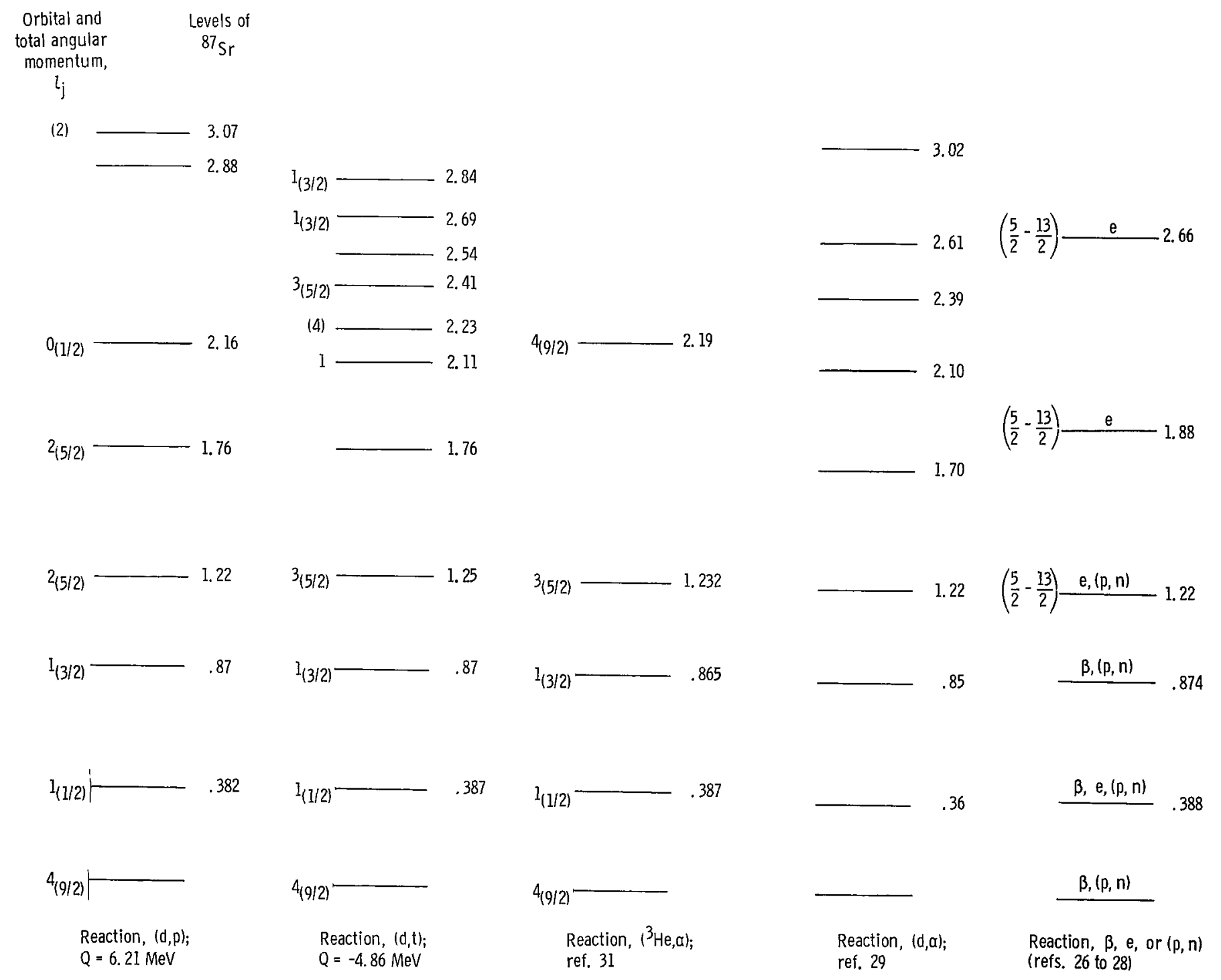

Figure 10. - Comparison of levels of strontium-87 below $3 \mathrm{MeV}$ obtained in present experiment with previous work. 
The spectroscopic factor is large, and exhausts two thirds of the total $f_{5 / 2}$ strength. Similar results are obtained from the $\left({ }^{3} \mathrm{He}, \alpha\right)$ reaction (ref. 31$)$. The DWBA fit to the $(d, t)$ reaction was not good (see fig. 6), however, and it was suspected that the level was a doublet. A check was made on the shape by measuring ${ }^{90} \mathrm{Zr}(\mathrm{d}, \mathrm{t})^{89} \mathrm{Zr}$ where it is known that there is an isolated $f_{5 / 2}$ state at nearly the same energy (ref. 33). The cross section was essentially identical to that in ${ }^{87} \mathrm{Sr}$ showing that the failure is in the DWBA and that there is no need to invoke a second state. However, it is not clear why the theory should be poorer for $l=3$ transfers than for others.

The $(\mathrm{d}, \mathrm{p})$ reaction also populates a state near this energy, but with an $l=2$ distribution which is almost identical to the ground state distribution in ${ }^{88} \mathrm{Sr}(\mathrm{d}, \mathrm{p}){ }^{89} \mathrm{Sr}$. It has about $1 / 5$ of the strength expected of an empty $2 d_{5 / 2}$ shell. The energy of the level is slightly less $(1.22 \mathrm{MeV})$, and it is believed that there are two $j=5 / 2$ levels at this energy. One is nearly full $(l=3)$ and is populated only in the $(d, t)$ reaction, but the other is nearly empty $(l=2)$ and is populated only in the $(d, p)$ reaction. A second $l=3$ state is seen at $2.41 \mathrm{MeV}$.

A state at $1.76 \mathrm{MeV}$ is populated by both the $(\mathrm{d}, \mathrm{p})$ and $(\mathrm{d}, \mathrm{t})$ reactions. The strongest observed transfer in the $(d, p)$ reaction is to this state. The sum of the strengths for the 1.22- and 1.76- MeV state (d, p) transitions is almost equal to that for the groundstate transition in the ${ }^{88} \mathrm{Sr}(\mathrm{d}, \mathrm{p}){ }^{89} \mathrm{Sr}$ reaction. The $(\mathrm{d}, \mathrm{t})$ transition to this state is very weak and does not have a pickup pattern. Since this transition is forbidden if the $N=50$ shell is well closed (i. e., no $d_{5 / 2}$ or higher orbitals in the ground state of ${ }^{89} \mathrm{Sr}$ ), the observation of it indicates the contrary. Only a slight admixture of the $2 \mathrm{~d}_{5 / 2}$ orbital, less than 0.1 particle, is required in ${ }^{88} \mathrm{Sr}$ to give the observed $(\mathrm{d}, \mathrm{t})$ strength. Although this would not be surprising, it is more likely that the reaction is not direct and represents a small breakdown of simple stripping theory. There is no evidence that the level is a doublet.

The $2.23-\mathrm{MeV}$ state is observed only in the $(\mathrm{d}, \mathrm{t})$ reaction. The cross section is best described by $l=4$, but the most forward datum is definitely above the curve. The anomaly could be explained either by an undetected contaminant or by an unresolved level having a smaller $l$-value. The level was also assigned $\mathrm{g}_{9 / 2}$ in a $\left({ }^{3} \mathrm{He}, \alpha\right)$ experiment (ref. 31). It gave $S=1.6$ in good agreement with this experiment (1.7). Since the $\left({ }^{3} \mathrm{He}, \alpha\right)$ reaction preferentially populates high spin states, contaminants would affect the $\left({ }^{3} \mathrm{He}, \alpha\right)$ results less than ours. This agreement suggests that only one state is populated.

Three levels above $2 \mathrm{MeV}$ were identified in the $(\mathrm{d}, \mathrm{t})$ spectra as having $l=1$ transfers: $2.11,2.69$, and $2.84 \mathrm{MeV}$. The data on the $2.84 \mathrm{-MeV}$ level are poor and only a tentative assignment is made. There is some evidence about the spins of the states. Table $\mathrm{III}(\mathrm{a})$ shows that the sum rule for $2 \mathrm{p}_{1 / 2}$ is almost exhausted by the $387-\mathrm{keV}$ transition suggesting that most of the states are spin $3 / 2$. The $2 \mathrm{p}_{1 / 2}$ and 
$2 \mathrm{p}_{3 / 2}$ sum rules would be the most uniformly filled if one of the levels were taken as $j=1 / 2$, but they all could be $j=3 / 2$ and be within the uncertainty of the experiment. The empirical $\mathrm{j}$-dependence seen in the experiment indicates that the 2.11-MeV state should be singled out as $j=1 / 2$ since its cross-section minimum near $80^{\circ}$ is as deep as that for the $j=1 / 2$ state at $387 \mathrm{keV}$.

\section{Levels of Strontium-85}

The only existing information about the levels of ${ }^{85} \mathrm{Sr}$ has been provided by a number of studies (e.g., refs. 34 and 35) of the positron and K-capture decay of the ground $\left(9 / 2^{+}\right)$and $40 \mathrm{keV}$ metastable $\left(1 / 2^{-}\right)$states of yttrium-85. We will refer mainly to the paper by Horen and Kelly (ref. 35) which is the most recent and complete, as the other studies are in basic agreement. A comparison of the levels seen in the different experiments is shown in figure 11; the results are tabulated in table III(b). The cross sections are shown in figures 12 to 15 .

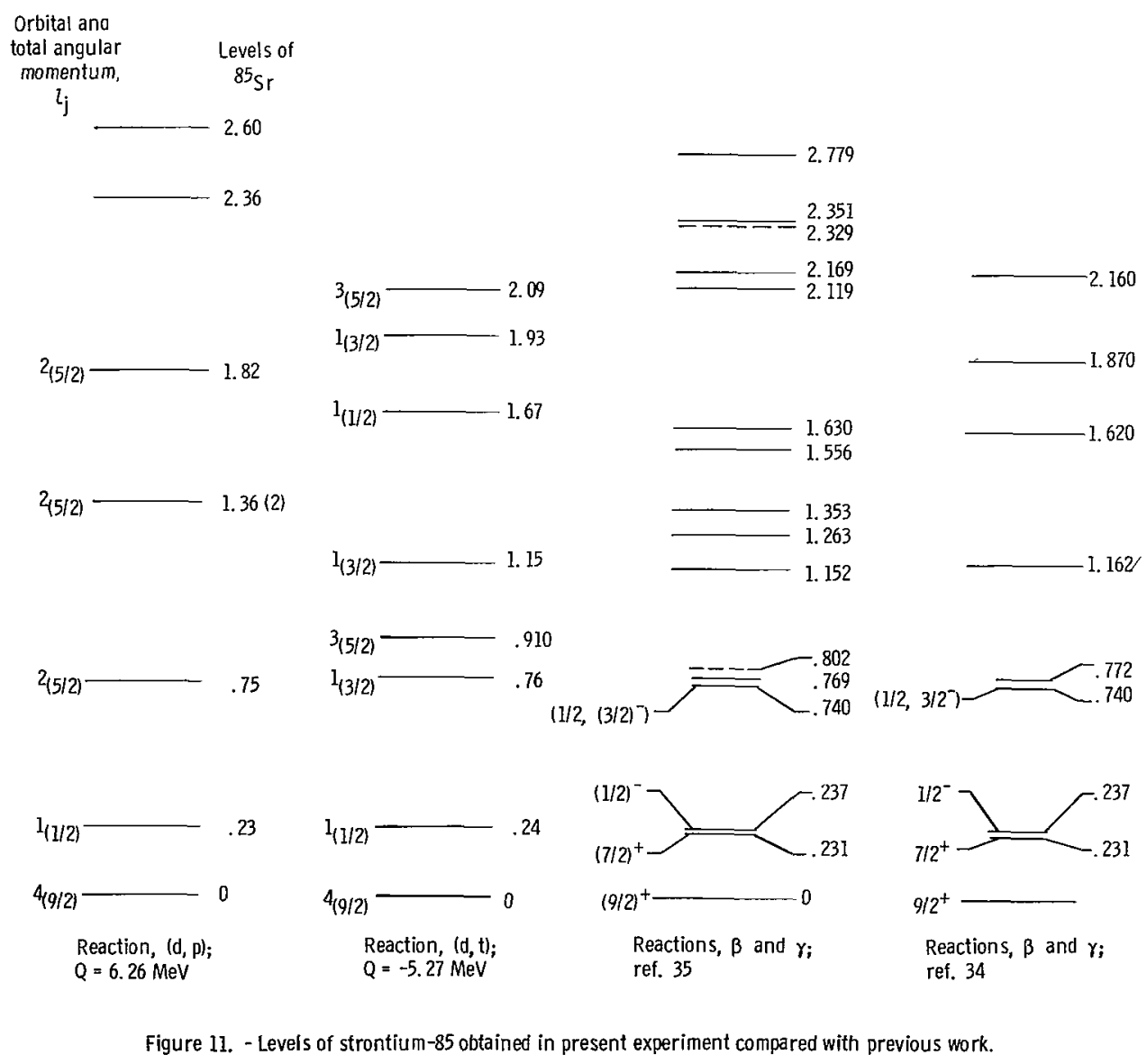




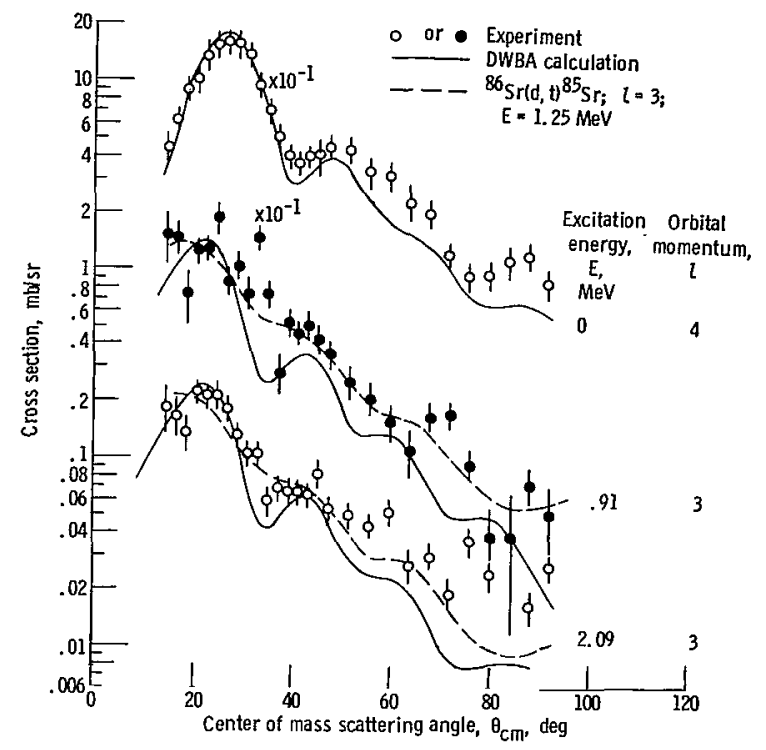

Figure 12. - Angular distributions of high orbital momentum transitions ${ }^{86} \mathrm{Sr}(\mathrm{d}, \mathrm{t})^{85} \mathrm{Sr}$ reaction.

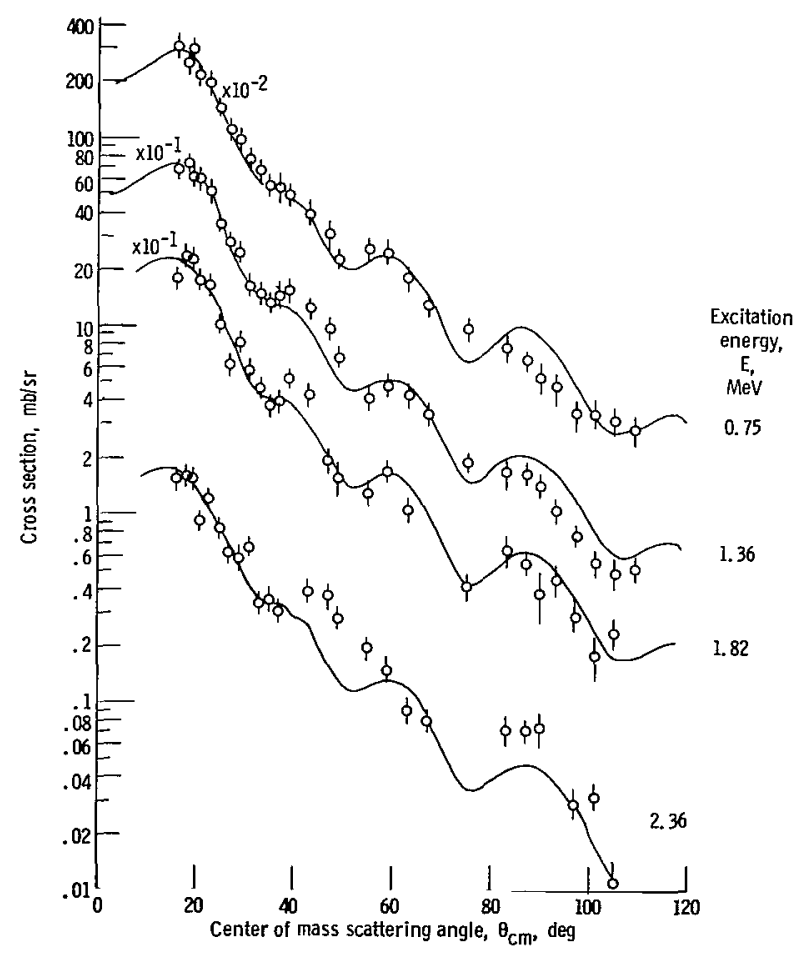

Figure 14. - Angular distributions of proton transitions assigned as $l=2$ in ${ }^{84} S r(d, p)^{85}$ Sr reaction.

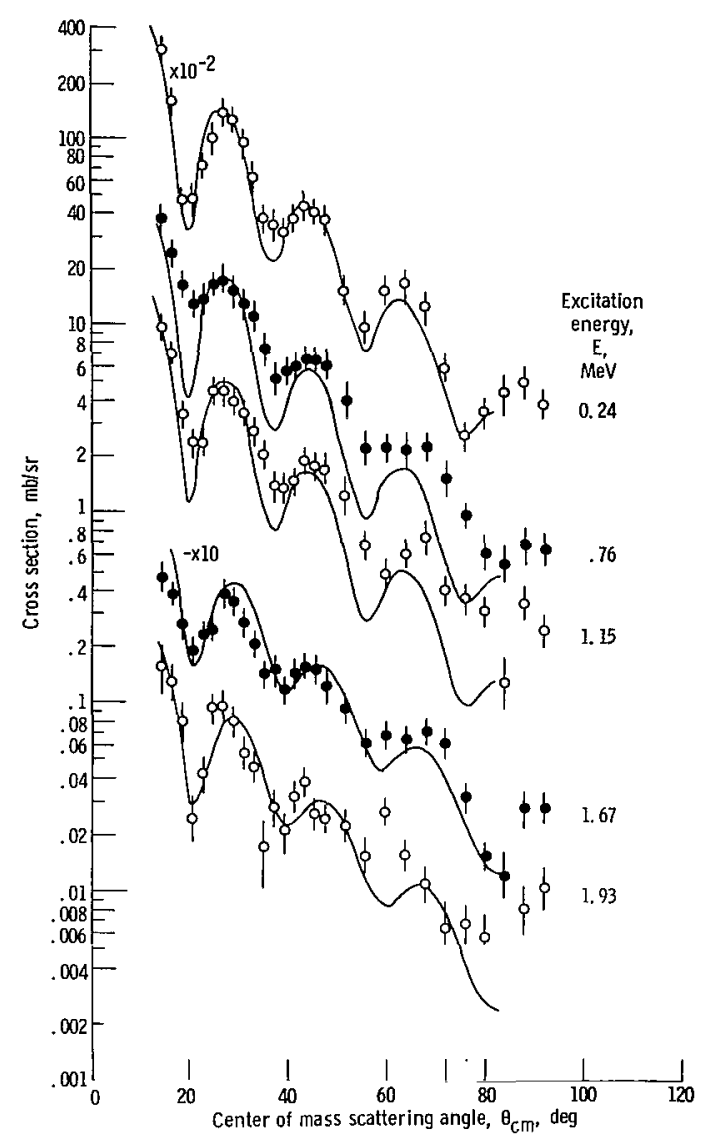

Figure 13. - Angular distributions of transitions assigned as $l=1$ obtained in ${ }^{86} \mathrm{Sr}(\mathrm{d}, \mathrm{t})^{85} \mathrm{Sr}$ reaction.

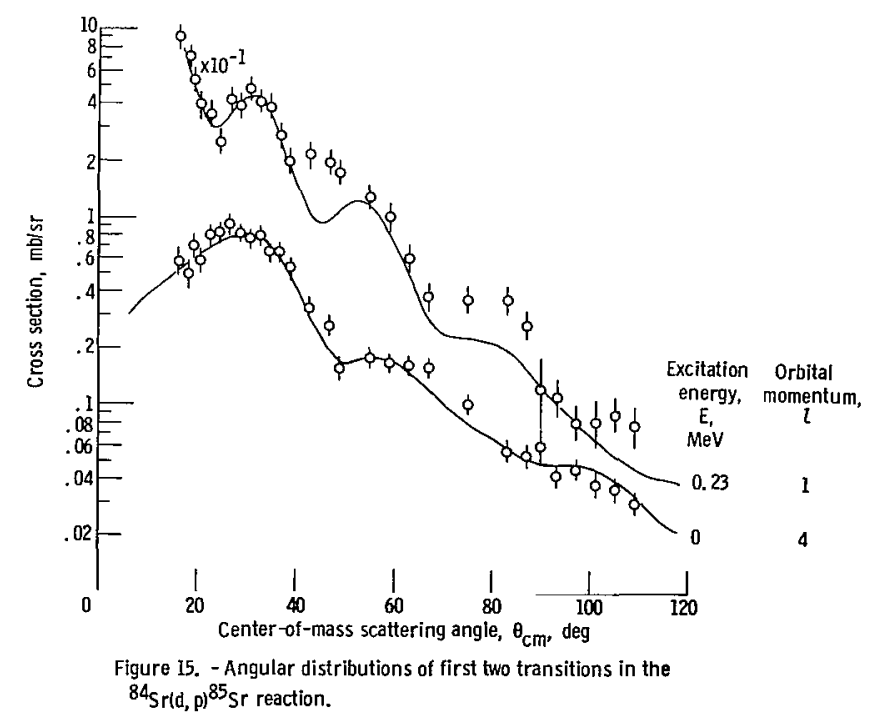


The ground state was populated by both the $(d, p)$ and $(d, t)$ reactions. The $l$-value (table III(b)) and spectroscopic factors were in good agreement. Decay studies give levels of 0.231 and $0.237 \mathrm{MeV}$ with $\mathrm{J}^{\pi}$ of $7 / 2^{+}$and $1 / 2^{-}$. Both $(\mathrm{d}, \mathrm{p})$ and $(\mathrm{d}, \mathrm{t})$ reactions yield clean $l=1$ diffraction patterns indicating that there is a negligible population of the $0.231-\mathrm{MeV}$ state. This state has been described (ref. 3) as a seniority-three combination of three $\mathrm{g}_{9 / 2}$ holes. Since single-particle transfer reactions can only change seniority by one, it is not surprising that it is not populated.

The $(\mathrm{d}, \mathrm{t})$ reaction strongly populates an $l=1$ level at $0.76 \mathrm{MeV}$. Its spin must be $3 / 2$ since an assignment of $1 / 2$ would result in a violation of the $p_{1 / 2}$ sum rule. This is probably the state observed by Horen and Kelly at $740 \mathrm{keV}$. The $(d, p)$ reaction also populates a level at this energy, but the stripping pattern is clearly $l=2$ which would be consistent with a state based on the $2 \mathrm{~d}_{5 / 2}$ orbital. We believe that there is an accidental degeneracy of a nearly full $\mathrm{p}_{3 / 2}$ level and an empty $\mathrm{d}_{5 / 2}$ level. It is doubtful that this is the state observed by Horen and Kelly at $769 \mathrm{keV}$ because the $\underset{\sim}{\sim}$ of a transition to a $5 / 2^{+}$level should be about 9 in contrast to the observed value of 7.1 . There is some additional evidence that there are three nearly degenerate states. The diffraction pattern in the $(\mathrm{d}, \mathrm{t})$ reaction is washed out, and the peak in the summed spectrum is significantly wider than the adjacent peaks. It is unlikely that these effects are due to the ${ }^{88} \mathrm{Sr}$ contamination in the target or to population of the $d_{5 / 2}$ level since the summed spectrum shows only a small yield for comparable levels of the ${ }^{88} \mathrm{Sr}$ contamination and for the other $d_{5 / 2}$ levels of ${ }^{85} \mathrm{Sr}$.

An interpretation consistent with all the data would be to assume that the $(d, t)$ reaction populates both the 740 - and $769-\mathrm{keV}$ levels seen by Horen and Kelly and that the $769-\mathrm{keV}$ has $\mathrm{J}^{\pi}=9 / 2^{+}$. The $(\mathrm{d}, \mathrm{p})$ reaction would only weakly populate these two states.

The states at 0.91 and $2.09 \mathrm{MeV}$ are identified as $l=3$ with a probable $\mathrm{j}$ of $5 / 2$. It is unlikely that either of these was observed by Horen and Kelly. The $910-\mathrm{keV}$ state required special handling to extract the cross section since it is weak and near the strong group at $760 \mathrm{keV}$. Its width was required to be the same as the $760-\mathrm{keV}$ peak, and its position was required to be 14 channels below the $760-\mathrm{keV}$ peak. As a consequence its energy is only known to about $60 \mathrm{keV}$.

The states at 1.36 and $1.82 \mathrm{MeV}$ are observed only in the $(\mathrm{d}, \mathrm{p})$ reaction and are identified as fractions of the $2 \mathrm{~d}_{5 / 2}$ orbital. The sum of $(2 \mathrm{j}+1) \mathrm{S}$ for these states plus the $760-\mathrm{keV}$ state is 3.49 as compared with 3.97 for the ground state of ${ }^{89} \mathrm{Sr}$. It is possible that the $1.36 \mathrm{-MeV}$ state is the same as the $1.35 \mathrm{-MeV}$ state seen by Horen and Kelly, but again the $\underset{\sim}{\mathrm{ft}}$ value should be higher than they reported (approximately 9 against 6.9).

Three states at $1.15,1.67$, and $1.93 \mathrm{MeV}$ are observed only in the $(\mathrm{d}, \mathrm{t})$ reaction, and all have $l=1$ transfers. The $j$-values are not certain. The sum rule would suggest that they are all $j=3 / 2$, however one state could be $j=1 / 2$ without violating it 
badly. The $\mathrm{j}$-dependence indicates that the $1.67-\mathrm{MeV}$ state is $\mathrm{j}=1 / 2$ and that the others are $j=3 / 2$.

Transitions at 2.36 and $2.60 \mathrm{MeV}$ are seen in the $(\mathrm{d}, \mathrm{p})$ reaction, but the quality of the data does not allow an $l$-value determination.

\section{Levels of Strontium-83}

It is only possible to study ${ }^{83} \mathrm{Sr}$ via the $(\mathrm{d}, \mathrm{t})$ reaction since ${ }^{82} \mathrm{Sr}$ is unstable. The $(d, t)$ results are of rather poor quality since the highest ${ }^{84} \mathrm{Sr}$ enrichment available was 75.69 percent. It was felt worthwhile to take the data, however, since there are no existing data on the level structure of the isotope. The three most energetic peaks (see fig. 3) resulted from the other strontium isotopes. The angular distributions for the two strong peaks were extracted and compared with the measured curves from the other experiments. Agreement was excellent, but the normalization indicated that the concentration of ${ }^{88} \mathrm{Sr}$ was 20 percent rather than the analysis value of 17 percent. This value was used as a normalization in subtracting the contaminants from the other angular distributions.

As in the other isotopes of strontium, the lowest state of ${ }^{83} \mathrm{Sr}$ excited by the (d, t) reaction was $l=4$. Normally this would be assumed to be the ground state, but there are some complications which will be discussed later. The cross sections are shown in figure 16. The smooth curves are the measured and smoothed cross sections for the ${ }^{88} \mathrm{Sr}(\mathrm{d}, \mathrm{t}){ }^{87} \mathrm{Sr}$ reaction, not the DWBA calculated curves. The raw data for the $l=4$ transition were contaminated with approximately 40 percent yield at the peak from the reaction to the $0.871-\mathrm{MeV}$ state of ${ }^{87} \mathrm{Sr}$ which has $l=1$. The corrected spectrum is quite well described by the DWBA $l=4$ theoretical curve, which gives confidence in the extraction procedure. The corrections for the contamination of the other states were smaller by at least a factor of two.

There has been some speculation as to the spin of the ground state of ${ }^{83} \mathrm{Sr}$ as the systematics in this region have been ambiguous. As we have been the heavier strontium isotopes had $9 / 2^{+}$ground states, but with the excited $1 / 2^{-}$states rapidly descending; however, all the other nearby $\mathrm{N}=45$ isotones have $7 / 2^{+}$ground states. The $7 / 2^{+}$ states must be rather complex since the $g_{7 / 2}$ single-particle orbital is believed to lie considerably above the $\mathrm{g}_{9 / 2}$ orbital. Talmi and Unna (ref. 3) have predicted a $9 / 2^{+}$ ground state with a $7 / 2^{+}$state at $320 \mathrm{keV}$. The decay of ${ }^{83} \mathrm{Sr}$ has been studied (ref. 36), and it was deduced that the decay originates from a $7 / 2^{+}$state which is probably the ground state. An alternative is that the ground state is actually $1 / 2^{-}$and that the $7 / 2^{+}$ state is an isomer but the investigators were unable to find evidence of an isomeric transition. 


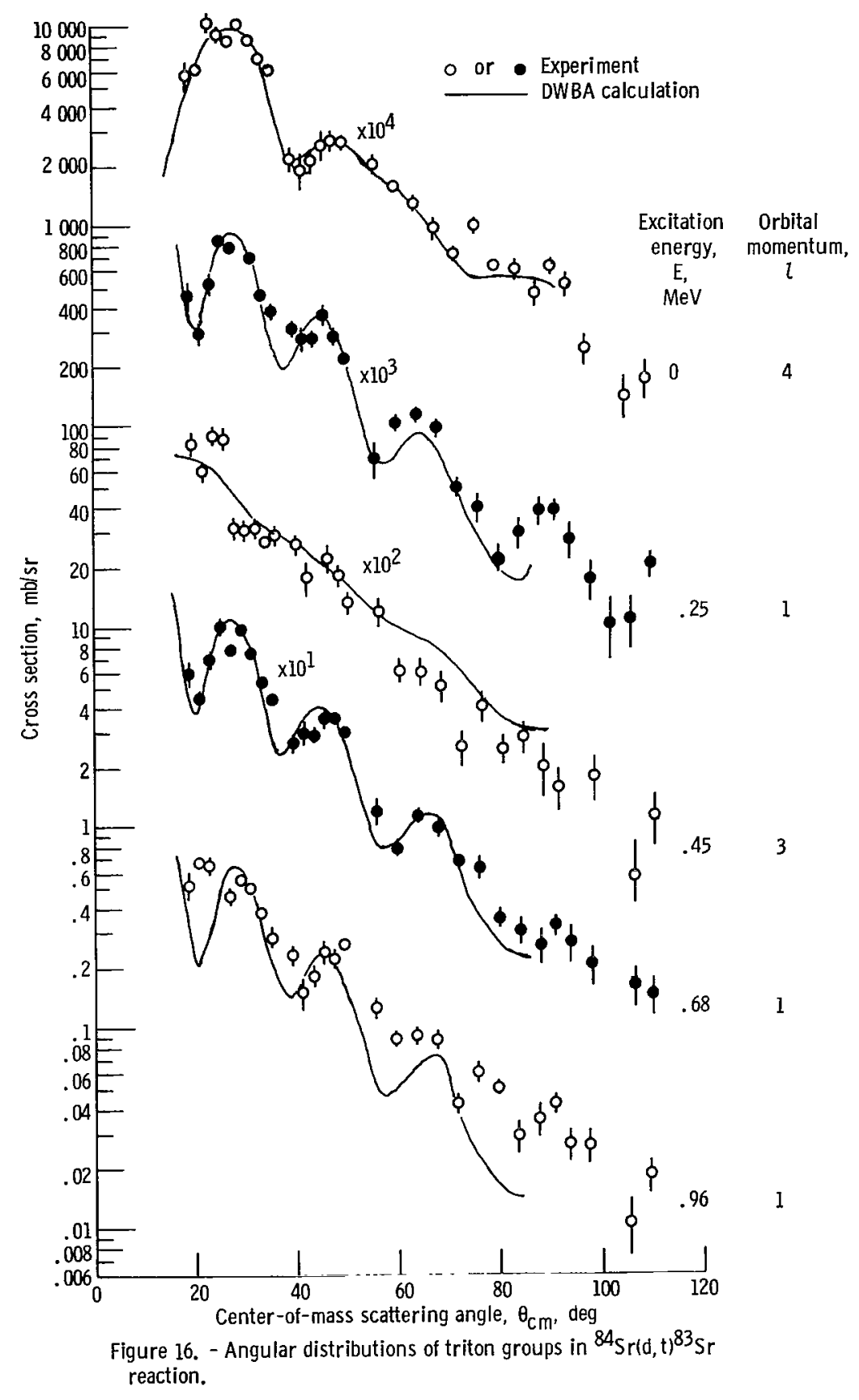




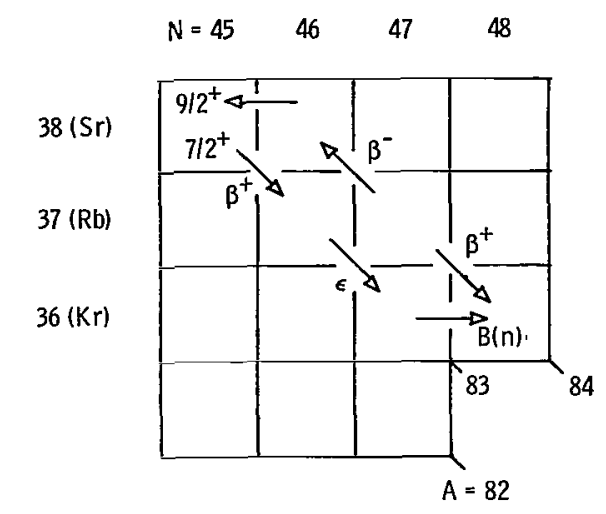

Figure 17. - Mass chain used in evaluating the energy difference between the $7 / 2^{+}$and $9 / 2^{+}$states of strontium-83.

The present experiment only excites seniority-one states and hence would not populate the complex $7 / 2$ state described by Talmi and Unna (ref. 3). It does show that the $9 / 2^{+}$state lies below any simple $1 / 2^{-}$or $3 / 2^{-}$states and so eliminates the choice of $1 / 2^{-}$. The $9 / 2^{+}$state must lie somewhat above the $7 / 2^{+}$state since there can be no isomerism between the two.

At present, only the lower limits of the mass of the ${ }^{83} \mathrm{Sr}$ and rubidium-83 nuclei are known. Their linkage to the masses of other nuclei is through the decay of rubidium-83. The decay is by $\mathrm{K}$-capture (ref. 37) and only a lower limit is known. The $Q$-value of the $(d, t)$ reaction, $-5.755 \pm 0.030 \mathrm{MeV}$, gives the mass of the $9 / 2^{+}$state and thus sets an upper limit on the nuclear mass. If we assume that the rubidium-83 decay energy is equal to the quoted lower limit and take the ${ }^{83} \mathrm{Sr}$ decay energies from Etherton et al. (ref. 36) and the other energy differences in the mass chain seen in figure 17 from the Berkeley tables (ref. 38), we then find that the excitation energy of the $9 / 2^{+}$state is $0.014 \pm 0.033 \mathrm{MeV}$ above that of the $7 / 2^{+}$state. The two states are nearly degenerate. The mass excess for the $9 / 2^{+}$state is $-76.70 \mathrm{MeV}$.

The cross sections for the $0.25 \mathrm{MeV}$-state are well described by the $l=1$ curve, and the deep minima near $80^{\circ}$ and $100^{\circ}$ are consistent with the $j$-dependence observed in ${ }^{88} \mathrm{Sr}(\mathrm{d}, \mathrm{t}){ }^{87} \mathrm{Sr}$, indicating a spin of $\mathrm{j}=1 / 2$. This is in accord with the systematics of the other isotopes.

The cross sections for the $0.47-\mathrm{MeV}$ state are described by an $l=3$ distribution with the exception of a few points which are well outside of statistics. It is believed that the discrepancies are caused by unidentified light contaminants and that the state is indeed a major fraction of the expected $f_{5 / 2}$ shell strength.

The angular distributions for the 0.68 - and $0.96-\mathrm{MeV}$ levels have been assigned, at least tentatively, to $l=1$ transfers. The $0.68-\mathrm{MeV}$ state data are well fitted by $\imath=1$, but the minima at $80^{\circ}$ and $100^{\circ}$ are absent, suggesting that $j=3 / 2$. An assumption 
of $\mathrm{j}=1 / 2$ for both this and the $0.25-\mathrm{MeV}$ level is untenable because the sum of the reduced widths would exceed the rule for even a full $\mathrm{p}_{1 / 2}$ shell. Again, the assignment of $\mathrm{j}=3 / 2$ is in agreement with the systematics of ${ }^{87} \mathrm{Sr}$ and ${ }^{85} \mathrm{Sr}$.

The shape of the angular distribution for the $0.96-\mathrm{MeV}$ level does not fit any of the predicted patterns, but it appears to be $l=1$ with the first minimum filled in. Although it is also similar to an $l=4$ curve, this assignment would lead to violation of the $g_{9 / 2}$ sum rule. We make a tentative assignment of $l=1$ and also specify it to be $j=3 / 2$ since the filling of the sum rules is more uniform.

\section{DISCUSSION}

The shell model suggests that the structures of ${ }^{87} \mathrm{Sr}$ and the other $\mathrm{N}=49$ is otones are very simple. They should each have four low lying states corresponding to single holes in the $g_{9 / 2}, 2 p_{1 / 2}, 2 p_{3 / 2}$, and $f_{5 / 2}$ shells, respectively. Below $1.5 \mathrm{MeV}$ the levels of these nuclei populated by the $(d, t)$ reaction (shown in fig. 18) agree with the simple picture. The order of the spins and orbital angular momenta of the levels are correct; they mostly show smooth variations with mass. The spectroscopic factors are also consistent with the model within the limits of their uncertainties.

This picture is compromised, however, by the results at higher excitation. A significant amount of the pickup strength for all the orbitals lies in the transitions to the higher states. This is true for all the isotones in figure 18 . The relative simplicity of molybdenum-91 and krypton-85 probably results from reduced sensitivity in these experiments (refs. 31 and 39). It has been suggested (ref. 40) that this fragmentation results from coupling of the holes with vibrations of the core, and an explicit calculation has been made by Zawischa and Werner (ref. 41) for the case of ${ }^{87} \mathrm{Sr}$. States consisting of a hole coupled to a vibration would normally not be populated by the $(\mathrm{d}, \mathrm{t})$ reaction, a one step process, but they can receive some strength by mixing with a single-hole state having the same spin and parity. A detailed calculation of the locations and strengths of the resulting states is beyond the scope of this paper, but some feeling for these quantities can be gained by inspecting the locations of the unperturbed states that can couple. One expects greater coupling the closer the states are in energy and the larger the number of possible configurations. The core state of ${ }^{88} \mathrm{Sr}$, which is expected to be most important, is the quadrupole vibration at $1.84 \mathrm{MeV}$, with the octupole state at 2. $74 \mathrm{MeV}$ having less influence. The single-hole states all lie below the vibrations, and it is expected that the higher ones will be affected the most. In addition, the $2 \mathrm{p}_{1 / 2}$ hole can only couple to the single configuration $\left(2^{+} \times p_{3 / 2}\right)$. The $p_{3 / 2}$ and $f_{5 / 2}$ holes can couple to more configurations and are expected to have more fragmentation. This is consistent with the data (table III). 


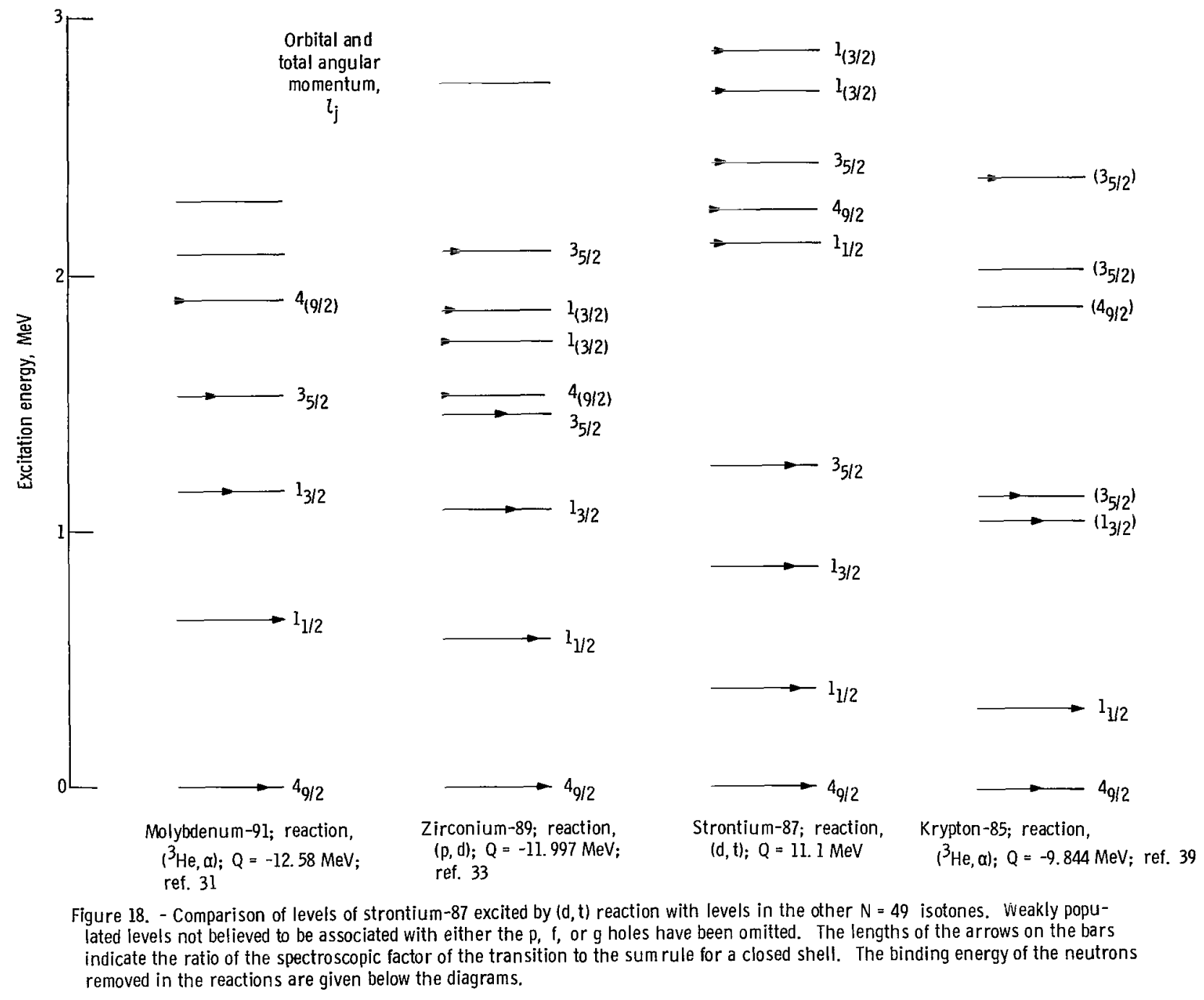

The calculations of Zawischa and Werner (ref. 41) show the states of ${ }^{87} \mathrm{Sr}$ to be badly fragmented with significant pieces extending to $5 \mathrm{MeV}$. Our data are not in agreement with the calculation; the splitting is less both in energy spread and in the number of states. Although it may be argued that the experiment may miss weak states, the states which are excited are not in agreement with the calculation. It is interesting, however, that both theory and experiment have splittings which are characterized by a single low-lying state containing the bulk of the transition strength and a number of weakly excited states all well separated from it.

Cohen (ref. 42) has argued that there is a great similarity between the relative positions of the neutron and proton single-particle levels. One would also expect the filling of the levels to be similar. Since the $2 p_{3 / 2}$ and $1 f_{5 / 2}$ proton shells are rather well 
filled at $\mathrm{Z}=38\left({ }^{88} \mathrm{Sr}\right)$ the corresponding neutron shells in the strontium isotopes studied $\left(\mathrm{N} \geq 45\right.$ ) should be filled, and only the $2 \mathrm{p}_{1 / 2}$ and $1 \mathrm{~g}_{9 / 2}$ shells should be filling. The $(d, p)$ spectroscopic factors are proportional to the emptiness of the target nucleus and allow us to check this conjecture. Table III(a) shows that the $2 \mathrm{p}_{3 / 2}$ state at $0.87 \mathrm{MeV}$ is approximately half as strongly populated as the ground state. Either the neutron and proton shell filling orders are not similar or the $2 p_{3 / 2}$ shell fills at $\mathrm{N}, \mathrm{Z}=38$ and then empties as particles are added.

87 The closure of the shell at $\mathrm{N}=50$ appears rather good. The $1.76-\mathrm{MeV}$ state in ${ }^{87} \mathrm{Sr}$ is known from the $(\mathrm{d}, \mathrm{p})$ results to correspond to a $d_{5 / 2}$ particle, and it should be populated in the $(d, t)$ reaction only if there is some $d_{5 / 2}$ admixture in the ${ }^{88}$ Sr ground

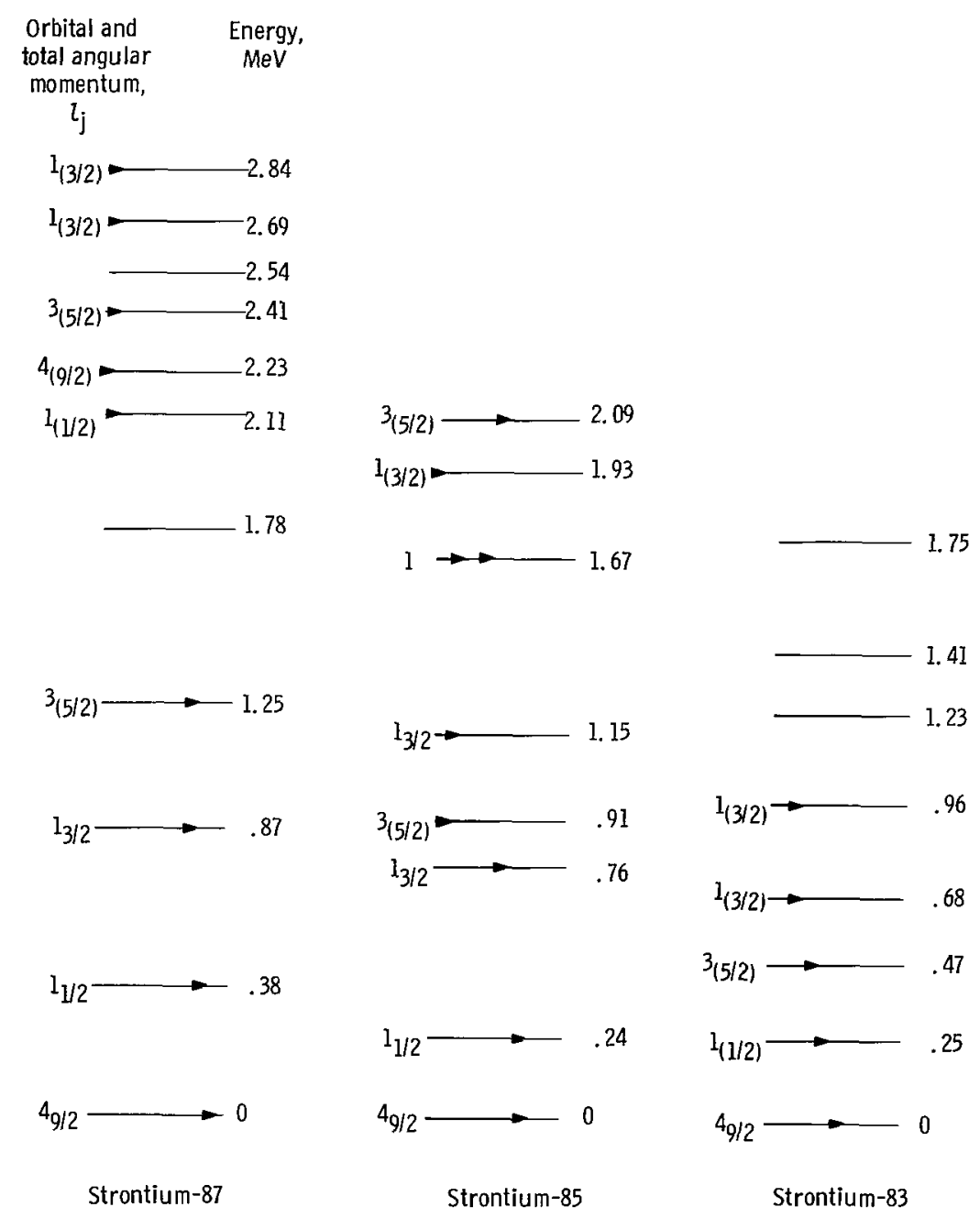

Figure 19. - Comparison of levels of different strontium isotopes excited by $(d, t)$ reaction. The lengths of the arrows on the bars indicate the ratio of the spectroscopic factor of the transition to the sum rule for a closed shell. 
state. The weak transition that is seen corresponds at most to an admixture of 0.1 particle. This is in accord with other results on the $\mathrm{N}=50$ isotones.

The systematics of the states populated by the $(d, t)$ reaction are summarized in table IV and figure 19. In table IV all the spectroscopic factors for each $j$ and $l$ have been summed, where we have assumed the most likely values of $j$ for the $l=1$ transitions. These should be equal to the number of particles in the shells. It has already been mentioned that there is a remarkable agreement (probably fortuitous) for ${ }^{87} \mathrm{Sr}$. We can probably conclude that most of the fragments of the orbitals have been found with the exception of those for $f_{5 / 2}$. The sums over $l$ and $j$ for ${ }^{85} \mathrm{Sr}$ and ${ }^{83} \mathrm{Sr}$ should be two and four less. It is quite obvious that this is not so and that more particles are missing. Evidently, not all the fragments have been located. Even if we discard the $f_{5 / 2}$ states, assuming that they have the same fullness in all of the isotopes, the sums over the $\mathrm{p}$ and $\mathrm{g}$ states are deficient by 1.9 and 3.3 particles in ${ }^{86} \mathrm{Sr}$ and ${ }^{84} \mathrm{Sr}$, respec-

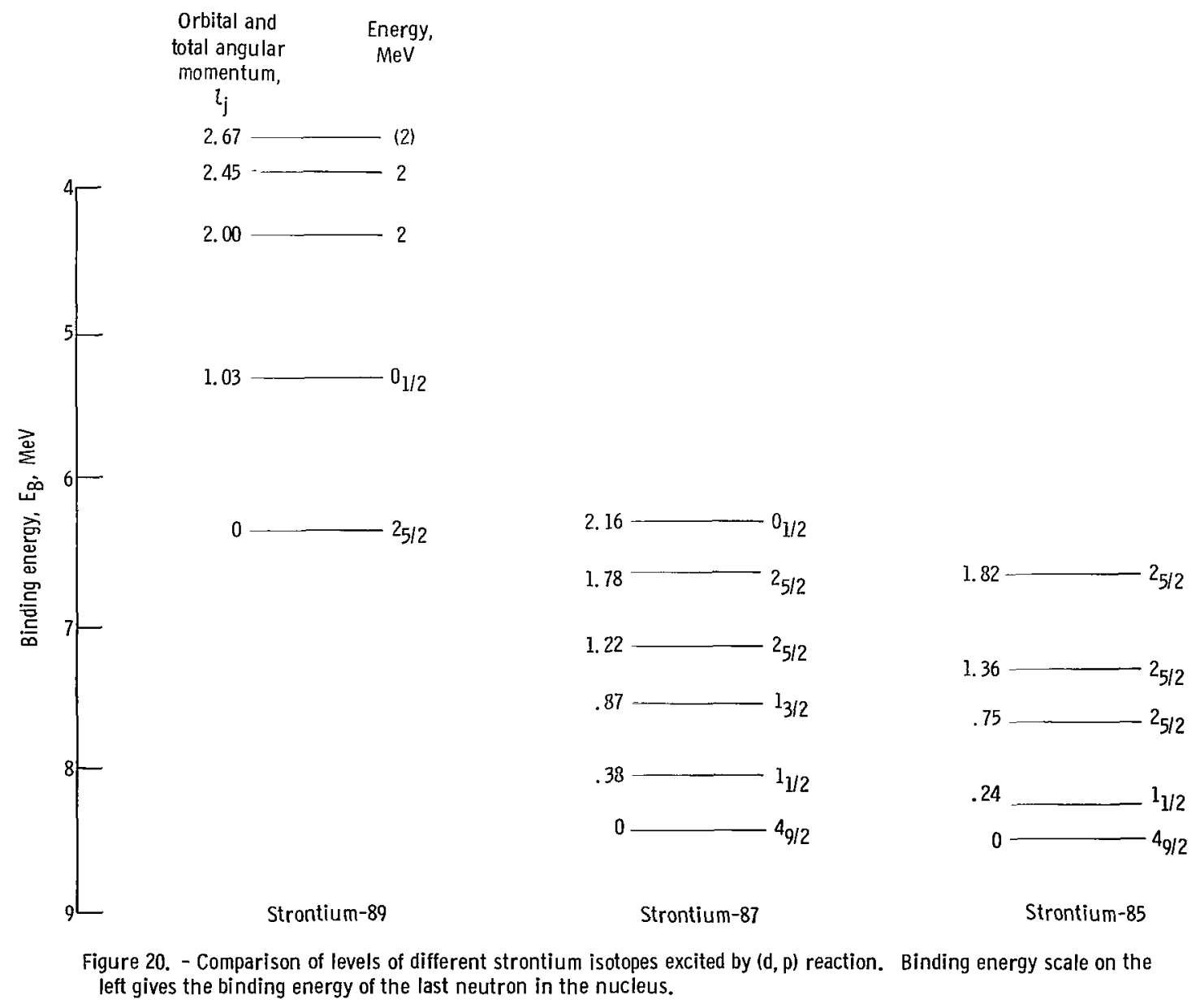


tively. This is interpreted as evidence for the expected increased fragmentation of the single-particle states as one leaves a closed shell.

Figure 19 summarizes the states populated by the $(d, t)$ reaction. It is clear that there is a smooth variation of the location of the lowest states of each spin, but it is not clear whether their descent as the neutrons are removed is due to a shift of the single-particle states or to its increased fragmentation.

The results of the $(d, p)$ studies are summarized in figure 20 . The results for the $p$ and $g$ shells are of limited scope, but are in good agreement with the $(d, t)$ work. Only limited conclusions can be made about the splitting of the $d$ and $s$ states since even in ${ }^{89} \mathrm{Sr}$ there is probably a good deal of strength which is missed in this experiment. The S-sums for the low lying $l=2$ states in ${ }^{87} \mathrm{Sr}$ and ${ }^{85} \mathrm{Sr}$ are both equal to 0.57. This is quite close to the $\mathrm{S}$-value $(0.61)$ of the ground state of ${ }^{89} \mathrm{Sr}$. There is substantial fragmentation of the ground state as neutrons are removed, but only to a few pieces. The ${ }^{87} \mathrm{Sr}$ data show that the $\mathrm{d}_{5 / 2}$ single-particle state is $1.6 \mathrm{MeV}$ or more above the $\mathrm{g}_{9 / 2}$ state.

Lewis Research Center,

National Aeronautics and Space Administration, Cleveland, Ohio, February 13, 1970, 129-02. 


\section{APPENDIX A}

\section{RESULTS OF FIRST $(\mathrm{d}, \mathrm{t})$ EXPERIMENT \\ ${ }^{84} \mathrm{Sr}(d, t)^{83} \mathrm{Sr}$}

\begin{tabular}{|c|c|c|c|c|c|c|c|c|}
\hline $\begin{array}{l}\text { Center of } \\
\text { mass } \\
\text { scattering } \\
\text { angle, } \\
{ }^{\theta} \mathrm{cm} \text { ' } \\
\text { deg }\end{array}$ & $\begin{array}{c}\text { Differ- } \\
\text { ential } \\
\text { cross } \\
\text { section, } \\
\sigma, \\
\text { mb }\end{array}$ & $\begin{array}{l}\text { Uncer- } \\
\text { tainty in } \\
\text { cross } \\
\text { section, } \\
\Delta \sigma \\
\mathrm{mb}\end{array}$ & $\begin{array}{l}\text { Center of } \\
\text { mass } \\
\text { scattering } \\
\text { angle, } \\
\theta_{\text {cm' }} \\
\text { deg }\end{array}$ & $\begin{array}{l}\text { Differ- } \\
\text { ential } \\
\text { cross } \\
\text { section, } \\
\sigma, \\
\text { mb }\end{array}$ & $\begin{array}{l}\text { Uncer- } \\
\text { tainty in } \\
\text { cross } \\
\text { section, } \\
\Delta \sigma, \\
\mathrm{mb}\end{array}$ & $\begin{array}{l}\text { Center of } \\
\text { mass } \\
\text { scattering } \\
\text { angle, } \\
{ }^{\theta} \mathrm{cm} \text { ' } \\
\text { deg }\end{array}$ & $\begin{array}{c}\text { Differ- } \\
\text { ential } \\
\text { cross } \\
\text { section, } \\
\sigma, \\
\text { mb }\end{array}$ & $\begin{array}{l}\text { Uncer- } \\
\text { tainty in } \\
\text { cross } \\
\text { section, } \\
\Delta \sigma, \\
\text { mb }\end{array}$ \\
\hline \multicolumn{3}{|c|}{$l=4 ; \mathrm{E}=0 ; \mathrm{Q}=-5.78 \mathrm{MeV}$} & \multicolumn{3}{|c|}{$l=1 ; E=0.25 \mathrm{MeV} ; \mathrm{Q}=-6.03 \mathrm{MeV}$} & \multicolumn{3}{|c|}{$l=3 ; \mathrm{E}=0.47 \mathrm{MeV} ; \mathrm{Q}=-6.25 \mathrm{MeV}$} \\
\hline 18.8 & 0.534 & 0.085 & 18.8 & 0.419 & 0.070 & 18.8 & 0.795 & 0.100 \\
\hline 20.9 & .573 & .044 & 20.9 & .269 & .032 & 20.9 & .581 & .050 \\
\hline 23.0 & .978 & .089 & 23.0 & .480 & .060 & 23.0 & .875 & .081 \\
\hline 25.0 & .857 & .080 & 25.0 & .805 & .070 & 25.0 & .843 & .085 \\
\hline 27.1 & .799 & .059 & 27.1 & .734 & .045 & 27.1 & .298 & .037 \\
\hline 29. 1 & .973 & .057 & $\ldots$ & $\ldots$ & --- & 29.2 & 289 & .033 \\
\hline 31.2 & .799 & .055 & 31.2 & .649 & .043 & 31.2 & .298 & .034 \\
\hline 33.3 & .646 & .029 & 33.3 & .420 & .033 & 33.3 & .254 & .020 \\
\hline 35.3 & .564 & .039 & 35.3 & .347 & .031 & 35.3 & .274 & .031 \\
\hline 39.4 & .200 & .027 & 39.4 & .283 & .025 & 39.4 & .247 & .031 \\
\hline 41.5 & .177 & .036 & 41.5 & .251 & .035 & 41.5 & 167 & .034 \\
\hline 43.5 & 196 & .026 & 43.5 & .253 & .023 & $\ldots$ & --- & $-\ldots$ \\
\hline 45.6 & .234 & .038 & 45.6 & .334 & .037 & 45.6 & .209 & .035 \\
\hline 47.6 & .246 & .028 & 47.6 & .258 & .024 & 47.7 & .171 & .021 \\
\hline 49.7 & .242 & .021 & 49.7 & .199 & .016 & 49.7 & .124 & .015 \\
\hline 55.8 & .188 & .020 & 55.8 & .062 & .012 & 55.8 & .112 & .018 \\
\hline 59.9 & .145 & .010 & 59.9 & .095 & .008 & 59.9 & .056 & .008 \\
\hline 64.0 & .119 & .011 & 64.0 & .104 & .009 & 64.0 & .055 & .009 \\
\hline 68.0 & .089 & .011 & 68.0 & .088 & .010 & 68.0 & .047 & .009 \\
\hline 72.1 & .066 & .006 & 72.1 & .044 & .005 & 72.1 & .023 & .005 \\
\hline 76.1 & .093 & .009 & 76.1 & .035 & .006 & 76.1 & .037 & .006 \\
\hline 80.1 & .058 & .005 & 80.2 & .019 & .003 & 80.2 & .022 & .004 \\
\hline 84.2 & .056 & .006 & 84.2 & .026 & .005 & 84.2 & .026 & .005 \\
\hline 88.2 & .042 & .006 & 88.2 & .034 & .005 & 88.2 & .018 & .005 \\
\hline 91.2 & .058 & .005 & 91.2 & .034 & .004 & 91.2 & .014 & .004 \\
\hline 94.2 & .047 & .006 & 94.2 & .024 & .005 & --- & -- &.-- \\
\hline 98.2 & .022 & .004 & 98.2 & .015 & .003 & 98.2 & .016 & .004 \\
\hline---- & $-\cdots$ & --- & 102.2 & .009 & .003 & --- & $\ldots$ & --- \\
\hline 106.1 & .013 & .003 & 106.1 & .010 & .003 & 106.2 & .005 & .003 \\
\hline 110.1 & .016 & .003 & 110.1 & .018 & .003 & 110.1 & .010 & .003 \\
\hline
\end{tabular}




\section{${ }^{84} \mathrm{Sr}(\mathrm{d}, \mathrm{t})^{83} \mathrm{Sr}$}

\begin{tabular}{|c|c|c|c|c|c|}
\hline $\begin{array}{l}\text { Center of } \\
\text { mass } \\
\text { scattering } \\
\text { angle, } \\
\theta^{\circ} \mathrm{cm} \text { ' } \\
\text { deg }\end{array}$ & $\begin{array}{l}\text { Differ- } \\
\text { ential } \\
\text { cross } \\
\text { section, } \\
\sigma, \\
\mathrm{mb}\end{array}$ & $\begin{array}{l}\text { Uncer- } \\
\text { tainty in } \\
\text { cross } \\
\text { section, } \\
\Delta \sigma \\
m b\end{array}$ & $\begin{array}{l}\text { Center of } \\
\text { mass } \\
\text { scattering } \\
\text { angle, } \\
\theta_{\text {cm }} \\
\text { deg }\end{array}$ & $\begin{array}{c}\text { Differ- } \\
\text { ential } \\
\text { cross } \\
\text { section, } \\
\sigma, \\
\mathrm{mb}\end{array}$ & $\begin{array}{l}\text { Uncer- } \\
\text { tainty in } \\
\text { cross } \\
\text { section, } \\
\Delta \sigma, \\
\text { mb }\end{array}$ \\
\hline \multicolumn{3}{|c|}{$l=1 ; E=0.68 \mathrm{MeV} ; Q=-6.46 \mathrm{MeV}$} & \multicolumn{3}{|c|}{$l=(1) ; E=0.96 \mathrm{MeV} ; \mathrm{Q}=-6.74 \mathrm{MeV}$} \\
\hline 18.8 & 0.588 & 0.080 & 18.8 & 0.489 & 0.074 \\
\hline--- & $-\ldots$ & ---- & $-\cdots$ & $-\ldots-$ & $-\cdots--$ \\
\hline 20.9 & .441 & .038 & 20.9 & .637 & .041 \\
\hline 23.0 & .687 & .066 & 23.0 & .613 & .060 \\
\hline 25.0 & 1.01 & .098 & $-=-:$ & $\ldots$ & --- \\
\hline 27.1 & .773 & .045 & 27.1 & .428 & .041 \\
\hline 29.2 & .967 & .045 & 29.1 & .518 & .036 \\
\hline 31.2 & .736 & .043 & 31.2 & .470 & .039 \\
\hline 33.3 & .527 & .023 & 33.3 & .352 & .019 \\
\hline 35.3 & .432 & .034 & 35.3 & .264 & .027 \\
\hline 39.5 & .257 & .028 & 39.5 & .215 & .022 \\
\hline 41.5 & .290 & .039 & 41.5 & .138 & .024 \\
\hline 43.6 & .283 & .024 & 43.6 & .169 &. .020 \\
\hline 45.6 & .344 & .039 & 45.6 & .224 & .029 \\
\hline 47.7 & .344 & .027 & 47.7 & .207 & .024 \\
\hline 49.7 & .292 & .020 & 49.7 & .245 & .017 \\
\hline 55.9 & .115 & .016 & 55.9 & .115 & .013 \\
\hline 59.9 & .076 & .007 & 59.9 & .0808 & .0071 \\
\hline 64.0 & .110 & .010 & 64.0 & .0846 & .0081 \\
\hline 68.1 & .094 & .010 & 68.1 & .0803 & .0087 \\
\hline 72.1 & .064 & .005 & 72.1 & .0381 & .0043 \\
\hline 76.2 & .060 & .007 & 76.2 & .0553 & .0066 \\
\hline 80.2 & .033 & .004 & 80.2 & .0457 & .0036 \\
\hline 84.2 & .029 & .004 & 84.2 & .0263 & .0048 \\
\hline 88.2 & .024 & .005 & 88.3 & .0318 & .0060 \\
\hline 91.2 & .030 & .004 & 91.3 & .0381 & .0041 \\
\hline 94.2 & .025 & .005 & 94.3 & .0239 & .0040 \\
\hline 98.2 & .019 & .004 & 98.2 & .0234 & .0043 \\
\hline -.-- & ---- & $-\ldots$ & $-\cdots$ &.--- & $-\ldots$ \\
\hline 106.2 & .015 & .004 & 106.2 & .0095 & .0030 \\
\hline 110.1 & .013 & .003 & 110.1 & .0166 & .0031 \\
\hline
\end{tabular}




\section{${ }^{86} \mathrm{Sr}(\mathrm{d}, \mathrm{t})^{87} \mathrm{Sr}$}

\begin{tabular}{|c|c|c|c|c|c|}
\hline $\begin{array}{l}\text { Center of } \\
\text { mass } \\
\text { scattering } \\
\text { angle, } \\
\theta_{\text {cm' }} \text { ' } \\
\text { deg }\end{array}$ & $\begin{array}{c}\text { Differ- } \\
\text { ential } \\
\text { cross } \\
\text { section, } \\
\sigma, \\
\mathrm{mb}\end{array}$ & $\begin{array}{l}\text { Uncer- } \\
\text { tainty in } \\
\text { cross } \\
\text { section, } \\
\Delta \sigma \text {, } \\
\text { mb }\end{array}$ & $\begin{array}{l}\text { Center of } \\
\text { mass } \\
\text { scattering } \\
\text { angle, } \\
\theta_{\text {cm' }} \text { ' } \\
\text { deg }\end{array}$ & $\begin{array}{c}\text { Differ- } \\
\text { ential } \\
\text { cross } \\
\text { section, } \\
\sigma, \\
\mathrm{mb}\end{array}$ & $\begin{array}{l}\text { Uncer- } \\
\text { tainty in } \\
\text { cross } \\
\text { section, } \\
\Delta \sigma \text {, } \\
\mathrm{mb}\end{array}$ \\
\hline \multicolumn{3}{|c|}{$l=4 ; \mathrm{E}=0 ; \mathrm{Q}=-5.27 \mathrm{MeV}$} & \multicolumn{3}{|c|}{$l=1 ; \mathrm{E}=0.24 \mathrm{MeV} ; \mathrm{Q}=-5.51 \mathrm{MeV}$} \\
\hline 13.4 & 0.618 & 0.103 & 13.4 & 3.64 & 0.2 \\
\hline 15.5 & .436 & .154 & 15.5 & 1.62 & .17 \\
\hline 17.6 & .918 & .109 & 17.6 & .944 & .115 \\
\hline 19.6 & .743 & .075 & 19.6 & .408 & .063 \\
\hline 21.7 & .975 & .083 & 21.7 & .488 & .062 \\
\hline 23.7 & 1. 36 & .136 & 23.7 & 1.01 & .12 \\
\hline 27.9 & 1.49 & .08 & 27.9 & 1. 13 & .07 \\
\hline 29.9 & 1.28 & .14 & 29.9 & 1. 28 & .16 \\
\hline 32.0 & 1. 21 & .05 & 32.0 & .876 & .049 \\
\hline 34.0 & .551 & .066 & 34.0 & .493 & .062 \\
\hline 36.1 & .509 & .034 & 36.1 & .392 & .029 \\
\hline 38.1 & .275 & .046 & 38.2 & .267 & .046 \\
\hline 40.2 & .343 & .028 & 40.2 & .309 & .027 \\
\hline 42.2 & .369 & .024 & 42.3 & .397 & .026 \\
\hline 44.3 & .392 & .021 & 44. 3 & .403 & .021 \\
\hline 46.3 & .495 & .021 & 46.4 & .393 & .019 \\
\hline 48.4 & .452 & .021 & 48.4 & .330 & .018 \\
\hline 50.4 & .417 & .041 & 50.4 & .249 & .031 \\
\hline 52.5 & .399 & .019 & 52.5 & .148 & .012 \\
\hline 54.5 & .297 & .033 & 54.5 & .114 & .020 \\
\hline 56.6 & .283 & .022 & 56.6 & .111 & .015 \\
\hline 58.6 & .223 & .029 & 58.6 & .157 & .024 \\
\hline 60.6 & .201 & .020 & 60.6 & .147 & .017 \\
\hline 62.7 & .220 & .015 & 62.7 & .141 & .012 \\
\hline 64.7 & .226 & .019 & 64.7 & .181 & .017 \\
\hline 68.8 & .167 & .016 & 68.8 & .113 & .014 \\
\hline 72.8 & .137 & .014 & 72.8 & .057 & .008 \\
\hline 76.8 & .088 & .013 & 76.9 & .020 & .007 \\
\hline 80.9 & .099 & .010 & 80.9 & .022 & .007 \\
\hline 84.9 & .057 & .012 & 84.9 & .028 & .010 \\
\hline 88.9 & .092 & .008 & 88.9 & .051 & .006 \\
\hline 92.9 & .066 & .008 & 92.9 & .027 & .004 \\
\hline 96.9 & .045 & .006 & 96.9 & .021 & .004 \\
\hline 100.9 & .036 & .007 & 100.9 & .012 & .005 \\
\hline 104.9 & .025 & .005 & 104.9 & .013 & .005 \\
\hline 108.8 & .030 & .007 & 108.8 & .009 & .004 \\
\hline 112.8 & .031 & .005 & 112.8 & .011 & .003 \\
\hline
\end{tabular}




\section{${ }^{86} \mathrm{Sr}(\mathrm{d}, \mathrm{t})^{87} \mathrm{Sr}$}

\begin{tabular}{|c|c|c|c|c|c|}
\hline $\begin{array}{l}\text { Center of } \\
\text { mass } \\
\text { scattering } \\
\text { angle, } \\
\theta_{\text {cm' }} \\
\text { deg }\end{array}$ & $\begin{array}{c}\text { Differ- } \\
\text { ential } \\
\text { cross } \\
\text { section, } \\
\sigma \\
\mathrm{mb}\end{array}$ & $\begin{array}{l}\text { Uncer- } \\
\text { tainty in } \\
\text { cross } \\
\text { section, } \\
\Delta \sigma, \\
\mathrm{mb}\end{array}$ & $\begin{array}{c}\text { Center of } \\
\text { mass } \\
\text { scattering } \\
\text { angle, } \\
\theta_{\mathrm{cm}}, \\
\text { deg }\end{array}$ & $\begin{array}{c}\text { Differ- } \\
\text { ential } \\
\text { cross } \\
\text { section, } \\
\sigma \\
\mathrm{mb}\end{array}$ & $\begin{array}{l}\text { Uncer- } \\
\text { tainty in } \\
\text { cross } \\
\text { section, } \\
\Delta \sigma \\
\mathrm{mb}\end{array}$ \\
\hline \multicolumn{3}{|c|}{$l=1 ; \mathrm{E}=0.76 \mathrm{MeV} ; \mathrm{Q}=-6.03 \mathrm{MeV}$} & \multicolumn{3}{|c|}{$l=1 ; E=1.15 \mathrm{MeV} ; Q=-6.42 \mathrm{MeV}$} \\
\hline 13.4 & 3. 15 & 0.20 & 13.4 & 2.58 & 0.271 \\
\hline 15.5 & 2. 59 & .24 & --- & --- & $\ldots$ \\
\hline 17.6 & 1. 51 & .15 & 17.6 & .618 & .167 \\
\hline 19.6 & 1. 20 & .09 & 19.6 & .218 & .098 \\
\hline 21.7 & 1.08 & .09 & 21.7 & .218 & .047 \\
\hline 23.8 & 1. 44 & .14 & 23.8 & .155 & .062 \\
\hline 27.9 & 1. 67 & .08 & 27.9 & .437 & .047 \\
\hline 29.9 & 1. 41 & .16 & 30.0 & .436 & .097 \\
\hline 32.0 & 1.07 & .05 & 32.0 & .292 & .024 \\
\hline 34.1 & .632 & .070 & 34.1 & .230 & .045 \\
\hline 36.1 & .574 & .036 & 36.1 & .106 & .018 \\
\hline 38.2 & .494 & .062 & - - & $\ldots$ & --- \\
\hline 40.2 & .499 & .033 & 40.2 & .115 & .020 \\
\hline 42.3 & .621 & .032 & 42.3 & .196 & .019 \\
\hline 44.3 & .596 & .024 & 44.3 & .193 & .015 \\
\hline 46.4 & .618 & .024 & 46.4 & .184 & .014 \\
\hline 48.4 & .563 & .024 & 48.4 & .156 & .014 \\
\hline 50.5 & .346 & .037 & 50.5 & .172 & .025 \\
\hline 52.5 & .361 & .019 & 52.5 & .099 & .012 \\
\hline 54.6 & .200 & .029 & 54.6 & .037 & .018 \\
\hline 56.6 & .143 & .017 & --- & ---- & ---- \\
\hline 58.6 & .161 & .024 & 58.7 & .051 & .013 \\
\hline 60.7 & .216 & .020 & 60.7 & .047 & .014 \\
\hline 62.7 & .217 & .016 & 62.7 & .079 & .009 \\
\hline 64.7 & .245 & .021 & 64.8 & .103 & .012 \\
\hline 68.8 & .171 & .017 & 68.8 & .052 & .009 \\
\hline 72.8 & .127 & .014 & 72.9 & .060 & .009 \\
\hline 76.9 & .071 & .011 & 76.9 & .039 & .009 \\
\hline 80.9 & .068 & .009 & 80.9 & .022 & .007 \\
\hline 84.9 & .049 & .012 & 85.0 & .028 & .010 \\
\hline 88.9 & .046 & .006 & 89.0 & .027 & .004 \\
\hline 93.0 & .046 & .006 & 93.0 & .017 & .004 \\
\hline 96.9 & .048 & .007 & 97.0 & .024 & .004 \\
\hline 100.9 & .027 & .006 & 101.0 & .014 & .005 \\
\hline 104.9 & .019 & .005 & 104.9 & .012 & .005 \\
\hline 108.9 & .032 & .007 & 108.9 & .014 & .004 \\
\hline 112.8 & .016 & .003 & 112.8 & .008 & .002 \\
\hline
\end{tabular}




\section{${ }^{88} \mathrm{Sr}(\mathrm{d}, \mathrm{t})^{87} \mathrm{Sr}$}

\begin{tabular}{|c|c|c|c|c|c|}
\hline $\begin{array}{l}\text { Center of } \\
\text { mass } \\
\text { scattering } \\
\text { angle, } \\
\theta_{\text {cm' }} \\
\text { deg }\end{array}$ & $\begin{array}{c}\text { Differ- } \\
\text { ential } \\
\text { cross } \\
\text { section, } \\
\sigma, \\
\text { mb }\end{array}$ & $\begin{array}{l}\text { Uncer- } \\
\text { tainty in } \\
\text { cross } \\
\text { section, } \\
\Delta \sigma, \\
\mathrm{mb}\end{array}$ & $\begin{array}{l}\text { Center of } \\
\text { mass } \\
\text { scattering } \\
\text { angle, } \\
\theta_{\text {cm' }}, \\
\text { deg }\end{array}$ & $\begin{array}{c}\text { Differ- } \\
\text { ential } \\
\text { cross } \\
\text { section, } \\
\sigma \\
\text { mb }\end{array}$ & $\begin{array}{l}\text { Uncer- } \\
\text { tainty in } \\
\text { cross } \\
\text { section, } \\
\Delta \sigma, \\
\text { mb }\end{array}$ \\
\hline \multicolumn{3}{|c|}{$l=4 ; \quad \mathrm{E}=0 ; \mathrm{Q}=-4.86 \mathrm{MeV}$} & \multicolumn{3}{|c|}{$l=1 ; \mathrm{E}=0.38 \mathrm{MeV}, \mathrm{Q}=-5.24 \mathrm{MeV}$} \\
\hline 17.5 & 1. 24 & 0.18 & 17.5 & 1. 26 & 0.16 \\
\hline 19.6 & 1.56 & .13 & 19.6 & .60 & .08 \\
\hline 21.7 & 1. 84 & .09 & 21.7 & .77 & .05 \\
\hline 22.7 & 1.72 & .07 & 22.7 & 1. 10 & .06 \\
\hline 25.8 & 2.08 & .08 & 25.8 & 1. 60 & .07 \\
\hline 26.8 & 2. 59 & .10 & 26.8 & 2.06 & .04 \\
\hline 29.9 & 1.91 & .08 & 29.9 & 1. 37 & .06 \\
\hline 31.9 & 1.63 & .07 & 32.0 & 1. 10 & .05 \\
\hline 34.0 & 1. 35 & .06 & 34.0 & .738 & .044 \\
\hline 36.1 & .978 & .071 & 36.1 & .482 & .051 \\
\hline 40.2 & .543 & .055 & 40.2 & .489 & .051 \\
\hline 42.2 & .570 & .039 & 42.2 & .628 & .042 \\
\hline 44.3 & .605 & .051 & 44.3 & .606 & .051 \\
\hline 47.3 & .574 & .039 & 47.3 & .595 & .039 \\
\hline 49.4 & .606 & .054 & 49.4 & .269 & .036 \\
\hline 52.4 & .482 & .036 & 52.4 & .151 & .023 \\
\hline 54.5 & .420 & .031 & 54.5 & .137 & .019 \\
\hline 58.5 & .380 & .029 & 58.6 & .192 & .021 \\
\hline 62.6 & .331 & .022 & 62.6 & .214 & .017 \\
\hline 64.6 & .241 & .017 & 64.7 & .205 & .015 \\
\hline 66.7 & .292 & .020 & 66.7 & .185 & .016 \\
\hline 68.7 & .230 & .023 & 68.7 & .151 & .019 \\
\hline 72.7 & .176 & .012 & 72.8 & .048 & .007 \\
\hline 76.8 & .144 & .017 & 76.8 & .025 & .008 \\
\hline 80.8 & .135 & .013 & 80.8 & .057 & .010 \\
\hline 84.8 & .173 & .014 & 84.8 & .067 & .009 \\
\hline 88.8 & .155 & .013 & 88.9 & .048 & .007 \\
\hline 92.8 & .150 & .012 & 92.9 & .040 & .006 \\
\hline 95.8 & .074 & .008 & 95.9 & .018 & .004 \\
\hline 100.8 & .043 & .007 & 100.8 & .011 & .005 \\
\hline 104.8 & .058 & .007 & 104.8 & .014 & .003 \\
\hline 112.7 & .056 & .008 & 112.7 & .020 & .005 \\
\hline 116.7 & .065 & .009 & 116.7 & .026 & .006 \\
\hline 124.5 & .040 & .007 & 124.6 & .006 & .003 \\
\hline 128.5 & .050 & .007 & 128.5 & .016 & .005 \\
\hline
\end{tabular}




\section{${ }^{88} \mathrm{Sr}(\mathrm{d}, \mathrm{t})^{87} \mathrm{Sr}$}

\begin{tabular}{|c|c|c|c|c|c|}
\hline $\begin{array}{l}\text { Center of } \\
\text { mass } \\
\text { scattering } \\
\text { angle, } \\
\theta_{\text {cm' }} \\
\text { deg }\end{array}$ & $\begin{array}{l}\text { Differ- } \\
\text { ential } \\
\text { cross } \\
\text { section, } \\
\sigma, \\
\mathrm{mb}\end{array}$ & $\begin{array}{l}\text { Uncer- } \\
\text { tainty in } \\
\text { cross } \\
\text { section, } \\
\Delta \sigma \\
\text { mb }\end{array}$ & $\begin{array}{l}\text { Center of } \\
\text { mass } \\
\text { scattering } \\
\text { angle, } \\
{ }^{\theta} \mathrm{cm} \text { ' } \\
\text { deg }\end{array}$ & $\begin{array}{l}\text { Differ- } \\
\text { ential } \\
\text { cross } \\
\text { section, } \\
\sigma, \\
\mathrm{mb}\end{array}$ & $\begin{array}{l}\text { Uncer- } \\
\text { tainty in } \\
\text { cross } \\
\text { section, } \\
\Delta \sigma \\
\text { mb }\end{array}$ \\
\hline \multicolumn{3}{|c|}{$l=1 ; E=0.87 \mathrm{MeV} ; Q=-5.73 \mathrm{MeV}$} & \multicolumn{3}{|c|}{$l=3 ; E=1.25 \mathrm{MeV} ; \mathrm{Q}=-6.11 \mathrm{MeV}$} \\
\hline 17.6 & 2. 14 & 0.22 & 17.6 & 1. 16 & 0.18 \\
\hline 19.6 & .81 & .09 & 19.6 & .966 & .102 \\
\hline 21.7 & 1.08 & .06 & 21.7 & .906 & .053 \\
\hline 22.7 & 1. 35 & .07 & 22.7 & .579 & .051 \\
\hline 25.8 & 2.24 & .08 & 25.8 & .678 & .049 \\
\hline 26.8 & 2.70 & .10 & 26.8 & .607 & .055 \\
\hline 29.9 & 1. 78 & .07 & 29.9 & .469 & .039 \\
\hline 32.0 & 1. 50 & .06 & 32.0 & .407 & .031 \\
\hline 34.0 & .955 & .049 & 34.0 & .370 & .031 \\
\hline 36.1 & .614 & .058 & 36.1 & .306 & .043 \\
\hline 40.2 & .705 & .062 & 40.2 & .316 & .041 \\
\hline 42.2 & .809 & .046 & 42.3 & .257 & .027 \\
\hline 44.3 & 1.04 & .06 & 44.3 & .318 & .035 \\
\hline 47.4 & .919 & .047 & 47.4 & .263 & .026 \\
\hline 49.4 & .598 & .049 & 49.4 & .183 & .03 \\
\hline 52.5 & .256 & .027 & 52.2 & .091 & .017 \\
\hline 54.5 & .169 & .019 & 54.5 & .100 & .016 \\
\hline 58.6 & .211 & .021 & 58.6 & .114 & .016 \\
\hline 62.7 & .244 & .018 & 62.7 & .117 & .013 \\
\hline 64.7 & .240 & .018 & 64.7 & .109 & .012 \\
\hline 66.7 & .284 & .019 & 66.7 & .112 & .013 \\
\hline 68.7 & .261 & .025 & 68.8 & .089 & .014 \\
\hline 72.8 & .134 & .011 & 72.8 & .075 & .009 \\
\hline 76.8 & .065 & .012 & 76.8 & .040 & .010 \\
\hline 80.9 & .051 & .008 & 80.9 & .069 & .011 \\
\hline 84.9 & .055 & .008 & 84.9 & .054 & .008 \\
\hline 88.9 & .061 & .008 & 88.9 & .038 & .006 \\
\hline 92.9 & .067 & .008 & 92.9 & .036 & .006 \\
\hline 95.9 & .049 & .007 & 95.9 & .022 & .005 \\
\hline 100.9 & .056 & .007 & 100.9 & .031 & .007 \\
\hline 104.8 & .028 & .005 & 104.9 & .019 & .005 \\
\hline 112.8 & .026 & .006 & 112.8 & .014 & .005 \\
\hline 116.7 & .019 & .005 & 116.7 & .015 & .005 \\
\hline 124.6 & .025 & .006 & 124.6 & .009 & .004 \\
\hline 128.5 & .018 & .006 & 128.5 & .013 & .004 \\
\hline
\end{tabular}




\section{RESULTS OF (d, p) EXPERIMENT}

\section{${ }^{84} \operatorname{sr}(d, t)^{85} s r$}

\begin{tabular}{|c|c|c|c|c|c|c|c|c|}
\hline $\begin{array}{l}\text { Center of } \\
\text { mass } \\
\text { scattering } \\
\text { angle, } \\
\theta_{\text {cm' }} \text { ' } \\
\text { deg }\end{array}$ & $\begin{array}{c}\text { Differ- } \\
\text { ential } \\
\text { cross } \\
\text { section, } \\
\sigma, \\
\mathrm{mb}\end{array}$ & $\begin{array}{l}\text { Uncer- } \\
\text { tainty in } \\
\text { cross } \\
\text { section, } \\
\Delta \sigma, \\
\mathrm{mb}\end{array}$ & $\begin{array}{c}\text { Center of } \\
\text { mass } \\
\text { scattering } \\
\text { angle, } \\
\theta_{\text {cm }} \\
\text { deg }\end{array}$ & $\begin{array}{c}\text { Differ- } \\
\text { ential } \\
\text { cross } \\
\text { section, } \\
\sigma \\
\mathrm{mb}\end{array}$ & $\begin{array}{l}\text { Uncer- } \\
\text { tainty in } \\
\text { cross } \\
\text { section, } \\
\Delta \sigma, \\
\mathrm{mb}\end{array}$ & $\begin{array}{c}\text { Center of } \\
\text { mass } \\
\text { scattering } \\
\text { angle, } \\
\theta_{\text {cm' }} \\
\text { deg }\end{array}$ & $\begin{array}{c}\text { Differ- } \\
\text { ential } \\
\text { cross } \\
\text { section, } \\
\sigma, \\
\mathrm{mb}\end{array}$ & $\begin{array}{l}\text { Uncer- } \\
\text { tainty in } \\
\text { cross } \\
\text { section, } \\
\Delta \sigma \text {, } \\
\text { mb }\end{array}$ \\
\hline \multicolumn{3}{|c|}{$l=4 ; \mathrm{E}=0 ; \mathrm{Q}=6.26 \mathrm{MeV}$} & \multicolumn{3}{|c|}{$l=1 ; E=0.24 \mathrm{MeV} ; \quad Q=6.02 \mathrm{MeV}$} & \multicolumn{3}{|c|}{$l=2 ; E=0.75 \mathrm{MeV} ; \mathrm{Q}=5.51 \mathrm{MeV}$} \\
\hline 16.0 & 0.575 & 0.064 & 16.0 & 0.913 & 0.082 & 16.0 & 3.09 & 0.17 \\
\hline 18.1 & .499 & .053 & 18.1 & .721 & .063 & 18.1 & 2.54 & .14 \\
\hline 19.1 & .704 & .104 & 19.1 & .541 & .101 & 19.1 & 2. 98 & .23 \\
\hline 20.5 & .592 & .059 & 20.5 & .405 & .048 & 20.5 & 2.20 & .12 \\
\hline 22.5 & .810 & .062 & 22.5 & .355 & .042 & 22.5 & 2.01 & 10 \\
\hline 24.5 & .842 & .066 & 24.5 & .251 & .044 & 24.5 & 1. 46 & .08 \\
\hline 26.6 & .927 & .044 & 26.6 & .422 & .030 & 26.6 & 1. 12 & .05 \\
\hline 28.6 & .815 & .027 & 28.6 & .389 & .020 & 28.6 & .986 & .031 \\
\hline 30.6 & .780 & .041 & 30.6 & .487 & .035 & 30.6 & .782 & .042 \\
\hline 32.6 & .789 & .026 & 32.6 & .413 & .020 & 32.7 & .689 & .025 \\
\hline 34.7 & .660 & .036 & 34.7 & .389 & .030 & 34.7 & .564 & .037 \\
\hline 36.7 & .643 & .030 & 36.7 & .272 & .020 & 36.7 & .552 & .028 \\
\hline 38.7 & .536 & .032 & 38.7 & .201 & .021 & 38.7 & .504 & .032 \\
\hline 42.8 & .332 & .023 & 42.8 & .221 & .018 & 42.8 & .396 & .020 \\
\hline 46.8 & .267 & .022 & 46.8 & .209 & .020 & 46.8 & .313 & .026 \\
\hline 48.8 & .159 & .021 & 48.8 & .177 & .022 & 48.8 & .229 & .025 \\
\hline 54.9 & .182 & .018 & 54.9 & .131 & .016 & 54.9 & .262 & .021 \\
\hline 58.9 & .173 & .010 & 58.9 & .103 & .008 & 58.9 & .254 & .012 \\
\hline 62.9 & .166 & .010 & 62.9 & .062 & .006 & 63.0 & .186 & .011 \\
\hline 67.0 & .162 & .012 & 67.0 & .039 & .006 & 67.0 & 131 & .012 \\
\hline 75.0 & .102 & .009 & 75.0 & .038 & .006 & 75.0 & .099 & .009 \\
\hline 83.0 & .057 & .007 & 83.0 & .038 & .006 & 83.0 & .079 & .009 \\
\hline 87.0 & .055 & .006 & 87.0 & .027 & .004 & 87.0 & .068 & .007 \\
\hline 89.8 & .062 & .011 & 89.8 & .013 & .006 & 89.8 & .055 & .011 \\
\hline 93.0 & .043 & .005 & 93.0 & .011 & .003 & 93.0 & .050 & .005 \\
\hline 97.0 & .047 & .004 & 97.0 & .008 & .002 & 97.0 & .036 & .004 \\
\hline 101.0 & .040 & .005 & 101.0 & .008 & .003 & 101.0 & .036 & .005 \\
\hline 105.0 & .037 & .004 & 105.0 & .009 & .002 & 105.0 & .033 & .004 \\
\hline 109.0 & .031 & .004 & 109.0 & .008 & .002 & 109.0 & .029 & .004 \\
\hline
\end{tabular}




\section{${ }^{84} \mathrm{Sr}(\mathrm{d}, \mathrm{t})^{85} \mathrm{Sr}$}

\begin{tabular}{|c|c|c|c|c|c|}
\hline $\begin{array}{l}\text { Center of } \\
\text { mass } \\
\text { scattering } \\
\text { angle, } \\
\theta_{\mathrm{cm}} \text { ' } \\
\text { deg }\end{array}$ & $\begin{array}{c}\text { Differ- } \\
\text { ential } \\
\text { cross } \\
\text { section, } \\
\sigma, \\
\text { mb }\end{array}$ & $\begin{array}{l}\text { Uncer- } \\
\text { tainty in } \\
\text { cross } \\
\text { section, } \\
\Delta \sigma \text {, } \\
\text { mb }\end{array}$ & $\begin{array}{l}\text { Center of } \\
\text { mass } \\
\text { scattering } \\
\text { angle, } \\
\theta_{\text {cm' }} \text { ' } \\
\text { deg }\end{array}$ & $\begin{array}{l}\text { Differ- } \\
\text { ential } \\
\text { cross } \\
\text { section, } \\
\sigma, \\
\mathrm{mb}\end{array}$ & $\begin{array}{l}\text { Uncer- } \\
\text { tainty in } \\
\text { cross } \\
\text { section, } \\
\Delta \sigma \\
\text { mb }\end{array}$ \\
\hline \multicolumn{3}{|c|}{$\iota=2 ; \mathrm{E}=1.36 \mathrm{MeV} ; \mathrm{Q}=4.90 \mathrm{MeV}$} & \multicolumn{3}{|c|}{$l=2 ; E=1.82 \mathrm{MeV} ; \quad Q=4.44 \mathrm{MeV}$} \\
\hline 16.0 & 6.88 & 0.24 & 16.0 & 1. 84 & 0.16 \\
\hline 18.1 & 7.36 & .21 & 18.1 & 2. 34 & .15 \\
\hline 19.1 & 6.29 & .32 & 19.1 & 2. 33 & .22 \\
\hline 20.5 & 6.12 & .19 & 20.5 & 1.80 & 12 \\
\hline 22.5 & 5.29 & 17 & 22.5 & 1. 69 & .10 \\
\hline 24.6 & 3.58 & .12 & 24.6 & 1.05 & .072 \\
\hline 26.6 & 2.82 & .08 & 26.6 & .637 & .040 \\
\hline 28.6 & 2. 49 & .05 & 28.6 & .842 & .040 \\
\hline 30.6 & 1. 68 & .06 & 30.6 & .591 & .041 \\
\hline 32.7 & 1. 49 & .04 & 32.7 & .482 & .027 \\
\hline 34.7 & 1.37 & .06 & 34.7 & .390 & .036 \\
\hline 36.7 & 1. 48 & .05 & 36.7 & .419 & .029 \\
\hline 38.7 & 1. 58 & .06 & 38.7 & .544 & .039 \\
\hline 42.8 & 1. 28 & .05 & 42.8 & .448 & .030 \\
\hline 46.8 & .997 & .045 & 46.8 & .197 & .022 \\
\hline 48.8 & .697 & .044 & 48.8 & .160 & .032 \\
\hline 54.9 & .427 & .036 & 54.9 & .134 & .019 \\
\hline 58.9 & .494 & .018 & 58.9 & .175 & .011 \\
\hline 63.0 & .442 & .017 & 63.0 & 108 & .016 \\
\hline 67.0 & .352 & .019 & $-\cdots$ & --- & --- \\
\hline 75.0 & .195 & .013 & 75.0 & .043 & .007 \\
\hline 83.1 & .174 & .014 & 83.1 & .067 & .010 \\
\hline 87.1 & .168 & .011 & 87.1 & .057 & .007 \\
\hline 89.9 & .148 & .021 & 89.9 & .039 & .011 \\
\hline 93.1 & .108 & .008 & 93.1 & .046 & .007 \\
\hline 97.1 & .079 & .006 & 97.1 & .030 & .004 \\
\hline 101.0 & .057 & .006 & 101.1 & .018 & .005 \\
\hline 105.0 & .051 & .006 & 105.0 & .024 & .004 \\
\hline 109.0 & .053 & .005 & & & \\
\hline
\end{tabular}


RESULTS OF SECOND $(d, t)$ EXPERIMENT

${ }^{86} S r(d, t)^{85} S r$

\begin{tabular}{|c|c|c|c|c|c|c|c|c|}
\hline $\begin{array}{l}\text { Center of } \\
\text { mass } \\
\text { scattering } \\
\text { angle, } \\
\theta_{\mathrm{cm}}, \\
\text { deg }\end{array}$ & $\begin{array}{c}\text { Differ- } \\
\text { ential } \\
\text { cross } \\
\text { section, } \\
\sigma, \\
\text { mb }\end{array}$ & $\begin{array}{l}\text { Uncer- } \\
\text { tainty in } \\
\text { cross } \\
\text { section, } \\
\Delta \sigma \\
\mathrm{mb}\end{array}$ & $\begin{array}{l}\text { Center of } \\
\text { mass } \\
\text { scattering } \\
\text { angle, } \\
{ }^{\theta} \text { cm' } \\
\text { deg }\end{array}$ & $\begin{array}{c}\text { Differ- } \\
\text { ential } \\
\text { cross } \\
\text { section, } \\
\sigma \\
\mathrm{mb}\end{array}$ & $\begin{array}{l}\text { Uncer- } \\
\text { tainty in } \\
\text { cross } \\
\text { section, } \\
\Delta \sigma, \\
\text { mb }\end{array}$ & $\begin{array}{l}\text { Center of } \\
\text { mass } \\
\text { scattering } \\
\text { angle, } \\
\theta_{\mathrm{cm}} \\
\text { deg }\end{array}$ & $\begin{array}{c}\text { Differ- } \\
\text { ential } \\
\text { cross } \\
\text { section, } \\
\sigma, \\
\mathrm{mb}\end{array}$ & $\begin{array}{c}\text { Uncer- } \\
\text { tainty in } \\
\text { cross } \\
\text { section, } \\
\Delta \sigma \text {, } \\
\text { mb }\end{array}$ \\
\hline \multicolumn{3}{|c|}{$l=4 ; \mathrm{E}=0 ; \mathrm{Q}=-5.27 \mathrm{MeV}$} & \multicolumn{3}{|c|}{$l=1 ; E=0.24 \mathrm{MeV} ; \mathrm{Q}=-5.51 \mathrm{MeV}$} & \multicolumn{3}{|c|}{$l=1 ; E=0.76 \mathrm{MeV} ; Q=-6.03 \mathrm{MeV}$} \\
\hline 14.5 & 0.44 & 0.07 & 14.5 & 3.03 & 0.19 & 14.5 & 3.77 & 0.21 \\
\hline 16.5 & .62 & .05 & 16.5 & 1.61 & .10 & 16.5 & 2.44 & .12 \\
\hline 18.6 & .90 & .05 & 18.6 & .480 & .05 & 18.6 & 1.66 & .09 \\
\hline 20.7 & 1.03 & .04 & 20.7 & .491 & .028 & 20.7 & 1. 31 & .04 \\
\hline 22.7 & 1. 37 & .05 & 22.7 & .737 & .034 & 22.7 & 1. 40 & .05 \\
\hline 24.8 & 1.58 & .05 & 24.8 & 1.03 & .04 & 24.8 & 1. 67 & .05 \\
\hline 26.8 & 1.63 & .04 & 26.8 & 1. 39 & .04 & 26.9 & 1. 75 & .04 \\
\hline 28.9 & 1. 58 & .04 & 28.9 & 1. 29 & .03 & 28.9 & 1. 55 & .04 \\
\hline 31.0 & 1. 40 & .04 & 31.0 & .973 & .033 & 31.0 & 1. 33 & .04 \\
\hline 33.0 & .942 & .026 & 33.0 & .644 & .023 & 33.0 & 1. 13 & .03 \\
\hline 35.1 & .703 & .022 & 35.1 & .386 & .018 & 35.1 & .757 & .022 \\
\hline 37.1 & .513 & .018 & 37.1 & .355 & .016 & 37.2 & .530 & .018 \\
\hline 39.2 & .409 & .015 & 39.2 & .325 & .013 & 39.2 & .583 & .017 \\
\hline 41.2 & .369 & .013 & 41.2 & .382 & .013 & 41.3 & .616 & .016 \\
\hline 43.3 & .409 & .015 & 43.3 & .451 & .016 & 43.3 & .672 & .019 \\
\hline 45.3 & .418 & .016 & 45.3 & .417 & .016 & 45.4 & .666 & .020 \\
\hline 47.4 & .449 & .010 & 47.4 & .376 & .010 & 47.4 & .625 & .012 \\
\hline 51.5 & .436 & .013 & 51.5 & .158 & .009 & 51.5 & .398 & .012 \\
\hline 55.5 & .341 & .011 & 55.6 & .100 & .006 & 55.6 & .227 & .010 \\
\hline 59.6 & .322 & .010 & 59.6 & .157 & .007 & 59.7 & .231 & .009 \\
\hline 63.7 & .232 & .009 & 63.7 & .174 & .008 & 63.7 & .222 & .009 \\
\hline 67.7 & .203 & .007 & 67.8 & .130 & .006 & 67.8 & .234 & .008 \\
\hline 71.8 & .124 & .006 & 71.8 & .062 & .004 & 71.8 & .158 & .007 \\
\hline 75.8 & .095 & .005 & 75.9 & .027 & .003 & 75.9 & .100 & .006 \\
\hline 79.9 & .097 & .005 & 79.9 & .037 & .003 & 79.9 & .064 & .004 \\
\hline 83.9 & .115 & .009 & 83.9 & .046 & .006 & 83.9 & .056 & .007 \\
\hline 87.9 & .121 & .006 & 87.9 & .051 & .004 & 88.0 & .069 & .005 \\
\hline 91.9 & .087 & .005 & 91.9 & .040 & .004 & 92.0 & .066 & .005 \\
\hline
\end{tabular}




\section{${ }^{86} \mathrm{Sr}(\mathrm{d}, \mathrm{t})^{85} \mathrm{Sr}$}

\begin{tabular}{|c|c|c|c|c|c|c|c|c|}
\hline $\begin{array}{l}\text { Center of } \\
\text { mass } \\
\text { scattering } \\
\text { angle, } \\
\theta_{\text {cm' }} \text { ' } \\
\text { deg }\end{array}$ & $\begin{array}{c}\text { Differ- } \\
\text { ential } \\
\text { cross } \\
\text { section, } \\
\sigma, \\
\text { mb }\end{array}$ & $\begin{array}{l}\text { Uncer- } \\
\text { tainty in } \\
\text { cross } \\
\text { section, } \\
\Delta \sigma \text {, } \\
\mathrm{mb}\end{array}$ & $\begin{array}{l}\text { Center of } \\
\text { mass } \\
\text { scattering } \\
\text { angle, } \\
0^{\mathrm{cm}} \text { ' } \\
\text { deg }\end{array}$ & $\begin{array}{c}\text { Differ- } \\
\text { ential } \\
\text { cross } \\
\text { section, } \\
\sigma \\
\mathrm{mb}\end{array}$ & $\begin{array}{l}\text { Uncer- } \\
\text { tainty in } \\
\text { cross } \\
\text { section, } \\
\Delta \sigma \text {, } \\
\text { mb }\end{array}$ & $\begin{array}{l}\text { Center of } \\
\text { mass } \\
\text { scattering } \\
\text { angle, } \\
{ }^{\theta} \mathrm{cm} \text { ' } \\
\text { deg }\end{array}$ & $\begin{array}{c}\text { Differ- } \\
\text { ential } \\
\text { cross } \\
\text { section, } \\
\sigma, \\
\text { mb }\end{array}$ & $\begin{array}{l}\text { Uncer- } \\
\text { tainty in } \\
\text { cross } \\
\text { section, } \\
\Delta \sigma, \\
\mathrm{mb}\end{array}$ \\
\hline \multicolumn{3}{|c|}{$l=3 ; \mathrm{E}=0.91 \mathrm{MeV} ; \mathrm{Q}=-6.18 \mathrm{MeV}$} & \multicolumn{3}{|c|}{$l=1 ; \mathrm{E}=1.15 \mathrm{MeV} ; \mathrm{Q}=-6.42 \mathrm{MeV}$} & \multicolumn{3}{|c|}{$l=1 ; \quad E=1.67 \mathrm{MeV} ; \mathrm{Q}=-6.94 \mathrm{MeV}$} \\
\hline 14.5 & 0.153 & 0.047 & 14.5 & 0.964 & 0.102 & 14.5 & 0.474 & 0.079 \\
\hline 16.5 & .147 & .027 & 16.5 & .705 & .061 & 16.6 & .387 & .045 \\
\hline 18.6 & .075 & .023 & 18.6 & .332 & .037 & 18.6 & .266 & .035 \\
\hline 20.7 & .127 & .015 & 20.7 & .237 & .019 & 20.7 & .191 & .017 \\
\hline 22.7 & .128 & .014 & 22.7 & .236 & .020 & 22.8 & .234 & .020 \\
\hline 24.8 & .188 & .018 & 24.8 & .447 & .032 & 24.8 & .250 & .023 \\
\hline 26.9 & .085 & .012 & 26.9 & .445 & .021 & 26.9 & .387 & .020 \\
\hline 28.9 & .103 & .012 & 28.9 & .392 & .019 & 29.0 & .358 & .018 \\
\hline 31.0 & .074 & .012 & 31.0 & .339 & .020 & 31.0 & .272 & .018 \\
\hline 33.0 & .147 & .012 & 33.1 & .273 & .016 & 33.1 & .210 & .013 \\
\hline 35.1 & .073 & .009 & 35.1 & .205 & .015 & 35.1 & .146 & .013 \\
\hline 37.2 & .028 & .006 & 37.2 & .138 & .011 & 37.2 & .154 & .011 \\
\hline 39.2 & .052 & .006 & 39.2 & .137 & .009 & 39.3 & .119 & .009 \\
\hline 41.3 & .046 & .005 & 41.3 & .148 & .008 & 41.3 & .148 & .008 \\
\hline 43.3 & .050 & .007 & 43.3 & .190 & .011 & 43.4 & .161 & .010 \\
\hline 45.4 & .043 & .006 & 45.4 & .177 & .011 & 45.4 & .154 & .010 \\
\hline 47.4 & .036 & .004 & 47.4 & .169 & .007 & 47.5 & .125 & .006 \\
\hline 51.5 & .025 & .004 & 51.5 & .122 & .007 & 51.6 & .094 & .007 \\
\hline 55.6 & .020 & .004 & 55.6 & .068 & .005 & 55.6 & .062 & .005 \\
\hline 59.7 & .016 & .003 & 59.7 & .047 & .005 & 59.7 & .069 & .005 \\
\hline 63.7 & .011 & .003 & 63.8 & .061 & .006 & 63.8 & .066 & .005 \\
\hline 67.8 & .016 & .002 & 67.8 & .074 & .005 & 67.9 & .073 & .005 \\
\hline 71.9 & .017 & .002 & 71.9 & .039 & .004 & 71.9 & .063 & .005 \\
\hline 75.9 & .009 & .002 & 75.9 & .036 & .004 & 76.0 & .032 & .004 \\
\hline 79.9 & .004 & .002 & 79.9 & .030 & .003 & 80.0 & .016 & .002 \\
\hline 84.0 & .004 & .003 & 84.0 & .013 & .004 & 84.0 & .013 & .004 \\
\hline 88.0 & .007 & .002 & 88.0 & .033 & .004 & 88.0 & .029 & .004 \\
\hline 92.0 & .005 & .002 & 92.0 & .023 & .003 & 92.0 & .028 & .004 \\
\hline
\end{tabular}




\begin{tabular}{|c|c|c|c|c|c|}
\hline $\begin{array}{l}\text { Center of } \\
\text { mass } \\
\text { scattering } \\
\text { angle, } \\
\theta_{\mathrm{cm}}, \\
\text { deg }\end{array}$ & $\begin{array}{l}\text { Differ- } \\
\text { ential } \\
\text { cross } \\
\text { section, } \\
\sigma \\
\mathrm{mb}\end{array}$ & $\begin{array}{l}\text { Uncer- } \\
\text { tainty in } \\
\text { cross } \\
\text { section, } \\
\Delta \sigma, \\
\text { mb }\end{array}$ & $\begin{array}{l}\text { Center of } \\
\text { mass } \\
\text { scattering } \\
\text { angle, } \\
\theta_{\text {cm' }} \\
\text { deg }\end{array}$ & $\begin{array}{c}\text { Differ- } \\
\text { ential } \\
\text { cross } \\
\text { section, } \\
\sigma, \\
\mathrm{mb}\end{array}$ & $\begin{array}{l}\text { Uncer- } \\
\text { tainty in } \\
\text { cross } \\
\text { section, } \\
\Delta \sigma \\
\text { mb }\end{array}$ \\
\hline \multicolumn{3}{|c|}{$l=1 ; E=1.93 \mathrm{MeV} ; \mathrm{Q}=-7.20 \mathrm{MeV}$} & \multicolumn{3}{|c|}{$\imath=3 ; \mathrm{E}=2.09 \mathrm{MeV} ; \mathrm{Q}=-7.36 \mathrm{MeV}$} \\
\hline 14.5 & 0.156 & 0.047 & 14.5 & 0.184 & 0.050 \\
\hline 16.6 & .129 & .028 & 16.6 & .167 & .034 \\
\hline 18.6 & .080 & .020 & 18.6 & .137 & .026 \\
\hline 20.7 & .024 & .006 & 20.7 & .226 & .019 \\
\hline 22.8 & .042 & .010 & 22.8 & .215 & .019 \\
\hline 24.8 & .095 & .013 & 24.8 & .214 & .019 \\
\hline 26.9 & .096 & .012 & 26.9 & .181 & .015 \\
\hline 29.0 & .080 & .010 & 29.0 & .132 & .012 \\
\hline 31.0 & .054 & .009 & 31.0 & .105 & .012 \\
\hline 33.1 & .046 & .008 & 33.1 & .105 & .011 \\
\hline 35.1 & .017 & .007 & 35.2 & .059 & .008 \\
\hline 37.2 & .028 & .006 & 37.2 & .069 & .008 \\
\hline 39.3 & .021 & .005 & 39.3 & .067 & .009 \\
\hline 41.3 & .032 & .005 & 41.3 & .067 & .006 \\
\hline 43.4 & .039 & .006 & 43.4 & .064 & .007 \\
\hline 45.4 & .026 & .005 & 45.4 & .082 & .008 \\
\hline 47.5 & .025 & .003 & 47.5 & .054 & .004 \\
\hline 51.6 & .022 & .004 & 51.6 & .050 & .005 \\
\hline 55.7 & .015 & .003 & 55.7 & .044 & .005 \\
\hline 59.7 & .026 & .003 & 59.8 & .052 & .004 \\
\hline 63.8 & .016 & .003 & 63.8 & .027 & .004 \\
\hline 67.9 & .011 & .002 & 67.9 & .030 & .003 \\
\hline 71.9 & .0064 & .0025 & 71.9 & .019 & .003 \\
\hline 76.0 & .0068 & .0017 & 76.0 & .036 & .003 \\
\hline 80.0 & .0058 & .0018 & 80.0 & .024 & .003 \\
\hline$-\cdots$ & $-\ldots$ & ---- & ---- & $-\cdots$ & ---- \\
\hline 88.0 & .0082 & .0024 & 88.1 & .016 & .003 \\
\hline 92.1 & .0105 & .0024 & 92.1 & .027 & .003 \\
\hline
\end{tabular}




\section{${ }^{88} \mathrm{Sr}(\mathrm{d}, \mathrm{t})^{87} \mathrm{Sr}$}

\begin{tabular}{|c|c|c|c|c|c|c|c|c|}
\hline $\begin{array}{l}\text { Center of } \\
\text { mass } \\
\text { scattering } \\
\text { angle, } \\
\theta_{\text {cm' }} \text { ' } \\
\text { deg }\end{array}$ & $\begin{array}{c}\text { Differ- } \\
\text { ential } \\
\text { cross } \\
\text { section, } \\
\sigma, \\
\mathrm{mb}\end{array}$ & $\begin{array}{l}\text { Uncer- } \\
\text { tainty in } \\
\text { cross } \\
\text { section, } \\
\Delta \sigma \\
\text { mb }\end{array}$ & $\begin{array}{l}\text { Center of } \\
\text { mass } \\
\text { scattering } \\
\text { angle, } \\
\theta_{\mathrm{cm}}, \\
\text { deg }\end{array}$ & $\begin{array}{c}\text { Differ- } \\
\text { ential } \\
\text { cross } \\
\text { section, } \\
\sigma, \\
\mathrm{mb}\end{array}$ & $\begin{array}{l}\text { Uncer- } \\
\text { tainty in } \\
\text { cross } \\
\text { section, } \\
\Delta \sigma \\
\text { mb }\end{array}$ & $\begin{array}{l}\text { Center of } \\
\text { mass } \\
\text { scattering } \\
\text { angle, } \\
\theta_{\text {cm' }} \text { ' } \\
\text { deg }\end{array}$ & $\begin{array}{c}\text { Differ- } \\
\text { ential } \\
\text { cross } \\
\text { section, } \\
\sigma, \\
\text { mb }\end{array}$ & $\begin{array}{l}\text { Uncer- } \\
\text { tainty in } \\
\text { cross } \\
\text { section, } \\
\Delta \sigma \\
\text { mb }\end{array}$ \\
\hline \multicolumn{3}{|c|}{$l=4 ; \mathrm{E}=0 ; \mathrm{Q}=-4.86 \mathrm{MeV}$} & \multicolumn{3}{|c|}{$l=1 ; \mathrm{E}=0.38 \mathrm{MeV} ; \mathrm{Q}=-5.24 \mathrm{MeV}$} & \multicolumn{3}{|c|}{$l=1 ; \quad E=0.87 \mathrm{MeV} ; Q=-5.73 \mathrm{MeV}$} \\
\hline 14.4 & 0.44 & 0.09 & 14.5 & 3.33 & 0.217 & 14.5 & 5.03 & 0.27 \\
\hline 16.5 & .75 & .07 & 16.5 & 1.62 & .090 & 16.5 & 2. 46 & .11 \\
\hline 18.6 & 1.07 & .05 & 18.6 & .691 & .045 & 18.6 & 1. 19 & .05 \\
\hline 20.6 & 1. 48 & .06 & 20.6 & .615 & .037 & 20.7 & .84 & .05 \\
\hline 22.7 & 1. 97 & .07 & 22.7 & 1.03 & .050 & 22.7 & 1. 46 & .06 \\
\hline 24.8 & 2.28 & .07 & 24.8 & 1. 67 & .064 & 24.8 & 2. 11 & .07 \\
\hline 26.8 & 2. 43 & .07 & 26.8 & 1. 94 & .059 & 26.8 & 2. 50 & .07 \\
\hline 28.9 & 2. 18 & .07 & 28.9 & 1. 72 & .063 & 28.9 & 2. 26 & .07 \\
\hline 30.9 & 1. 91 & .06 & 30.9 & 1. 38 & .048 & 31.0 & 1. 80 & .06 \\
\hline 33.0 & 1. 53 & .05 & 33.0 & .885 & .035 & 33.0 & 1. 18 & .04 \\
\hline 35.0 & 1.01 & .03 & 35.1 & .513 & .024 & 35.1 & .596 & .025 \\
\hline 37.1 & .781 & .024 & 37.1 & .416 & .018 & 37.1 & .495 & .019 \\
\hline 39.1 & .585 & .024 & 39.2 & .483 & .022 & 39.2 & .590 & .024 \\
\hline 41.2 & .543 & .021 & 41.2 & .555 & .021 & 41.2 & .783 & .025 \\
\hline 43.2 & .596 & .018 & 43.3 & .639 & .019 & 43.3 & .920 & .022 \\
\hline 45.3 & .655 & .023 & 45.3 & .560 & .022 & 45.3 & .860 & .026 \\
\hline 47.3 & .628 & .017 & 47.4 & .430 & .014 & 47.4 & .814 & .019 \\
\hline 51.4 & .595 & .019 & 51.4 & .228 & .012 & 51.5 & .430 & .017 \\
\hline 55.5 & .405 & .014 & 55.5 & .129 & .008 & 55.5 & .166 & .009 \\
\hline 59.6 & .393 & .012 & 59.6 & .207 & .009 & 59.6 & .179 & .008 \\
\hline 63.6 & .292 & .013 & 63.7 & .194 & .010 & 63.7 & .244 & .012 \\
\hline 67.7 & .242 & .010 & 67.7 & .129 & .007 & 67.7 & .249 & .010 \\
\hline 71.7 & .157 & .008 & 71.8 & .053 & .004 & 71.8 & .130 & .007 \\
\hline 75.8 & .126 & .007 & 75.8 & .030 & .003 & 75.8 & .074 & .006 \\
\hline 79.8 & .130 & .007 & 79.8 & .040 & .004 & 79.9 & .056 & .005 \\
\hline 83.8 & .131 & .007 & 83.9 & .067 & .005 & 83.9 & .042 & .004 \\
\hline 87.9 & .132 & .007 & 87.9 & .064 & .005 & 87.9 & .057 & .005 \\
\hline 91.9 & .121 & .007 & 91.9 & .033 & .004 & 91.9 & .052 & .004 \\
\hline
\end{tabular}




\section{${ }^{88} \mathrm{Sr}(\mathrm{d}, \mathrm{t})^{87} \mathrm{Sr}$}

\begin{tabular}{|c|c|c|c|c|c|c|c|c|}
\hline $\begin{array}{c}\text { Center of } \\
\text { mass } \\
\text { scattering } \\
\text { angle, } \\
\theta_{\text {cm' }} \\
\text { deg }\end{array}$ & $\begin{array}{c}\text { Differ- } \\
\text { ential } \\
\text { cross } \\
\text { section, } \\
\sigma, \\
\text { mb }\end{array}$ & $\begin{array}{l}\text { Uncer- } \\
\text { tainty in } \\
\text { cross } \\
\text { section, } \\
\Delta \sigma \text {, } \\
\text { mb }\end{array}$ & $\begin{array}{l}\text { Center of } \\
\text { mass } \\
\text { scattering } \\
\text { angle, } \\
\theta_{\text {cm' }} \text { ' } \\
\text { deg }\end{array}$ & $\begin{array}{c}\text { Differ- } \\
\text { ential } \\
\text { cross } \\
\text { section, } \\
\sigma, \\
\mathrm{mb}\end{array}$ & $\begin{array}{l}\text { Uncer- } \\
\text { tainty in } \\
\text { cross } \\
\text { section, } \\
\Delta \sigma, \\
\text { mb }\end{array}$ & $\begin{array}{l}\text { Center of } \\
\text { mass } \\
\text { scattering } \\
\text { angle, } \\
\theta_{\text {cm' }} \\
\text { deg }\end{array}$ & $\begin{array}{c}\text { Differ- } \\
\text { ential } \\
\text { cross } \\
\text { section, } \\
\sigma \\
\text { mb }\end{array}$ & $\begin{array}{l}\text { Uncer- } \\
\text { tainty in } \\
\text { cross } \\
\text { section, } \\
\Delta \sigma, \\
\mathrm{mb}\end{array}$ \\
\hline \multicolumn{3}{|c|}{$l=3 ; E=1.25 \mathrm{MeV} ; \mathrm{Q}=-6.11 \mathrm{MeV}$} & \multicolumn{3}{|c|}{$l=1 ; E=2.11 \mathrm{MeV} ; Q=-6.97 \mathrm{MeV}$} & \multicolumn{3}{|c|}{$l=(4) ; E=2.24 \mathrm{MeV} ; \mathrm{Q}=-7.09 \mathrm{MeV}$} \\
\hline 14.5 & 0.911 & 0.109 & 14.5 & 0.33 & 0.072 & 14.5 & 0.208 & 0.057 \\
\hline 16.5 & .857 & .078 & --- & $\ldots$ & ----- & ---- & ---- & $-\ldots$ \\
\hline 18.6 & .943 & .052 & 18.6 & .160 & .029 & 18.6 & .151 & .029 \\
\hline 20.7 & .854 & .047 & 20.7 & .080 & .017 & 20.7 & .168 & .020 \\
\hline 22.7 & .831 & .045 & 22.8 & .113 & .019 & 22.8 & .144 & .020 \\
\hline 24.8 & .627 & .040 & 24.8 & .172 & .025 & 24.8 & .254 & .029 \\
\hline 26.8 & .578 & .032 & 26.9 & .136 & .016 & 26.9 & .203 & .020 \\
\hline 28.9 & .581 & .037 & 28.9 & .141 & .019 & 28.9 & .202 & .021 \\
\hline 31.0 & .394 & .026 & 31.0 & .143 & .017 & 31.0 & .169 & .018 \\
\hline 33.0 & .385 & .023 & 33. 1 & .105 & .013 & 33.1 & .146 & .015 \\
\hline 35.1 & .329 & .019 & 35.1 & .057 & .010 & 35.1 & .084 & .011 \\
\hline 37.1 & .327 & .016 & 37.2 & .060 & .007 & 37.2 & .109 & .010 \\
\hline 39.2 & .303 & .018 & 39.2 & .054 & .004 & 39.2 & .040 & .008 \\
\hline 41.2 & .294 & .016 & 41.3 & .053 & .007 & 41. 3 & .055 & .008 \\
\hline 43.3 & .295 & .013 & 43.3 & .071 & .006 & 43. 3 & .041 & .005 \\
\hline 45.3 & .233 & .014 & 45.4 & .057 & .008 & 45.4 & .050 & .006 \\
\hline 47.4 & .225 & .010 & 47.4 & .040 & .005 & 47.4 & .068 & .006 \\
\hline 51.5 & .177 & .011 & 51.5 & .025 & .005 & 51.5 & .063 & .007 \\
\hline 55.6 & .116 & .007 & 55.6 & .023 & .003 & 55.6 & .066 & .006 \\
\hline 59.6 & .122 & .007 & 59.7 & .024 & .003 & 59.7 & .061 & .005 \\
\hline 63.7 & .108 & .008 & 63.8 & .033 & .005 & 63.8 & .031 & .005 \\
\hline 67.8 & .090 & .006 & 67.8 & .035 & .004 & 67.8 & .024 & .004 \\
\hline 71.8 & .069 & .005 & 71.9 & .037 & .004 & 71.9 & .035 & .004 \\
\hline 75.9 & .048 & .004 & 75.9 & .0144 & .0027 & 75.9 & .021 & .003 \\
\hline 79.9 & .038 & .004 & 80.0 & .0042 & .0015 & 80.0 & .026 & .003 \\
\hline 83.9 & .036 & .004 & 84.0 & .0055 & .0016 & 84.0 & .025 & .003 \\
\hline 87.9 & .033 & .004 & 88.0 & .0115 & .0024 & 88.0 & .028 & .004 \\
\hline 91.9 & .038 & .004 & 92.0 & .0120 & .0021 & 92.0 & .019 & .003 \\
\hline
\end{tabular}




\section{${ }^{88} \mathrm{Sr}(\mathrm{d}, \mathrm{t})^{87} \mathrm{Sr}$}

\begin{tabular}{|c|c|c|c|c|c|c|c|c|}
\hline $\begin{array}{l}\text { Center of } \\
\text { mass } \\
\text { scattering } \\
\text { angle, } \\
\theta_{\text {cm' }} \\
\text { deg }\end{array}$ & $\begin{array}{c}\text { Differ- } \\
\text { ential } \\
\text { cross } \\
\text { section, } \\
\sigma, \\
\text { mb }\end{array}$ & $\begin{array}{l}\text { Uncer- } \\
\text { tainty in } \\
\text { cross } \\
\text { section, } \\
\Delta \sigma \text {, } \\
\text { mb }\end{array}$ & $\begin{array}{l}\text { Center of } \\
\text { mass } \\
\text { scattering } \\
\text { angle, } \\
{ }^{\theta} \mathrm{cm} \text { ' } \\
\text { deg }\end{array}$ & $\begin{array}{l}\text { Differ- } \\
\text { ential } \\
\text { cross } \\
\text { section, } \\
\sigma, \\
\mathrm{mb}\end{array}$ & $\begin{array}{l}\text { Uncer- } \\
\text { tainty in } \\
\text { cross } \\
\text { section, } \\
\Delta \sigma \\
\text { mb }\end{array}$ & $\begin{array}{l}\text { Center of } \\
\text { mass } \\
\text { scattering } \\
\text { angle, } \\
\theta_{\text {cm }}, \\
\text { deg }\end{array}$ & $\begin{array}{c}\text { Differ- } \\
\text { ential } \\
\text { cross } \\
\text { section, } \\
\quad \sigma \\
\mathrm{mb}\end{array}$ & $\begin{array}{l}\text { Uncer- } \\
\text { tainty in } \\
\text { cross } \\
\text { section, } \\
\Delta \sigma \text {, } \\
\mathrm{mb}\end{array}$ \\
\hline \multicolumn{3}{|c|}{$l=3 ; \mathrm{E}=2.41 \mathrm{MeV} ; \mathrm{Q}=-7.27 \mathrm{MeV}$} & \multicolumn{3}{|c|}{$l=1 ; \mathrm{E}=2.96 \mathrm{MeV} ; \mathrm{Q}=-7.55 \mathrm{MeV}$} & \multicolumn{3}{|c|}{$\iota=1 ; E=2.84 \mathrm{MeV} ; \mathrm{Q}=-7.70 \mathrm{MeV}$} \\
\hline 14.5 & 0.088 & 0.052 & 14.5 & 0.218 & 0.056 & 14.5 & 0.092 & 0.049 \\
\hline 18.6 & .094 & .026 & 18.6 & .149 & .028 & 18.6 & .179 & .028 \\
\hline---- & --- & --- & 20.7 & .088 & .013 & 20.7 & .096 & .017 \\
\hline 22.8 & .071 & .015 & 22.8 & .108 & .017 & 22.8 & .069 & .015 \\
\hline 26.9 & .041 & .010 & 26.9 & 183 & .020 & 26.9 & .143 & .017 \\
\hline 29.0 & .057 & .011 & 29.0 & .145 & .016 & 29.0 & .086 & .012 \\
\hline 31.0 & .036 & .009 & 31.0 & .128 & .015 & 31.0 & .077 & .011 \\
\hline 33.1 & .024 & .007 & 33.1 & .113 & .013 & 33.1 & .049 & .009 \\
\hline 35.1 & .025 & .008 & 35.1 & .044 & .009 & 35.2 & .029 & .008 \\
\hline 37.2 & .034 & .006 & 37.2 & .052 & .007 & 37.2 & .027 & .005 \\
\hline 39.2 & .031 & .006 & 39.3 & .074 & .019 & 39.3 & .055 & .009 \\
\hline 41.3 & .027 & .005 & 41.3 & .056 & .008 & 41.3 & .036 & .006 \\
\hline .43 .4 & .025 & .004 & 43.4 & .043 & .005 & 43.4 & .049 & .005 \\
\hline 45.4 & .030 & .005 & 45.4 & .053 & .007 & 45.4 & .051 & .007 \\
\hline 47.5 & .024 & .004 & 47.5 & .046 & .005 & 47.5 & .038 & .005 \\
\hline 51.6 & .0179 & .0046 & 51.6 & .044 & .006 & 51.6 & .042 & .006 \\
\hline 55.6 & .0192 & .0028 & 55.7 & .033 & .004 & 55.7 & .035 & .004 \\
\hline 59.7 & .0159 & .0029 & 59.7 & .021 & .004 & 59.7 & .020 & .003 \\
\hline 63.8 & .0086 & .0026 & 63.8 & .023 & .004 & 63.8 & .019 & .004 \\
\hline 67.9 & .0114 & .0027 & 67.9 & .027 & .004 & 67.9 & .015 & .003 \\
\hline 71.9 & .0095 & .0019 & 71.9 & .020 & .003 & 71.9 & .017 & .003 \\
\hline 75.9 & .0219 & .0036 & 76.0 & .0128 & .0024 & 76.0 & .015 & .003 \\
\hline 80.0 & .0090 & .0021 & 80.0 & .0123 & .0024 & 80.0 & .032 & .004 \\
\hline 84.0 & .0078 & .0020 & 84.0 & .0109 & .0024 & 84.0 & .017 & .003 \\
\hline 88.0 & .0072 & .0018 & 88.0 & .0144 & .0025 & 88.1 & .019 & .003 \\
\hline 92.0 & .0067 & .0017 & 92.0 & .0130 & .0024 & 92.1 & .018 & .002 \\
\hline
\end{tabular}




\begin{tabular}{|c|c|c|c|c|c|c|c|c|}
\hline $\begin{array}{l}\text { Center of } \\
\text { mass } \\
\text { scattering } \\
\text { angle, } \\
{ }^{\theta} \mathrm{cm} \text { ' } \\
\text { deg }\end{array}$ & $\begin{array}{c}\text { Differ- } \\
\text { ential } \\
\text { cross } \\
\text { section, } \\
\sigma, \\
\text { mb }\end{array}$ & $\begin{array}{l}\text { Uncer- } \\
\text { tainty in } \\
\text { cross } \\
\text { section, } \\
\Delta \sigma \text {, } \\
\mathrm{mb}\end{array}$ & $\begin{array}{l}\text { Center of } \\
\text { mass } \\
\text { scattering } \\
\text { angle, } \\
\theta_{\mathrm{cm}} \text { ' } \\
\text { deg }\end{array}$ & $\begin{array}{c}\text { Differ- } \\
\text { ential } \\
\text { cross } \\
\text { section, } \\
\sigma, \\
\text { mb }\end{array}$ & $\begin{array}{l}\text { Uncer- } \\
\text { tainty in } \\
\text { cross } \\
\text { section, } \\
\Delta \sigma \\
\text { mb }\end{array}$ & $\begin{array}{l}\text { Center of } \\
\text { mass } \\
\text { scattering } \\
\text { angle, } \\
\theta_{\mathrm{cm}} \\
\text { deg }\end{array}$ & $\begin{array}{c}\text { Differ- } \\
\text { ential } \\
\text { cross } \\
\text { section, } \\
\sigma, \\
\mathrm{mb}\end{array}$ & $\begin{array}{l}\text { Uncer- } \\
\text { tainty in } \\
\text { cross } \\
\text { section, } \\
\Delta \sigma, \\
\mathrm{mb}\end{array}$ \\
\hline$l=4 ; E=$ & \multicolumn{2}{|c|}{$Q=6.21 \mathrm{MeV}$} & \multicolumn{3}{|c|}{$l=1 ; \mathrm{E}=0.38 \mathrm{MeV} ; \mathrm{Q}=5.83 \mathrm{MeV}$} & \multicolumn{3}{|c|}{$l=1 ; \mathrm{E}=0.87 \mathrm{MeV} ; \mathrm{Q}=5.34 \mathrm{MeV}$} \\
\hline--- & ---- & $\cdots-$ & 13.2 & 0.805 & 0.084 & 13.2 & 0.933 & 0.094 \\
\hline$-\cdots$ & $-\cdots-$ & ---- & 15.2 & .531 & .093 & --- &.--- & ---- \\
\hline--- & $-\cdots$ & ---- & 17.2 & .296 & .051 & 17.2 & .281 & .053 \\
\hline$\cdots-$ & $m$ & $\cdots-$ & 19.3 & .186 & .030 & 19.3 & .303 & .039 \\
\hline---- & $-\cdots$ & ---- & 21.3 & .119 & .025 & 21.3 & .330 & .041 \\
\hline---- & ---- & ---- & 23.3 & .082 & .040 & 23.3 & .326 & .053 \\
\hline---- & $-\cdots$ & ---- & 27.4 & .073 & .016 & ---- & --- & $\ldots$ \\
\hline--- & $-\cdots$ & ---- & 31.4 & .153 & .017 & 31.4 & .178 & .019 \\
\hline 35.4 & 0.288 & 0.034 & 35.5 & .123 & .016 & 35.5 & .151 & .016 \\
\hline 39.5 & .290 & .024 & 39.5 & .059 & .010 & 39.5 & .111 & .014 \\
\hline 41.5 & .276 & .021 & 41.5 & .067 & .011 & 41.5 & .114 & .014 \\
\hline 45.6 & .164 & .011 & 45.6 & .047 & .006 & 45.6 & .070 & .009 \\
\hline 47.6 & .124 & .011 & 47.6 & .055 & .007 & 47.6 & .069 & .008 \\
\hline 49.6 & .162 & .028 & 49.6 & .065 & .024 & 49.6 & .065 & .018 \\
\hline 51.6 & .081 & .009 & 51.6 & .068 & .008 & 51.6 & .051 & .007 \\
\hline 53.7 & .099 & .033 & 53.7 & .047 & .025 & 53.7 & .036 & .017 \\
\hline 55.7 & .091 & .013 & 55.7 & .037 & .018 & 55.7 & .061 & .011 \\
\hline 57.7 & .096 & .018 & 57.7 & .049 & .022 & 57.7 & .030 & .015 \\
\hline 59.7 & .097 & .015 & 59.7 & .033 & .015 & 59.7 & .060 & .010 \\
\hline 61.7 & .095 & .010 & 61.7 & .033 & .022 & 61.7 & .046 & .008 \\
\hline 67.8 & .058 & .011 & 67.8 & .028 & .009 & 67.8 & .040 & .007 \\
\hline 75.8 & .047 & .008 & 75.8 & .0181 & .0060 & 75.8 & .030 & .008 \\
\hline 79.8 & .038 & .007 & 79.8 & .0073 & .0044 & 79.8 & .016 & .007 \\
\hline 83.8 & .051 & .010 & 83.8 & .0163 & .0081 & ---- & $-\cdots$ & --- \\
\hline 87.8 & .031 & .005 & 87.8 & .0049 & .0021 & --- & $\ldots-$ & $-\cdots$ \\
\hline 91.8 & .028 & .005 & 91.8 & .0062 & .0026 & $-\cdots$ & --- & ---- \\
\hline 95.8 & .026 & .005 & 95.8 & .0054 & .0027 & 95.8 & .004 & .002 \\
\hline 99.8 & .032 & .007 & 99.8 & .0049 & .0030 & 99.8 & .003 & .002 \\
\hline 103.8 & .023 & .005 & 103.8 & .0035 & .0023 & 103.8 & .005 & .003 \\
\hline 111.8 & .015 & .004 & 111.8 & .0035 & .0019 & 111.8 & .006 & .002 \\
\hline
\end{tabular}




\section{${ }^{86} \mathrm{Sr}(\mathrm{d}, \mathrm{t})^{87} \mathrm{Sr}$}

\begin{tabular}{|c|c|c|c|c|c|c|c|c|}
\hline $\begin{array}{l}\text { Center of } \\
\text { mass } \\
\text { scattering } \\
\text { angle, } \\
\theta_{\text {cm' }} \\
\text { deg }\end{array}$ & $\begin{array}{c}\text { Differ- } \\
\text { ential } \\
\text { cross } \\
\text { section, } \\
\sigma \\
\mathrm{mb}\end{array}$ & $\begin{array}{l}\text { Uncer- } \\
\text { tainty in } \\
\text { cross } \\
\text { section, } \\
\Delta \sigma, \\
m b\end{array}$ & $\begin{array}{l}\text { Center of } \\
\text { mass } \\
\text { scattering } \\
\text { angle, } \\
\theta_{\mathrm{cm}} \text { ' } \\
\mathrm{deg}\end{array}$ & $\begin{array}{c}\text { Differ- } \\
\text { ential } \\
\text { cross } \\
\text { section, } \\
\sigma \\
\mathrm{mb}\end{array}$ & $\begin{array}{l}\text { Uncer- } \\
\text { tainty in } \\
\text { cross } \\
\text { section, } \\
\Delta \sigma \\
\text { mb }\end{array}$ & $\begin{array}{l}\text { Center of } \\
\text { mass } \\
\text { scattering } \\
\text { angle, } \\
\theta_{\mathrm{cm}} \\
\text { deg }\end{array}$ & $\begin{array}{c}\text { Differ- } \\
\text { ential } \\
\text { cross } \\
\text { section, } \\
\sigma \\
\mathrm{mb}\end{array}$ & $\begin{array}{l}\text { Uncer- } \\
\text { tainty in } \\
\text { cross } \\
\text { section, } \\
\Delta \sigma \\
\mathrm{mb}\end{array}$ \\
\hline \multicolumn{3}{|c|}{$l=2 ; E=1.22 \mathrm{MeV} ; \mathrm{Q}=4.99 \mathrm{MeV}$} & \multicolumn{3}{|c|}{$l=2 ; E=1.78 \mathrm{MeV} ; \mathrm{Q}=4.43 \mathrm{MeV}$} & \multicolumn{3}{|c|}{$l=0 ; \mathrm{E}=2.16 \mathrm{MeV} ; \mathrm{Q}=4.05 \mathrm{MeV}$} \\
\hline 13.2 & 2. 16 & 0.17 & 13.2 & 10. 32 & 0.32 & 13.2 & 1. 55 & 0.12 \\
\hline 15.2 & 1.85 & .15 & 15.2 & 10.35 & .39 & 15.2 & .92 & .12 \\
\hline 17.2 & 2.15 & .15 & 17.2 & 10.58 & .33 & 17.3 & 1. 12 & .11 \\
\hline 19.3 & 1. 95 & .10 & 19.3 & 9.17 & .22 & 19.3 & 1.05 & .08 \\
\hline 21.3 & 1.53 & .09 & 21. 3 & 7.24 & .20 & 21.3 & 1. 21 & .09 \\
\hline 23.3 & 1. 48 & .11 & 23.3 & 6.04 & .22 & 23.3 & 1.38 & .11 \\
\hline 27.4 & .826 & .056 & 27.4 & 3. 13 & .11 & 27.4 & .839 & .060 \\
\hline 31.4 & .424 & .024 & 31.4 & 1.84 & .06 & 31.4 & .684 & .037 \\
\hline 35.5 & .391 & .028 & 35.5 & 1. 61 & .06 & 35.5 & .677 & .039 \\
\hline 39.5 & .353 & .028 & 39.5 & 1. 70 & .06 & 39.5 & .824 & .044 \\
\hline 41. 6 & .377 & .024 & 41.6 & 1. 62 & .05 & 41.6 & .819 & .037 \\
\hline 45.6 & .250 & .014 & 45.6 & 1. 10 & .04 & 45.6 & .513 & .022 \\
\hline 47.6 & .187 & .013 & 47.6 & .928 & .031 & 47.6 & .353 & .020 \\
\hline 49.6 & .193 & .025 & 49.6 & .836 & .059 & 49.6 & .337 & .041 \\
\hline 51.7 & .167 & .013 & 51.7 & .757 & .026 & 51.7 & .207 & .014 \\
\hline 53.7 & .169 & .030 & 53.7 & .742 & .058 & 53.7 & .230 & .035 \\
\hline 55.7 & .148 & .016 & 55.7 & .734 & .037 & 55.7 & .101 & .015 \\
\hline 57.7 & .155 & .024 & 57.7 & .605 & .046 & 57.7 & .257 & .033 \\
\hline 59.7 & .138 & .016 & 59.7 & .582 & .034 & 59.7 & .163 & .018 \\
\hline 61.7 & .126 & .012 & 61.7 & .473 & .024 & 61.7 & .211 & .016 \\
\hline 67.8 & .077 & .011 & 67.8 & .282 & .021 & 67.8 & .183 & .019 \\
\hline 75.8 & .039 & .009 & 75.8 & .241 & .019 & 75.8 & .071 & .010 \\
\hline 79.8 & .046 & .007 & 79.8 & .261 & .017 & 79.8 & .051 & .008 \\
\hline 83.8 & .048 & .009 & 83.8 & .247 & .022 & 83.8 & .039 & .012 \\
\hline 87.8 & .052 & .006 & 87.8 & .198 & .012 & 87.9 & .039 & .007 \\
\hline 91.8 & .041 & .006 & 91.8 & .131 & .011 & 91.9 & .043 & .006 \\
\hline 95.8 & .021 & .004 & 95.8 & .096 & .009 & 95.9 & .052 & .007 \\
\hline 99.8 & .018 & .005 & 99.8 & .061 & .009 & 99.8 & .041 & .007 \\
\hline 103.8 & .025 & .006 & 103.8 & .042 & .008 & 103.8 & .034 & .006 \\
\hline 111.8 & .013 & .003 & 111.8 & .054 & .007 & 111.8 & .022 & .004 \\
\hline
\end{tabular}




\section{APPENDIX D}

\section{SYMBOLS}

\begin{tabular}{|c|c|c|c|}
\hline $\begin{array}{l}\mathrm{d} \\
\mathrm{E}\end{array}$ & $\begin{array}{l}\text { atomic mass number } \\
\text { deuteron } \\
\text { kinetic energy }\end{array}$ & $\mathrm{s}, \mathrm{p}, \mathrm{d}, \mathrm{f}, \mathrm{g}$ & $\begin{array}{l}\text { single-particle states having } \\
\text { orbital angular mom entum } \\
\text { equal to } 0,1,2,3 \text {, or } 4 \\
\text { respectively }\end{array}$ \\
\hline $\mathrm{E}_{\mathrm{B}}$ & binding energy & $\mathbf{T}$ & isotopic spin \\
\hline $\mathrm{F}_{\mathrm{FR}}$ & finite wave correction & $\mathrm{t}$ & triton \\
\hline f & Woods-Saxon form factor & $\mathrm{U}$ & the optical potential \\
\hline $\begin{array}{l}\hbar \\
J\end{array}$ & $\begin{array}{l}\text { Plancks constant } / 2 \pi \\
\text { total angular momentum }\end{array}$ & V & $\begin{array}{l}\text { real part of nuclear optical } \\
\text { potential }\end{array}$ \\
\hline$l, \mathrm{j}$ & $\begin{array}{l}\text { orbital and total angular mo- } \\
\text { menta of the transferred } \\
\text { particle }\end{array}$ & $\mathrm{W}$ & $\begin{array}{l}\text { imaginary part of nuclear } \\
\text { optical potential } \\
\text { alpha particle }\end{array}$ \\
\hline M & $\begin{array}{l}\text { nuclear mass in atomic mass } \\
\text { units }\end{array}$ & $\beta_{\mathbf{i}}$ & $\begin{array}{l}\text { nonlocality of the optical poten- } \\
\text { tial, i refers to the particle }\end{array}$ \\
\hline$N($ or Z) & number of neutrons (or pro- & & type \\
\hline & tons) & $\beta_{r}$ & interaction range \\
\hline $\mathrm{n}$ & neutron & $x_{\pi}$ & pion compton wavelength $/ 2 \pi$ \\
\hline $\mathrm{p}$ & proton & $\mathrm{d} \sigma / \mathrm{d} \Omega, \sigma$ & differential cross section \\
\hline$r$ & $\begin{array}{l}\text { bound state function } \\
\text { spectroscopic factor }\end{array}$ & $\Delta \sigma$ & $\begin{array}{l}\text { uncertainty in the differential } \\
\text { cross section }\end{array}$ \\
\hline
\end{tabular}




\section{REFERENCES}

1. Bercaw, R. W.; and Warner, R. E.: Deuteron-Induced Reactions on $\mathrm{Sr}^{86}$ and $\mathrm{Sr}^{88}$. Bull. Am. Phys. Soc., vol. 12, no. 4, Apr. 1967, p. 511.

2. Bercaw, R. W. ; and Warner, R. E. : Levels of $\mathrm{Sr}^{83}$. Bull. Am. Phys. Soc. vol. 14, no. 4, Apr. 1969, p. 625.

3. Talmi, I. ; and Unna, I. : Energy Levels and Configuration Interaction in $\mathrm{Zr}^{90}$ and Related Nuclei. Nucl. Phys., vol. 19, 1960, pp. 225-242.

4. Auerbach, N.; and Talmi, I. : Energy Levels, Configuration Mixing and Proton Neutron Interaction in the Zr Region. Nucl. Phys., vol. 64, 1965, pp. 458-480.

5. Cohen, S.; Lawson, R. D. ; Macfarlane, M. H. ; and Soga, M. : The Effective Interaction and Identical-Nucleon Seniority for Nucleir Near $\mathrm{Zr}^{90}$. Phys. Letters, vol. 10, no. 2, June 1, 1964, pp. 195-198.

6. Picard, J.; and Bassani, G.: Spectroscopic Studies in the $\mathbf{A}=90$ Mass Region. (I) The ( $\left.{ }^{3} \mathrm{He}, \mathrm{d}\right)$ Reaction on ${ }^{88} \mathrm{Sr},{ }^{90} \mathrm{Zr}$ and ${ }^{92}$ Mo Nuclei. Nucl. Phys., vol. A131, 1969, pp. 636-652.

7. Stautberg, M. M. ; Kraushaar, J. J.; and Ridley, B. W. : Nuclear Structure Studies of $\mathrm{Sr}^{88}$ and $\mathrm{Y}^{89}$ Using $19-\mathrm{MeV}$ Proton Scattering and the $\mathrm{Sr}^{88}\left(\mathrm{He}^{3}, \mathrm{~d}\right)$ Reaction.

Phys. Rev., vol. 157, no. 4, May 20, 1967, pp. 977-990.

8. Kavaloski, C. D. ; Lilley, J. S. ; Shreve, D. C. ; and Stein, Nelson: (d, He ${ }^{3}$ ) Studies on $\mathrm{Zr}^{90}, \mathrm{Y}^{89}$, and $\mathrm{Sr}^{88}$. Phys. Rev., vol. 161, no. 4, Sept. 20, 1967, pp. $1107-$ 1115 .

9. Shreve, D. C.: Re-Analysis of the $\left(\mathrm{d},{ }^{3} \mathrm{He}\right)$ Studies on ${ }^{90} \mathrm{Zr},{ }^{89} \mathrm{Y}$, and ${ }^{88} \mathrm{Sr}$ and the Possible Configuration Mixing and the Ground States of ${ }^{88} \mathrm{Sr}$ and ${ }^{90} \mathrm{Zr}$. Annual Report of the Nuclear Physics Lab., Univ. Washington, June 1968, p. 32.

10. Stewart, W. M.; Baron, N.; and Leonard, R. F.: Core Excitations in ${ }^{107} \mathrm{Ag},{ }^{109} \mathrm{Ag}$, ${ }^{113} \mathrm{In},{ }^{115} \mathrm{In},{ }^{121} \mathrm{Sb}$, and ${ }^{12} 3_{\mathrm{Sb}}$ Resulting from Inelastic Scattering of $42-\mathrm{MeV}$ Alpha Particles. Phys. Rev., vol. 171, no. 4, July 20, 1968, pp. 1316-1324.

11. Goulding, Fred S.; Landis, Donald A. ; Cerny, Joseph, III; and Pehl, Richard H. : A New Particle Identifier Technique for $\mathrm{Z}=1$ and $\mathrm{Z}=2$ Particles in the Energy Range $>10 \mathrm{MeV}$. Rep. UCRL-11245, Univ. California Law rence Radiation Lab. , Feb. 3, 1964.

12. Pate, B. D.; and Yaffe, L.: A New Material and Techniques for the Fabrication and Measurement of Very Thin Films for Use in $4 \pi$-Counting. Can. J. Chem., vol. 33, no. 1, Jan. 1955, pp. 15-23. 
13. Sauer, J. M.: Preparation of Sr, Ca, and Mg Accelerator Targets. Rev. Sci. Instr., vol. 36, no. 9, Sept. 1965, p. 1374.

14. Tjin, H. R. E. ; Djie, A. ; and Brockman, K. W. , Jr. : Optical Model Analysis of $26 \mathrm{MeV}$ Deuteron Scattering. Nucl. Phys., vol. 74, 1965, pp. 417-437.

15. Perey, C. M.; and Perey, F. G.: Deuteron Optical-Model Analysis in the Range of 11 to $27 \mathrm{MeV}$. Phys. Rev., vol. 132, no. 2, Oct. 15, 1963, pp. 755-773.

16. Gibbs, W. R.; et al: Direct Reaction Calculation. NASA TN D-2170, 1964.

17. Satchler, G. R.: Optical Model for $30 \mathrm{MeV}$ Proton Scattering. Nucl. Phys., vol. A92, 1967, pp. 273-305.

18. Hafele, J. C.; Flynn, E. R.; and Blair, A. G.: Triton Elastic Scattering. Phys. Rev., vol. 155, no. 4, Mar. 20, 1967, pp. 1238-1245.

1尺. Boschitz, Edmund T.: Optical Model Analysis of Proton Scattering in the Range 16 to $22 \mathrm{MeV}$. NASA TN D-5067, 1969.

20. Takeuchi, K. ; and Moldauer, P. A.: Neutron Single Particle Levels in a WoodsSaxon Potential. Phys. Letters, vol. 28B, no. 6, Jan. 6, 1969, pp. 384-386.

21. Perey, F. G.; and Saxon, D. S.: The Local Energy Approximation to Nonlocality and Finite Range Effects. Phys. Letters, vol.10, no. 1, May 15, 1964, pp. $107-109$.

22. Dickens, J. K. ; Drisko, R. M.; Perey, F. G. ; and Satchler, G. R. : Local Energy Approximation for Finite-Range in Stripping Reactions. Phys. Letters, vol. 15, no. 4, Apr. 15, 1965, pp. 337-339.

23. Bassel, R. H.: Normalization of and Finite-Range Effects in $\left({ }^{3} \mathrm{He}, \mathrm{d}\right)$ and $(\mathrm{t}, \mathrm{d})$ Reactions. Phys. Rev., vol. 149, no. 3, Sept. 23, 1966, pp. 791-797.

24. French, J. B. ; and Macfarlane, M. H.: Isobaric-spin Splitting of Single-Particle Resonances. Nucl. Phys., vol. 26, 1961, pp. 168-176.

25. Cosman, E. R.; Enge, H. A. ; and Sperduto, A. : Nuclear-Reactions Studies in the Strontium Isotopes: The $\operatorname{Sr}^{88}(\mathrm{~d}, \mathrm{p}) \mathrm{Sr}^{89}$ Reaction. Phys. Rev., vol. 165, no. 4, Jan. 20, 1968, pp. 1175-1183.

26. Way, K. ; et al: Nuclear Data Sheets. Rep. NRC 60-3-56, National Academy of Sciences, National Research Council.

27. Elwyn, A. J. ; Landon, H. H. ; Oleksa, Sophie; and Glasoe, G. N. : Study of Some $(p, n)$ Reactions by Neutron Time of Flight. Phys. Rev., vol. 112, no. 4, Nov. 15, 1958, pp. 1200-1209. 
28. Booth, Edward C.; and Brownson, John: Electron and Photon Excitation of Nuclear Isomers. Nucl. Phys., vol. A98, 1967, pp. 529-541.

29. Micheletti, S. ; and Mead, J. B.: Direct Interaction Mechanism in (d, $\alpha$ ) Reactions. Nucl. Phys., vol. 37, 1962, pp. 201-214.

30. Irigaray, J. L. ; et al: Énergies et Intensités des Raies $\gamma$ dans la Capture des Neutrons Thermiques Par le Strontium. Nucl. Phys., vol. A113, 1968, pp. 134144.

31. Bassani, G.; and Picard, J.: Spectroscopic Studies in the $A=90$ Mass Region. (II) Neutron Hole States in $\mathrm{N}=49$ Nuclei. Nucl. Phys., vol. A131, 1969, pp. 653-672.

32. Kitching, J. E. ; et al: The Level Structures of ${ }^{85,87} \mathrm{Sr}$ from d-p Reactions. Bull. Am. Phys. Soc., vol. 14 no. 4, Apr. 1969, p. 625.

33. Ball, J. B.; and Fulmer, C. B.: Neutron Hole States in $Z=40$ Nuclei Studied with the (p,d) Reaction on $90 \mathrm{Zr},{ }^{91} \mathrm{Zr}$, and ${ }^{92} \mathrm{Zr}$. Phys. Rev., vol. 172, no. 4, Aug. 20, 1968, pp. 1199-1207.

34. Patro, A. P.; and Basu, B.: Decay of Yttrium-85. Nucl. Phys., vol. 37, 1962, pp. 272-278.

Dostrovsky, I. ; Katchoff, S. ; and Stoenner, R. W.: Decay of $\mathrm{Y}^{85}$ Isomers. Phys. Rev., vol. 132, no. 6, Dec. 15, 1963, pp. 2600-2606.

35. Horen, D. J.; and Kelly, W. H. : Levels of $\mathrm{Sr}^{85}$ Populated in the Decay of $\mathrm{Y}^{85}$ and $\mathrm{Y}^{85 \mathrm{~m}}$. Phys. Rev., vol. 145, no. 3, May 20, 1966, pp. 988-998.

36. Etherton, R. C. ; Beyer, L. M. ; Kelly, W. H. ; and Horen, D. J.: M2 Isomerison in ${ }^{83} \mathrm{Rb}$ and High-Resolution Spectroscopic Investigations of the Decay of ${ }^{83} \mathrm{Sr}$. Phys. Rev., vol. 168, no. 4, Apr. 20, 1968, pp. 1249-1265.

37. Dostrovsky, I.; Katcoff, S. ; and Stoenner, R. W.: Decay Scheme of Rb ${ }^{83}$. Phys. Rev., vol. 136, no. 1B, Oct. 12, 1964, pp. 44-49.

38. Maples, C. ; Goth, G. W. ; and Cerny, J.: Nuclear Reaction Q-Values. Rep. UCRL-16964, Univ. California Lawrence Radiation Lab. , July 1966.

39. Fou, C. M.; and Zurmühle, R. W. : $\left({ }^{3} \mathrm{He}, \alpha\right)$ Reaction on ${ }^{89} \mathrm{Y}$ and ${ }^{86} \mathrm{Kr}$ at $18 \mathrm{MeV}$. Phys. Rev., vol. 176, no. 4, Dec. 20, 1968, pp. 1339-1345.

40. Mottelson, B. R. : Properties of Individual Levels and Nuclear Models. Proceedings of the International Conference on Nuclear Structure. J. Sanada, ed. , Physical Society of Japan, 1968, p. 87. 
41. Zawischa, D.; and Werner, E.: Investigating of Single-Particle Core-Excitation Coupling in the Strontium and Lead Regions. Nucl. Phys., vol. A125, 1969, pp. 383-401.

42. Cohen, B. L. : Similarity Between Neutron and Proton Single Particle States at the Same Mass Number. Phys. Letters, vol. 27B, no. 5, Aug. 5, 1968, pp. 271-273. 


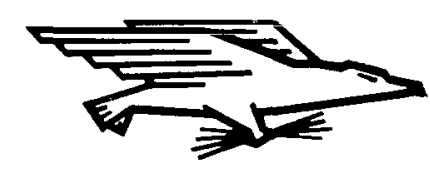

POSTAGE AND FEES PAID NATIONAL AERONAUTICS AND SPACE ADMINISTRATION

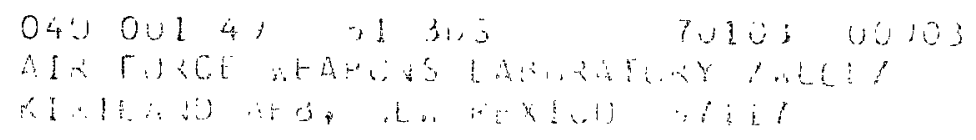

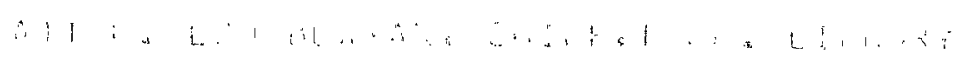

POSTMASTER: If Undeliveruble (Section 158

"The aeronautical and space activities of the United States shall be conducted so as to contribute... to the expansion of buman knouledge of phenomena in the atmospbere and space. The Administration shall provide for the u'idest practicable and appropriate dissemination of information concerning its activities and the results thereof."

- National Aeronautics And Space ACt of 1958

\section{NASA SCIENTIFIC AND TECHNICAL PUBLICATIONS}

TECHNICAL REPORTS: Scientific and technical information considered important, complete, and a lasting contribution to existing knowledge.

TECHNICAL'NOTES: Information less broad in scope but nevertheless of importance as a contribution to existing knowledge.

TECHNICAL MEMORANDUMS:

Information receiving limited distribution because of preliminary data, security classification, or other reasons.

CONTRACTOR REPORTS: Scientific and technical information generated under a NASA contract or grant and considered an important contribution to existing knowledge.
TECHNICAL TRANSLATIONS: Information published in a foreign language considered to merit NASA distribution in English.

SPECIAL PUBLICATIONS: Information derived from or of value to NASA activities. publications include conference proceedings, monographs, data compilations, handbooks, sourcebooks, and special bibliographies.

TECHNOLOGY UTILIZATION

PUBLICATIONS: Information on technology used by NASA that may be of particular interest in commercial and other non-aerospace applications. Publications include Tech Briefs, Tcchnology Utilization Reports and Notes, and Technology Surveys.

Details on the availability of these publications may be obtained from:

\section{SCIENTIFIC AND TECHNICAL INFORMATION DIVISION}

NATIONAL AERONAUTICS AND SPACE ADMINISTRATION

Washington, D.C. 20546 